\title{
CARACTERIZAÇÃO AGRONÔMICA E FENOLÓGICA DE CULTIVARES E CLONES DE VIDEIRA (Vitis spp.) MANTIDOS NO INSTITUTO AGRONÔMICO, CAMPINAS, SP.
}

\author{
Clotilde Pinheiro FerRi \\ Engenheira Agrônoma
}

Orientador: Dr. Celso Valdevino Pommer

Dissertação apresentada à Escola Superior de Agricultura "Luiz de Queiroz", da Universidade de São Paulo, para a obtenção do título de Mestre em Agronomia, Área de Concentração: Fitotecnia.

PIRACICABA

Estado de São Paulo - Brasil

Oútúbro - 1994 
Ficha catalográfica preparada pela seção de Iivros da Divisão de Biblioteca e Documentação - PCLQ/USP

Ferri, clotilde Pinheiro

F391C Caracterização agronômica e fenológica de cultivares e clones de videira (Vitis spp.) mantidos no Instituto Agronômico, Campinas, SP. Piracicaba, 1994. 89 .

Diss. (Mestre) - ESALQ

Bibliografia.

1. Clone de uva 2. Uva - Característica agronômica 3. Uva - Melhoramento I. Escola Superior de Agricultura Luiz de Queiroz, Piracicaba

CDD 634.8 


\title{
CARACTERIZAÇÃO AGRONÔMICA E FENOLÓGICA DE CULTIVARES E CLONES DE VIDEIRA (Vitis spp.) MANTIDOS NO INSTITUTO AGRONÔMICO, CAMPINAS, SP.
}

\author{
Clotilde Pinheiro Ferri
}

Aprovada em: 24.11 .94

Comissão julgadora:

Dr. Celso Valdevino Pommer

Dr. Mario José Pedro Junior

Prof. Dr. Antonio Augusto Lucchesi
$\mathrm{IAC} / \mathrm{SP}$

$\mathrm{IAC} / \mathrm{SP}$

ESALQ/USP

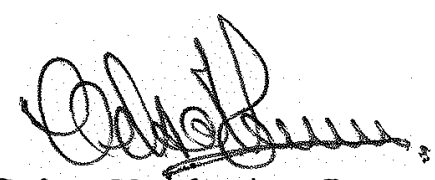

Dr. Celso Valdevino Pommer Orientador 
"Eu sou a verdadeira videira e meu Pai é o agricultor.

Todo ramo, que estando em mim, não der fruto, ele o corta; e todo o que dá fruto, limpa, para que produza mais frutos ainda".

João $15: 1-2$

\author{
A Deus e à minha família \\ que sempre estiveram presentes em minha vida.
}




\section{AGRADECIMENTOS}

À Escola Superior de Agricultura "Luiz de Queiroz", pela oportunidade concedida.

Ao Instituto Agronômico de Campinas, pelo uso de suas instalações e unidades de pesquisa.

A Coordenadoria de Aperfeiçoamento de Pessoal de Ensino Superior - CAPES, pela bolsa de mestrado fornecida.

À Fundação de Amparo à Pesquisa do Estado de São PauloFAPESP, pela bolsa de aperfeiçoamento.

Ao Dr. Celso V. Pommer, pela orientação e amizade.

A Claudio Takeda pelo apoio e carinho compartilhado.

Aos amigos, Julio Cesar da Silva Monteiro de Barros, Márcia Hiromi Habiro e Paulo Sérgio Rodrigues de Araújo pela colaboração, convívio, amizade e companheirismo.

Aos colegas do curso de pós-gradução, pelo convívio, companheirismo e troca de conhecimentos.

A todos aqueles que de alguma forma contribuíram para a realização deste trabalho. 
SUMÁRIO

Página

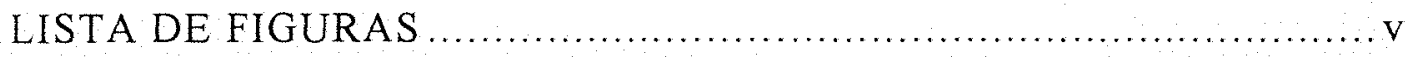



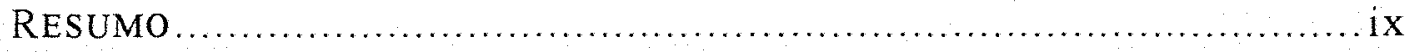

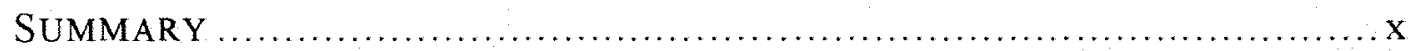

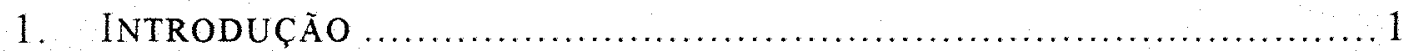

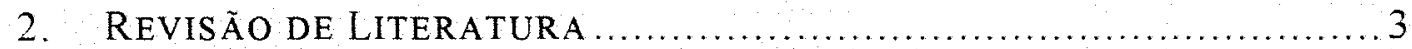

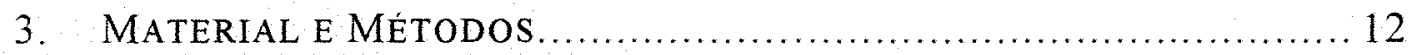

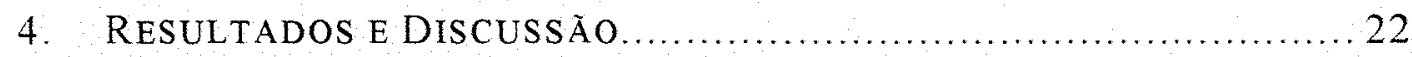

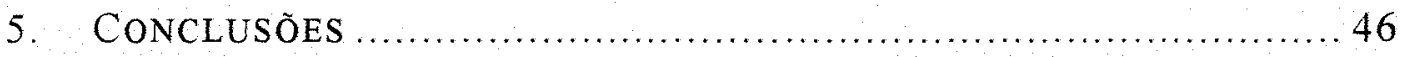

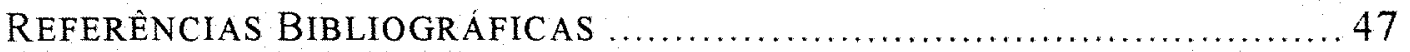

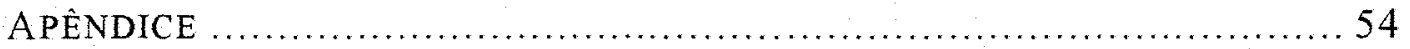




\section{LISTA DE FIGURAS}

Figura

Página

1. Distribuição dos ciclos dos cultivares de acordo com o número de dias, em relação ao ciclo do 'Niagara Rosada'

2. Distribuição dos ciclos dos cultivares, em dias, em relação ao ciclo do 'Niagara Rosada'. 29 


\section{Lista de Tabelas}

Tabela

Página

1. Grupo A: cultivares e clones IAC e outros sem sementes.

2. Grupo B: cultivares IAC, Jd e SR.

3. Grupo C clones IAC. 15

4. Grupo D: cultivares das séries Seibel e Couderc. 16

5. Grupo E: outros cultivares.

6. Distribuição dos cultivares, dentro de cada grupo, em relação ao peso dos cachos.

7. Distribuição dos cultivares, dentro de cada grupo, em relação ao comprimento dos cachos.

8. Distribuição dos cultivares, dentro de cada grupo, em relação à largura dos cachos.

9. Distribuição dos cultivares, dentro de cada grupo, em relação ao número de bagas por cacho.

10. Distribuição dos cultivares, dentro de cada grupo, em relação à compacidade dos cachos

11. Distribuição dos cultivares, dentro de cada grupo, em relação à forma dos cachos.

12. Distribuição dos cultivares, dentro de cada grupo, em relação ao peso das bagas. 24

13. Distribuição dos cultivares, dentro de cada grupo, em relação ao comprimento das bagas. 
14. Distribuição dos cultivares, dentro de cada grupo, em relação à largura das bagas.

15. Distribuição dos cultivares, dentro de cada grupo, em relação à forma das bagas. 26

16. Distribuição dos cultivares, dentro de cada grupo, em relação ao número de sementes por baga

17. Distribuição dos cultivares, dentro de cada grupo, em relação ao tamanho das sementes.

18. Distribuição dos cultivares, dentro de cada grupo, em relação à textura das bagas.

19. Distribuição dos cultivares, dentro de cada grupo, em relação ao sabor das bagas

20. Distribuição dos cultivares, dentro de cada grupo, em relação ao teor médio de sólidos solúveis totais.

21. Distribuição dos cultivares, dentro de cada grupo, em relação ao pH das bagas.

22. Ciclo total, da poda à colheita, em dias e em graus-dia, para o cultivar Niagara Rosada. Jundiaí, 1991 e 1993.

23. Médias de peso (g) de cachos e bagas, número de bagas e teor de sólidos solúveis totais ( $\left.{ }^{\circ} \mathrm{Brix}\right)$ dos cultivares destacados no grupo A.

24. Número total de dias e graus-dia acumulados no ciclo total das plantas, da poda à colheita $(\mathrm{P} / \mathrm{C})$, para os cultivares que se destacaram no grupo A (sem sementes). Jundiaí, 1991 e 1993. 
25. Médias de peso ( $\mathrm{g}$ ) de cachos e bagas, número de bagas e teor de sólidos solúveis totais $\left({ }^{\circ} \mathrm{Brix}\right)$ dos cultivares

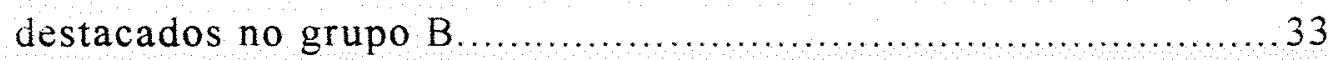

26. Número total de dias e graus-dia acumulados no ciclo total das plantas, da poda à colheita $(\mathrm{P} / \mathrm{C})$, para os cultivares que se destacram no grupo B (cultivares IAC, Jd e SR). Jundiaí, 1991 e 1993. 34

27. Médias de peso (g) de cachos e bagas, número de bagas e teor de sólidos solúveis totais $\left({ }^{\circ} \mathrm{Brix}\right)$ dos cultivares destacados no grupo $\mathrm{C}$. 37

28. Número total de dias e graus-dia acumulados no ciclo total das plantas, da poda à colheita $(\mathrm{P} / \mathrm{C})$, para os cultivares que se destacaram no grupo C (clones IAC). Jundiá, 1991 e 1993. 38

29. Médias de peso ( $\mathrm{g}$ ) de cachos e bagas, número de bagas e teor de sólidos solúveis totais $\left({ }^{\circ} \mathrm{Brix}\right)$ dos cultivares destacados no grupo D. 40

30. Número total de dias e graus-dia acumulados no ciclo total das plantas, da poda à colheita $(\mathrm{P} / \mathrm{C})$, para os cultivares que se destacaram no grupo D (cultivares Seibel e Couderc). Jundiaí, 1991 e 1993.

31. Médias de peso ( $\mathrm{g}$ ) de cachos e bagas, número de bagas e teor de sólidos solúveis totais ( $\left.{ }^{\circ} \mathrm{Brix}\right)$ dos cultivares destacados no grupo E. 42

32. Número total de dias e graus-dia acumulados no ciclo total das plantas, da poda à colheita $(\mathrm{P} / \mathrm{C})$, para os cultivares que se destacaram no grupo E (outros). Jundiai, 1991 e 1993. 


\title{
CARACTERIZAÇÃO AGRONÔMICA E FENOLÓGICA DE CULTIVARES E CLONES DE VIDEIRA (Vitis spp.) MANTIDOS NO INSTITUTO AGRONÔMICO, CAMPINAS, SP.
}

\author{
Autora: Clotilde Pinheiro Ferri \\ Orientador: Dr. Celso Valdevino Pommer
}

RESUMO

Sabendo-se da carência de novos, melhores e bem adaptados cultivares de uvas de mesa para as regiões vitícolas do Estado de São Paulo, foram avaliados, quanto às características agronômicas e fenológicas, 195 cultivares e clones mantidos na coleção de videiras da Estação Experimental do Instituto Agronômico de Campinas, em Jundiaí. Desses, 52 cultivares e clones apresentaram potencial para sua utilização como uvas de mesa, de acordo com suas características agronômicas: Ruby Seedless, Beauty Seedless, A Dona, Flame Seedless, Maria, Paulistinha, Patrícia, Lígia, Fada, Traviú, Madalena, , Seibel 5.213, Seibel 8.712, Seibel 4.643, Seibel 60, Seibel 13.693, Seibel 8.724, Niabel, Bicane, Diamante Negro, Chenin Blanc, Göethe, Golden Muscat, Highland, Patrícia Branca, Japonesa, J 7.602-44, IAC 512-11, IAC 772-41, IAC 503-25, IAC 547-2, IAC 915-2, IAC 699-1, IAC 407-26, IAC 1742, IAC 274-16, IAC 282, IAC 994-7, IAC 740-1, IAC 82-1, IAC 202-43, IAC 353-3, IAC 137-4, IAC 719-7, IAC 1319, IAC 670-1, IAC 387, IAC 720-1, IAC 746-3, IAC 486-3, IAC 871-18 e IAC 192-54. Por apresentarem períodos de colheita diferentes da época tradicional do cultivar Niagara Rosada, 14 se destacaram: a)-precoces: 'Beauty Seedless', 'Flame Seedless', 'Paulistinha', 'Bicane', 'Niabel', J 7.602-44, 'Traviú', 'Fada', 'Lígia', IAC 503-25, IAC 407-26 e IAC 274-16; b)- tardios: IAC 871-18 e 'Highland'. 


\title{
AGRONOMIC AND PHENOLOGIC CHARACTERIZATION OF GRAPE (Vitis spp) CULTIVARS AND CLONES KEPT IN THE INSTITUTO AGRONÔMICO, CAMPINAS, SP
}

\author{
Autora: Clotilde Pinheiro Ferri \\ Orientador: Dr. Celso Valdevino Pommer
}

SUMMARY

Knowing the lack of new, better, and well adapted table grape cultivars for use at viticulture regions of the State of São Paulo, 195 cultivars and clones kept in an ampelographic collection at the Experimental Station of Instituto Agronômico de Campinas, in Jundiaí, were evaluated in relation to agronomic and phenological characteristics. Among those, 52 cultivars and clones showed potential for use as table grapes, according to their agronomic characteristics: Ruby Seedless, Beauty Seedless, A Dona, Flame Seedless, Maria, Paulistinha, Patrícia, Lígia, Fada, Traviú, Madalena, Seibel 5.213, Seibel 8.712, Seibel 4.643, Seibel 60, Seibel 13.693, Seibel 8.724, Niabel, Bicane, Diamante Negro, Chenin Blanc, Göethe, Golden Muscat, Highland, Patrícia Branca, Japonesa, J 7.602-44, IAC 512-11, IAC 772-41, IAC 503-25, IAC 547-2, IAC 915-2, IAC 699-1, IAC 407-26, IAC 1742, IAC 274-16, IAC 282, IAC 994-7, IAC 740-1, IAC 82-1, IAC 202-43, IAC 353-3, IAC 137-4, IAC 719-7, IAC 1319, IAC 670-1, IAC 387, IAC 720-1, IAC 746-3, IAC 486-3, IAC 871-18 and IAC 192-54. By showing different harvest dates from the traditional Niagara Rosada cultivar, 14 cultivars and clones were pointed out: a) early harvest dates: 'Beauty Seedless', 'Flame Seedless', 'Paulistinha', 'Traviú', 'Fada', 'Lígia', 'Bicane', 'Niabel', J 7.602-44, IAC 503-25, IAC 407-26, IAC 274-16; b) late harvest dates: IAC 871-18 and 'Highland'. 


\section{INTRODUÇÃO}

A viticultura no Brasil está difundida por quase todos os Estados, tendo São Paulo uma área plantada de, aproximadamente, 10.000 ha. A viticultura de maior expressão no Estado continua sendo a de uvas comuns para mesa, onde predominam as variedades americanas. 'Niagara Rosada' constitui perto de $90 \%$ da uva comum de mesa do mercado paulista com uma produção de 63 mil toneladas.

A produção de uvas comuns de mesa concentra-se em Jundiaí e municipios vizinhos, onde são cultivadas 'Niagara Rosada' ( 95 a $98 \%$ ) e 'Niagara Branca' ( 2 a $5 \%$ ). Nessa região são cultivadas cerca de 25 milhões de plantas que produzem, anualmente, em torno de $50 \mathrm{mil}$ toneladas.

A atual fase da cultura da videira no Estado de São Paulo tem acrescentado à demanda natural dos viticultores uma grande premência na obtenção de novos e melhores cultivares que sirvam como novas opções permitindo incrementar a exportação e reduzir a importação.

A evolução da vitivinicultura mundial tem induzido cada vez mais a seleção de cultivares e clones economicamente mais interessantes em substituição a populações de plantas tradicionalmente cultivadas. No Brasil, onde a viticultura apresenta perspectivas de expansão, é fundamental que se disponha de ampla variabilidade genética de Vitis devidamente caracterizada e avaliada, para dar suporte à pesquisa e promover o desenvolvimento da atividade vitivinícola nacional.

No momento, toda a produção de uva de mesa está restrita a apenas dois ou três cultivares: Niagara Rosada, Itália e Rubi. Portanto, 
é visível a necessidade de oferta de novas opções de cultivares aos viticultores.

O objetivo do presente trabalho foi selecionar e caracterizar cultivares de uvas de mesa, como outras opções para cultivo, através da avaliação do germoplasma mantido na coleção do Instituto Agronômico, na Estaçăo Experimental localizada em Jundiaí. 


\section{REVISÃ O DE LITERATURA}

As videiras são cultivadas em quase todas as regiões temperadas e nos climas mais quentes e ensolarados mas que possuem invernos amenos (JANICK, 1966). No Brasil, elas são cultivadas desde o extremo sul até o nordeste, com o uso de técnicas de produção adaptadas aos climas específicos e considerando as diferenças na duração dos estádios de crescimento da planta: dormência e desenvolvimento vegetativo.

A videira apresenta uma sucessão de ciclos vegetativos, alternados com períodos de repouso. Durante um ciclo vegetativo, a planta sofre contínuas variações ou modificações de volume, peso, forma e estrutura, de maneira que suas exigèncias e susceptibilidade aos fatores do meio, também variam (HIDALGO, 1956). Essas variações constituem a fenologia, que é o ramo da ecologia onde são estudados os fenômenos periódicos dos seres vivos e suas relações com as condições do ambiente (De FINA \& RAVELO, 1973).

O estudo do comportamento fenológico, correlacionando$o$ às condições ambientais, propicia o conhecimento das épocas em que ocorrem as diversas fases do período vegetativo das plantas, o que pode favorecer a melhor utilização das práticas culturais, bem como fornecer informações ao viticultor para conhecimento antecipado das prováveis datas de colheita (ABRAHÃO \& NOGUEIRA, 1992 e PEDRO Jr. et al., 1993).

GALET (1983) relacionou os fenômenos periódicos que constituem o ciclo da videira:

- período de crescimento- do início da brotação ao fím do crescimento; 
- período reprodutivo- da floração à maturação dos frutos;

- período de amadurecimento dos tecidos- da paralisação do crescimento à maturação dos ramos;

- período vegetativo- do "choro" (exudação de seiva) à floração.

Esse autor destacou que os períodos vão se sucedendo paulatinamente, dependendo, cada um, daquele que o precede. Esse ciclo é indispensável à vida da videira e o amadurecimento dos tecidos é necessário à perenidade da cepa.

Um sistema de classificação dos estádios fenológicos da videira, até hoje muito utilizado, foi estabelecido por Baggiolini (1952), citado por PEDRO Jr, et al. (1989): A - gema dormente; B - gema algodão; C - ponto verde; D - saída da folha; E-folha separada; F - cachos visíveis; $\mathrm{G}$ - cachos separados; H-botões florais separados; I - florescimento; J - formação do fruto.

Da mesma forma, AZZI (1959) subdividiu as fases de vegetação da videira nos seguintes subperíodos:

- primeiro, desde o fim da colheita até $o$ início da brotação;

- segundo, do início da brotação até o fim da floração;

- terceiro, do início da floração até a frutificação;

- quarto, da frutificação até a mudança de cor;

- quinto, da mudança de cor à maturação completa;

- sexto, do início ao fim da vindima (colheita).

Para estudar a fenologia de 24 variedades de uvas, VILLASECA et al. (1986) dividiram seus ciclos nos seguintes estádios: gema inchada, gema algodão, ponta verde; floração; "enfeites" (quando $50 \%$ dos frutos apresentam diâmetro de $3 \mathrm{~mm}$ ); pinta (mudança de cor ou 
de textura das bagas em $50 \%$ dos frutos); maturação $\left(18^{\circ} \mathrm{Brix}\right.$ para uvas de mesa $22^{\circ}$ Brix para vinificar) e queda das folhas.

Por outro lado, ABRAHÃO \& NOGUEIRA (1992), para estudar o comportamento fenológico de videiras, híbridos franceses e americanos, definiram o seguinte critério, considerando, em suas observações, a ocorrência mínima de $50 \%$ das características nos estádios:

- brotação (pontas verdes emergindo das gemas);

- floração (inflorescências com as corolas abertas);

- pintor (mudança de coloração na epiderme dos frutos).

Uma escala ampliada com base em fotografias, foi proposta por PEDRO Jr. et al. (1989), com notas de 1 (início da brotação) a 17 (colheita) para permitir a identificação qualitativa e quantitativa do ciclo da videira.

A videira é uma cultura sensivel à influência do clima e, por isso, a duração dos períodos fenológicos é, geralmente, condicionada pela condição térmica das regiões (TERRA et al., 1993). Nas regiões de clima bem definido, continuam esses autores, as fases do ciclo da planta acompanham as variações estacionais, ou seja, a brotação ocorre na primavera e a queda das folhas no outono.

Pouget (1972), citado por MANDELLI (1984), avaliou o potencial de crescimento das gemas, baseando-se na variação da velocidade do início de seu desenvolvimento, e verificou que a temperatura apresentava estreita relação com a data de início da brotação.

Segundo VEGA (1969), a videira cresce melhor em regiões onde se observam verões longos e secos, moderadamente quentes, e invernos relativamente frios, para satisfazer as necessidades de repouso vegetativo e, essas mesmas condições, com ocorrências de precipitações 
mensais menores que $20 \mathrm{~mm}$, beneficiam a qualidade e a quantidade das uvas produzidas, de acordo com ALMEIDA (1972).

GOBATO (1940) considerou a temperatura de $15^{\circ} \mathrm{C}$ ótima para o florescimento da videira, sendo regular e lento entre $18^{\circ}$ e $20^{\circ} \mathrm{C}$ e menos regular, porém mais rápido, entre $20^{\circ}$ e $25^{\circ} \mathrm{C}$. O mesmo autor afirmou que o conteúdo de açúcar nas bagas é diretamente determinado pelas temperaturas médias do período que vai da mudança de cor à maturação.

No Estado de São Paulo a videira tem tido sua área de cultivo expandida para duas regiões: a de São Miguel Arcanjo, onde os valores mensais de precipitação apresentam-se, em um periodo (outubro e novembro), praticamente iguais aos da evapotranspiração, o que favorece a maturação; e a de Jales, onde ocorre o periodo seco de abril a outubro, porém as temperaturas elevadas permitem maturação mais rápida (PEDRO Jr., 1991). O clima da região tradicional de Jundiaí, continua o autor, apresenta inverno com temperaturas baixas e um período de seca de julho a setembro, o que favorece o repouso hibernal. Assim, as videiras cultivadas nessa região, apresentam um ciclo definido, ou seja, passam por um período de dormencia antes de retornar às fases vegetativa e reprodutiva, que ocorrerão nos meses de temperaturas e precipitações mais elevadas do ano.

As diferenças climáticas entre as regiões produtoras proporcionam uma variabilidade no comportamento fenológico da videira, o que permite a utilização de graus-dia para estimativa da época provável de colheita da videira no Estado (PEDRO Jr, 1991).

Segundo WINKLER (1965), o acúmulo ou soma de calor efetivo, equivale à soma das temperaturas médias diárias acima de $10^{\circ} \mathrm{C}$, para o período considerado. Fixou-se a base de $10^{\circ} \mathrm{C}$ porque não há início de crescimento abaixo dessa temperatura. Esse acúmulo se expressa em graus-dia.

O conceito de graus-dia, determinado pela diferença acumulada entre a temperatura média diária e a temperatura base 
(paralisação do crescimento), tem sido usado para avaliar a duração do ciclo da videira e a qualidade do produto (TERRA et al., 1993).

Usando as temperaturas médias diárias, calculam-se os graus-dia requeridos para cada estádio fenológico. Relacionando a fenologia com a soma de temperaturas, pode-se prever o comportamento de uma variedade em uma determinada região e, especialmente, antecipar a data aproximada da maturação (VILLASECA et al,, 1986).

O desenvolvimento dos frutos, envolvendo a formação dos tecidos e mudanças químicas, atravessa diferentes fases, que foram assim conceituadas por CHITARRA \& CHITARRA (1990):

- pré-maturação ocorre significativo aumento do volume, porém o fruto ainda não se encontra apto para o consumo;

- maturação: o fruto atinge o crescimento pleno e máxima qualidade comestivel;

- amadurecimento período final da maturação, onde o fruto apresentase completamente desenvolvido e as principais mudanças que ocorrem são químicas.

Portanto, o amadurecimento corresponde a mudanças nos fatores sensoriais do sabor, odor, cor e textura que tornam o fruto aceitável para o consumo. Algumas dessas mudanças podem ser detectadas por análise ou observação das transformações físicas ou endógenas, como modificações dos pigmentos, ácidos, taninos, carboidratos e pectinas.

Estudando as características de uvas cultivadas no município de Caldas, $\mathrm{MG}$, CARVALHO (1972) verificou que durante o período de maturação houve tendência a um aumento contínuo do teor de sólidos solúveis. Esse aumento é explicado como o resultado do metabolismo normal da baga, quando os ácidos orgânicos são consumidos pela respiração, resultando no acúmulo de açúcares (CARVALHO \& CHITARRA, 1984). 
AMERINE \& OUGH (1974) afirmaram que uma medida usual para verificar o grau de maturação de uvas é o conteúdo de sólidos solúveis no suco, o que também pode servir como indicação da época apropriada para colheita.

Devido à baixa concentração de ácidos em relação ao teor de açúcares, na prática é considerado somente o conteúdo de sólidos solúveis totais, medido em graus Brix, baseado em gramas de sacarose em $100 \mathrm{~g}$ de solução de açúcar e água (NELSON, 1985).

De acordo com observações de MATHIEU (1937), a maturação das uvas tornou-se um processo conhecido por um rápido aumento nos teores de açúcares, que podem passar de 1 a $20 \%$ em um mês, afirmando o autor que o acúmulo de açúcares não é um fator apenas quantitativo, porém importante qualitativamente. Em suas conclusões gerais, citou como um dos métodos de apreciação da maturação de uvas de mesa, a utilização do refratômetro, que deve indicar o minimo de $16,5^{\circ} \mathrm{Brix}$, indicando, ainda, que a aplicação desse método poderia evitar a colheita prematura e os graves inconvenientes dessa prática.

A aplicabilidade da medição dos teores de sólidos solúveis pode ser considerada para avaliação dos níveis de maturação de uvas de mesa e, consequientemente, para determinar suas melhores datas de colheita, conforme explanado por diversos autores, entre eles MATHIEU (1937), KLIEWER et al. (1965), CARVALHO (1972), AMERINE \& OUGH (1974), SHOEMAKER (1977) e TERRA et al. (1989).

$\mathrm{Na}$ região vitícola do Rio Grande do Sul, TRÍPOLI \& MÜLLER (1981) estudaram o desenvolvimento dos frutos de 19 cultivares de videira e, analisando o comprimento, o peso seco e o peso fresco das uvas, constataram que o tamanho morfológico máximo dos frutos nem sempre coincide com a maturação fisiológica.

Os frutos da videira, denominados bagas, encontram-se reunidos em cachos. Compostos de um esqueleto denominado engaço, formado pelo pedúnculo, ou ráquis, que se ramifica em pedicelos e bagas, 
os cachos são muito variáveis quanto à forma, tamanho e compacidade, podendo, ainda, ser simples ou alados (ROJA, 1934). Para diversos autores, a forma dos cachos pode ser connica, cilíndrica ou alada (BIOLETTI, 1938; GALET, 1976; KUHN et al,, 1986). Para HIDALGO (1993), eles podem ser: cônicos curtos, cônicos com ombros, cônicos longos, cilíndricos, cilíndricos com asas e dobrados com asas.

Segundo GAYET (1993), os cachos devem ter comprimento ao redor de $20 \mathrm{~cm}$, de acordo com as características da variedade e a região onde é produzida. $O$ peso pode variar entre 300 e $1000 \mathrm{~g}$, como no caso da variedade Itália.

Por outro lado, GALET (1976) classificou os cachos, conforme sua dimensão (comprimento), em:

1- cachos muito pequenos (inferiores a $6 \mathrm{~cm}$ );

2- cachos pequenos (entre 6 e $12 \mathrm{~cm}$ );

3- cachos médios (entre 12 e $18 \mathrm{~cm}$ );

4- cachos grandes (entre 18 e $24 \mathrm{~cm}$ );

5- cachos muito grandes $(>24 \mathrm{~cm})$.

A dimensão e a forma dos cachos têm forte influência sobre o peso dos cachos, peso este evidentemente relacionado com as bagas, podendo ser dividido, segundo GALET (1976), em 6 classes:

$$
\begin{aligned}
& \text { 1- inferior a } 50 \mathrm{~g} \\
& \text { 2- entre } 51 \text { e } 125 \mathrm{~g} \\
& \text { 3-entre } 126 \text { e } 250 \mathrm{~g} \\
& \text { 4- entre } 251 \text { e } 500 \mathrm{~g} \\
& \text { 5-entre } 501 \text { e } 1000 \mathrm{~g} \\
& \text { 6- superior a } 1000 \mathrm{~g} \text {. }
\end{aligned}
$$


Para este mesmo autor, a compacidade dos cachos depende das dimensões das bagas e, também, do comprimento do pedicelo e das suas ramificações, podendo ainda, complementa SOUSA (1959), ser devido a muitos fatores (doenças, adversidades do clima) e tratos culturais (adubação, poda verde, incisão anelar, desbaste) classificando-os em: muito compactos, medianamente compactos, bem cheios, soltos e muito soltos.

Da mesma forma que os cachos, as bagas podem ser classificadas em diversas formas, resumindo-se principalmente em: arredondadas, ovais e alongadas (SOUSA, 1959); grandes ou pequenas conforme o seu tamanho (HIDALGO, 1993) ou, segundo GALET (1976) em muito pequenas, pequenas, medias, grandes ou muito grandes em relação ao diâmetro, volume e peso das bagas.

As bagas recebem outras classificações dependendo do seu sabor: amoscateladas, de sabor simples ou foxadas, cor: brancas, tintas, rosadas ou vermelhas; consistência da polpa: sucosas, crocantes, carnosas (SOUSA, 1959; GALET, 1976; HIDALGO, 1993).

O número, o tamanho e a forma das sementes é típico de cada variedade, podendo elas estar ou não presentes.

A apirenia, ou ausência de sementes é uma característica desejável para a obtenção de passas e uvas de mesa.

Segundo POMMER (1993) a videira ideal deveria apresentar, dentre outras, as seguintes características:

Dos cachos:

I- Uvas para vinho:

a) livres de podridões; b) em grande número.

II- Uvas para mesa: 
a) livres de podridões; b) beleza e atratividade; c) bom tamanho; d) pequena densidade ou compacidade, isto é, que sejam soltos.

Das bagas:

I- Uvas para vinho:

a) boa aderência ao pedicelo; b) sabor vinoso;

c) aroma atraente; d) maturação uniforme; e) alto teor de açúcar; f) alto equilibrio de acidez.

II- Uvas de mesa

a) tamanho grande e uniforme; b) boa aderência ao pedicelo; c) formato característico; d) pericarpo resistente, mas delgado; e) boa coloração, de preferência rosada, f) polpa carnosa, de textura crocante; g) sabor delicado; h) aroma atraente; i) sementes pequenas, tenras, em pequeno número ou ausentes; j) maturação uniforme; k) alto teor de açúcar e equilíbrio de acidez.

Para ALVARENGA \& ABRAHÃO (1984), os cultivares para mesa devem apresentar cachos grandes, atraentes e sem defeitos. Bagas bem distribuídas, soltas ou semi-soltas e de preferência de tamanho grande, firme ao pedicelo e película resistente, de preferencia brancas ou rosadas. Polpa doce, baixa acidez e sabor foxado ou moscatel. Maturação precoce, para evitar o período chuvoso e atingir a maturação na época de maior procura no mercado.

Portanto, a carência de novos, melhores e bem adaptados cultivares de mesa para as regiões vitícolas do Estado de São Paulo, evidencia a necessidade do conhecimento das características fenológicas e agronòmicas de materiais mantidos em coleções, buscando conhecer seu potencial como opção para a produção de uvas de mesa fora da época tradicional de colheita do cultivar Niagara Rosada. 


\section{MATERIAL E MÉTODOS}

O trabalho foi realizado utilizando-se os cultivares e clones da coleção de videiras do Instituto Agronômico de Campinas, na Estação Experimental, em Jundiaí, São Paulo, com coordenadas $23^{\circ} 08^{\prime} \mathrm{S}$ e $46^{\circ} 55^{\prime} \mathrm{W}$.

O relevo é predominantemente ondulado, com altitudes que variam de 680 a $760 \mathrm{~m}$. O solo onde está implantada a coleção de videiras é um Cambissolo álico, $\mathrm{Tb}$, textura média, segundo análise específica efetuada pela Seção de Pedologia do Instituto Agronômico de Campinas.

Pela classificação de Köppen, a área tem clima subtropical úmido com inverno seco, Cwa, também chamado de Tropical de Altitude, com temperatura média do mês mais frio inferior a $18^{\circ} \mathrm{C}$, e do mês mais quente superior a $22^{\circ} \mathrm{C}$, sendo que a precipitação total do mês mais seco é inferior a $30 \mathrm{~mm}$. A temperatura média anual é de $20,6^{\circ} \mathrm{C}$ e a precipitação anual fica em torno de $1297 \mathrm{~mm}$ (VALADARES et al., 1971).

Foram utilizados 195 cultivares, separados didaticamente para este trabalho em grupos da seguinte forma: A- sem sementes; B- IAC, Jd e SR; C-clones IAC; D- séries Seibel e Couderc; E- outros.

O grupo A, composto por 35 cultivares, apresenta seis cultivares IAC, 23 clones IAC e 5 cultivares provenientes de outros locais, relacionados na Tabela 1 .

O grupo $\mathrm{B}$, composto por 28 cultivares, apresenta 16 cultivares IAC, 11 clones SR e 1 clone Jd, relacionados na Tabela 2.

O grupo C contém 53 clones IAC, representados na Tabela 3. 
O grupo D, apresentado na Tabela 4, possui 30 representantes, sendo 28 da série Seibel e 2 da série Couderc.

O grupo E ficou composto por 49 cultivares provenientes de diferentes locais, representados na Tabela 5 .

Tabela 1. Grupo A: cultivares e clones IAC e outros sem sementes.

\begin{tabular}{|c|c|c|c|}
\hline \multicolumn{2}{|r|}{ Cultivar } & \multicolumn{2}{|r|}{ Cultivar } \\
\hline № & Nome & № & Nome \\
\hline 9 & Beauty Seedless & 110 & IAC $911-2$ \\
\hline 10 & Flame Seedless & 111 & $1 A C$ 915-2 \\
\hline 40 & Paulistinha & 123 & IAC $1117-6$ \\
\hline 47 & Maria & 129 & IAC 1193 \\
\hline 50 & IAC 544-14 & 131 & IAC 1238-8 \\
\hline 51 & IAC 547-2 & 144 & IAC $1851-2$ \\
\hline 58 & Ruby Seedless & 150 & IAC $460-1$ \\
\hline 78 & IAC 768-2 & 156 & IAC 503-25 \\
\hline 79 & $1 \mathrm{AC} \mathrm{772-41}$ & 158 & IAC 504-1 \\
\hline 80 & Aurora & 159 & IAC $510-8$ \\
\hline 90 & IAC $860-5$ & 161 & IAC 512-11 \\
\hline 94 & Geni & 164 & IAC 540-3 \\
\hline 95 & A Dona & 170 & IAC 733-39 \\
\hline 101 & IAC 901-1 & 206 & Sultanina Branca \\
\hline 103 & IAC $903-47$ & 360 & H. 4.49 .69 \\
\hline 105 & LAC $904-30$ & 373 & Rosinha \\
\hline 106 & IAC $904-41$ & 459 & Suffolk Red \\
\hline 107 & IAC $904-47$ & & \\
\hline
\end{tabular}


Tabela 2. Grupo B: cultivares IAC, Jd e SR.

\begin{tabular}{rlll}
\hline & Cultivar & & Cultivar \\
\hline No & Nome & No & Nome \\
\hline 6 & Madalena & 133 & Traviú \\
\hline 7 & Rainha & 134 & Ezequiel \\
12 & Máximo & 138 & Ligia \\
23 & SR 496-26 & 139 & Angelina \\
24 & SR 507-8 & 140 & Marta \\
32 & Santa Tereza & 148 & Fada \\
44 & Soraya & 149 & Branca de Neve \\
46 & Isaura & 183 & Jd 930 \\
48 & SR 5.010-8 & 217 & SR 496-9 \\
55 & SR 507-38 & 218 & SR 496-15 \\
69 & Iara & 219 & SR 496-25 \\
87 & SR 501-17 & 222 & SR 5.012-34 \\
93 & SR 5.010-21 & 246 & Roberta \\
97 & Patricia & 247 & SR 49 \\
\hline \hline
\end{tabular}


Tabela 3. Grupo C: clones IAC.

\begin{tabular}{|c|c|c|c|}
\hline \multicolumn{2}{|r|}{ Cultivar } & \multicolumn{2}{|c|}{ Cultivar } \\
\hline № & Nome & № & Nome \\
\hline 1 & IAC $16-2$ & 70 & IAC $699-1$ \\
\hline 4 & IAC $23-8$ & 73 & IAC $719-17$ \\
\hline 11 & $\mathrm{IAC} 137-4$ & 74 & IAC $720-1$ \\
\hline 13 & IAC $158-12$ & 75 & IAC $740-1$ \\
\hline 16 & IAC $192-54$ & 76 & IAC 746-3 \\
\hline 18 & IAC 202-24 & 81 & IAC 778-4 \\
\hline 19 & IAC 202-28 & 82 & IAC $804-13$ \\
\hline 20 & IAC $202-43$ & 83 & IAC $813-1$ \\
\hline 21 & IAC 274-16 & 85 & IAC $822-21$ \\
\hline 22 & IAC 282 & 91 & IAC $861-3$ \\
\hline 25 & IAC $338-4$ & 96 & LAC 871-18 \\
\hline 26 & IAC 339-3 & 99 & IAC $877-2$ \\
\hline 27 & IAC $341-2$ & 100 & IAC $882-11$ \\
\hline 29 & IAC $351-5$ & 104 & IAC 904-11 \\
\hline 30 & IAC $353-3$ & 116 & IAC $960-11$ \\
\hline 31 & IAC 387 & 117 & LAC $960-12$ \\
\hline 33 & IAC $393-4$ & 118 & IAC $966-1$ \\
\hline 34 & IAC $393-5$ & 119 & IAC 994-7 \\
\hline 37 & IAC 403-1 & 122 & IAC $1035-12$ \\
\hline 38 & IAC $405-6$ & 127 & IAC 1193-1 \\
\hline 41 & IAC $407-26$ & 143 & IAC 1742 \\
\hline 56 & LAC 583-3 & 145 & IAC 82-1 \\
\hline 57 & IAC 584-53 & 151 & IAC $473-7$ \\
\hline 59 & IAC $588-12$ & 152 & IAC 486-3 \\
\hline 60 & IAC 589-2 & 153 & IAC $496-15$ \\
\hline 61 & IAC 592-1 & 316 & IAC 1319 \\
\hline 66 & IAC $670-1$ & & \\
\hline
\end{tabular}


Tabela 4. Grupo D. cultivares das séries Seibel e Couderc.

\begin{tabular}{|c|c|c|c|}
\hline \multicolumn{2}{|c|}{ Cultivar } & \multicolumn{2}{|c|}{ Cultivar } \\
\hline № & Nome & № & Nome \\
\hline 2 & Seibel 10.146 & 264 & Seibel 5.145 \\
\hline 15 & Couderc 1 & 265 & Seibel 5.163 \\
\hline 36 & Seibel 7.144 & 266 & Seibel 5.213 \\
\hline 136 & Seibel 5.318 & 269 & Seibel 5.520 \\
\hline 165 & Seibel 4.995 & 270 & Seibel 5.915 \\
\hline 205 & Couderc 3 & 276 & Seibel 7.052 \\
\hline 215 & Seibel 2.021 & 278 & Seibel 8.357 \\
\hline 245 & Seibel 11.342 & 279 & Seibel 8.712 \\
\hline 249 & Seibel 2 & 280 & Seibel 8.724 \\
\hline 250 & Seibel 60 & 285 & Seibel 10.878 \\
\hline 251 & Seibel 159 & 287 & Seibel 12.583 \\
\hline 256 & Seibel 1.077 & 291 & Seibel 13.693 \\
\hline 257 & Seibel 1.394 & 304 & Seibel 11.813 \\
\hline 258 & Seibel 4.638 & 305 & Seibel 7.053 \\
\hline 259 & Seibel 4.643 & 313 & Seibel 5.593 \\
\hline
\end{tabular}


Tabela 5. Grupo E: outros cultivares.

\begin{tabular}{rlll}
\hline & Cultivar & & Cultivar \\
\hline № & Nome & No & Nome \\
\hline 3 & Niabel & 318 & Bordô \\
\hline 5 & Bicane & 320 & Cynthiana \\
\hline 17 & Isabel Sport & 324 & Pinot Noir \\
\hline 11 & Concord & 326 & Diamante Negro \\
142 & Elvira & 335 & Ives \\
172 & Isabelão & 344 & Herbemont \\
173 & Isabel & 377 & Niagara Rosada Escura \\
174 & Hubard & 380 & Niagara Branca Oval \\
175 & Golden Muscat & 388 & Cunningham \\
176 & Göethe & 391 & Iona \\
185 & Liberty & 395 & Dutchess \\
195 & Saint Emilion & 399 & Lucile \\
203 & Aspiran Bousan & 410 & Ananaz \\
204 & Lubeck & 417 & Diamond \\
207 & Lindley & 420 & Lomanto \\
212 & Aramon & 427 & Highland \\
224 & Syrah & 430 & Hidalgo \\
229 & Merlot & 436 & Fern Munson \\
230 & Baco 22-A & 439 & Black July \\
237 & Moscatel Azul & 444 & J 7.604-15 \\
293 & Moscatel Branca & 445 & J 7.602-44 \\
300 & Chenin Blanc & 446 & J 7.605-15 \\
303 & Gold & 447 & J 7.602-66 \\
307 & Chardonnay & 456 & Patrícia Branca \\
315 & Japonesa & & \\
\hline
\end{tabular}


As plantas, distribuídas em quatro campos, encontram-se espaçadas de $2 \times 1 \mathrm{~m}$ e conduzidas no sistema de espaldeira com três fios de arame a $1,0 \mathrm{~m}, 1,3 \mathrm{~m}$ e $1,7 \mathrm{~m}$, respectivamente, acima do solo. A poda normalmente utilizada é curta (coroa e uma gema), realizada no inverno (PEREIRA, 1982a), formando-se o cordão esporonado. Durante os anos de realização das coletas dos dados, as podas foram realizadas em $14 / 08 / 91$ e 16/08/93. Não foram realizados tratamentos específicos para os cachos, mantendo-os na sua forma natural. Outros tratos culturais inerentes à cultura, foram realizados de acordo com as recomendações de TERRA et al. (1990).

Caracterizando-se a região de Jundiaí como tradicionalmente produtora de uvas de mesa, foram descritos apenas os cultivares que produziram uvas cujos aspectos agronômicos, quando comparados as uvas de mesa, apresentaram similaridades a essas, considerando principalmente o peso médio mínimo dos cachos de $200 \mathrm{~g}$, peso médio mínimo das bagas de $2,1 \mathrm{~g}$ e teor de sólidos solúveis maior ou igual a $14,5^{\circ} \mathrm{Brix}$.

Para caracterização agronômica, segundo metodologia proposta por CAMARGO \& DIAS (1986), foram observados os seguintes parâmetros:

\section{Cachos}

- Comprimento e largura;

- Peso;

- Forma cônico, cilíndrico ou alado;

- Compacidade: solto, médio ou compacto.

\section{Bagas}

- Número de bagas produzidas em cada cacho;

- Cor: branca, rosada, vermelha ou tinta;

- Forma das bagas: cilindrica ou oval; 
- Consistência da polpa: fundente (padrão Niagara), média (intermediária entre Niagara e Itália) ou trincante (padrão Itália);

- Sabor: foxado (padrão Niagara), neutro (padrão Patrícia, Traviú) ou moscatel (padrão Moscatel Rosado, Madalena);

- Comprimento e largura,

- Peso médio das bagas;

- Sementes número e tamanho médios de 10 bagas;

- Características tecnológicas: teor de sólidos solúveis ( ${ }^{\circ}$ Brix) medido através de refratômetro de campo e $\mathrm{pH}$, medido através de peagâmetro.

Quanto ao tamanho, de acordo com adaptação de GALET (1976), os cachos foram classificados em:

-pequeno, com comprimento $<13 \mathrm{~cm}$

-médio, entre 14 e $18 \mathrm{~cm}$ de comprimento;

-grande, com comprimento $>18 \mathrm{~cm}$.

Da mesma forma, as bagas foram classificadas em pequenas, médias e grandes, quando apresentaram diâmetro $\leq 12 \mathrm{~mm}$, entre 13 e $17 \mathrm{~mm} \mathrm{e} \geq 18 \mathrm{~mm}$, respectivamente.

Foram realizadas observações fenológicas durante os anos de 1991 e 1993, com frequeencia semanal, utilizando-se escala de notas comparativas, com base em fotografias, proposta por Pedro Jr. et al (1989), variando de 1 a 17: 1. início da brotação, 2. gema algodão, 3 ponto verde, 4. saida das folhas, 5. uma folha aberta, 6. até três folhas abertas, 7. até quatro folhas abertas, 8. mais de quatro folhas abertas, 9. préflorescimento, 10. florescimento, 11. pós-florescimento, 12. chumbinho, 13. grão-de-café, 14. meia baga, 15. baga verde, 16. "de vez" e 17. madura (colheita), contendo uma fotografia de cada estádio para orientar a avaliação. Essas observações iniciaram-se duas semanas após realizada a poda de inverno. 
onde:

$\mathrm{GD}=$ graus-dia

$T_{M}=$ temperatura máxima diária $\left({ }^{\circ} \mathrm{C}\right)$,

$\mathrm{T}_{\mathrm{m}}=$ temperatura mínima diária $\left({ }^{\circ} \mathrm{C}\right) ;$

$\mathrm{T}_{\mathrm{b}}=$ temperatura base $\left({ }^{\circ} \mathrm{C}\right)$.

Foi considerada $T_{b}=12^{\circ} \mathrm{C}$, como utilizado por PEDRO Jr. et al. (1993), para a região de Jundiaí. 


\section{RESULTADOS E DISCUSSÃO}

Os cultivares analisados foram agrupados em relação às características agronômicas e sua distribuição está representada nas tabelas de 6 a 21 , a seguir.

Tabela 6. Distribuição dos cultivares, dentro de cada grupo, em relação ao peso dos cachos.

\begin{tabular}{cccccc}
\hline Peso dos cachos & \multicolumn{5}{c}{ Total de cultivares } \\
\cline { 2 - 6 }$(\mathrm{g})$ & A & B & C & D & E \\
\hline$\leq 100$ & 13 & 1 & 6 & 6 & 7 \\
$101-150$ & 9 & 6 & 10 & 7 & 15 \\
$151-200$ & 6 & 14 & 13 & 10 & 15 \\
$\geq 201$ & 7 & 7 & 24 & 7 & 12 \\
\hline Total & 35 & 28 & 53 & 30 & 49 \\
\hline
\end{tabular}

No grupo A, representado pelos cultivares sem sementes, foi encontrado maior número de cachos com menor peso e no grupo $\mathrm{C}$ (clones IAC), ficou concentrado o maior número de cachos com maior peso. Nos demais grupos nota-se distribuição dos cultivares entre as diversas faixas de peso dos cachos, principalmente nas intermediárias, compreendidas entre 101 e $200 \mathrm{~g}$.

Tabela 7. Distribuição dos cultivares, dentro de cada grupo, em relação ao comprimento dos cachos.

\begin{tabular}{cccccc}
\hline Comprimento dos & \multicolumn{5}{c}{ Total de cultivares } \\
\cline { 2 - 6 } cachos (cm) & A & B & C & D & E \\
\hline$\leq 10$ & 6 & 3 & 6 & 9 & 8 \\
$11-14$ & 12 & 21 & 28 & 17 & 26 \\
$15-17$ & 15 & 4 & 14 & 3 & 12 \\
$\geq 18$ & 2 & 0 & 5 & 1 & 3 \\
\hline Total & 35 & 28 & 53 & 30 & 49 \\
\hline
\end{tabular}


Foi verificado que a distribuição dos cultivares em relação ao comprimento dos cachos concentrou-se entre 11 e $17 \mathrm{~cm}$

Tabela 8. Distribuição dos cultivares, dentro de cada grupo, em relação à largura dos cachos.

\begin{tabular}{ccccccc}
\hline \hline Largura dos & \multicolumn{5}{c}{ Total de cultivares } & \\
\cline { 2 - 6 } cachos $(\mathrm{cm})$ & $\mathrm{A}$ & $\mathrm{B}$ & $\mathrm{C}$ & $\mathrm{D}$ & $\mathrm{E}$ \\
\hline$\leq 6,0$ & 4 & 0 & & 4 & 5 & 4 \\
$6,1-8,0$ & 12 & 12 & 15 & 13 & 19 \\
$8,1-10,0$ & 23 & 12 & 24 & 10 & 18 \\
$\geq 10,1$ & 7 & 4 & 10 & 2 & 8 \\
\hline Total & 35 & 28 & 53 & 30 & 49 \\
\hline
\end{tabular}

Em relação à largura dos cachos, pode ser notado que todos os grupos distribuiram-se uniformemente dentro das faixas compreendidas entre $6,1 \mathrm{e} 10 \mathrm{~cm}$.

Tabela 9. Distribuição dos cultivares, dentro de cada grupo, em relação ao número de bagas por cacho.

\begin{tabular}{cccccc}
\hline Número & \multicolumn{4}{c}{ Total de cultivares } & \\
\cline { 2 - 6 } de bagas & $\mathrm{A}$ & $\mathrm{B}$ & $\mathrm{C}$ & $\mathrm{D}$ & $\mathrm{E}$ \\
\hline$\leq 39$ & 4 & 3 & 2 & 1 & 17 \\
$40-79$ & 7 & 8 & 17 & 13 & 20 \\
$80-119$ & 16 & 10 & 19 & 12 & 9 \\
$\geq 120$ & 8 & 7 & 15 & 4 & 3 \\
\hline Total & 35 & 28 & 53 & 30 & 49 \\
\hline
\end{tabular}

Percebe-se que os cultivares do grupo E apresentaram cachos com menor número de bagas, concentrando-se nas faixas até 79 bagas por cacho. Quanto aos outros grupos, a maior concentração de cultivares foi encontrada na faixa de 80 a 119 bagas por cacho, sendo que o grupo $\mathrm{C}$ apresentou a melhor distribuição de seus componentes entre as faixas que incluíram desde 40 até $\geq 120$ bagas por cacho.

Verifica-se na Tabela 10 que os grupos mostraram-se bem distribuidos em relação à compacidade dos cachos, colocando-se, principalmente na classificação média. Os grupos A e C apresentaram maior 
quantidade de cachos entre médios e soltos, enquanto que nos grupos $B, D$ e E ocorreu maior quantidade de cachos entre compactos e médios.

Tabela 10. Distribuição dos cultivares, dentro de cada grupo, em relação à compacidade dos cachos.

\begin{tabular}{cccccc}
\hline Compacidade & \multicolumn{5}{c}{ Total de cultivares } \\
\cline { 2 - 6 } dos cachos & A & B & C & D & E \\
\hline Compacto & 4 & 10 & 5 & 19 & 15 \\
Médio & 15 & 11 & 27 & 9 & 27 \\
Solto & 16 & 7 & 21 & 2 & 7 \\
\hline Total & 35 & 28 & 53 & 30 & 49 \\
\hline \hline
\end{tabular}

Tabela 11. Distribuição dos cultivares, dentro de cada grupo, em relação à forma dos cachos.

\begin{tabular}{cccccc}
\hline Forma & \multicolumn{5}{c}{ Total de cultivares } \\
\cline { 2 - 6 } dos cachos & $\mathrm{A}$ & $\mathrm{B}$ & $\mathrm{C}$ & $\mathrm{D}$ & $\mathrm{E}$ \\
\hline Cônica & 8 & 12 & 21 & 13 & 30 \\
Cônica/Alada & 16 & 12 & 29 & 9 & 12 \\
Cilíndrica & 9 & 4 & 2 & 7 & 5 \\
Cilíndrica/Alada & 2 & 0 & 1 & 1 & 2 \\
\hline Total & 35 & 28 & 53 & 30 & 49 \\
\hline
\end{tabular}

Observa-se que as formas predominantes dos cachos dentro dos grupos são a cônica e a cônica alada.

Tabela 12. Distribuição dos cultivares, dentro de cada grupo, em relação ao peso médio das bagas.

\begin{tabular}{cccccc}
\hline Peso das bagas & \multicolumn{5}{c}{ Total de cultivares } \\
\cline { 2 - 6 }$(\mathrm{g})$ & $\mathrm{A}$ & $\mathrm{B}$ & $\mathrm{C}$ & $\mathrm{D}$ & $\mathrm{E}$ \\
\hline$\leq 2,0$ & 22 & 13 & 23 & 17 & 12 \\
$2,1-3,0$ & 10 & 5 & 14 & 10 & 10 \\
$3,1-4,0$ & 2 & 4 & 12 & 2 & 6 \\
$\geq 4,1$ & 1 & 6 & 4 & 1 & 21 \\
\hline Total & 35 & 28 & 53 & 30 & 49 \\
\hline \hline
\end{tabular}


Pode ser verificado que em todos os grupos houve maior concentração de cultivares com pequeno peso médio de bagas, ou seja, entre $\leq$ $2,0 \mathrm{~g}$ a $3,0 \mathrm{~g}$. Todavia, observou-se que o grupo $\mathrm{E}$ contem maior número de cultivares com peso médio de bagas na faixa $\geq 4,1 \mathrm{~g}$.

Tabela 13. Distribuição dos cultivares, dentro de cada grupo, em relação ao comprimento médio das bagas.

\begin{tabular}{cccccc}
\hline Comprimento & \multicolumn{5}{c}{ Total de cultivares } \\
das bagas $(\mathrm{mm})$ & $\mathrm{A}$ & $\mathrm{B}$ & $\mathrm{C}$ & $\mathrm{D}$ & $\mathrm{E}$ \\
\hline$\leq 13,0$ & 12 & 4 & 4 & 2 & 3 \\
$13,1-15,0$ & 8 & 7 & 14 & 15 & 10 \\
$15,1-17,0$ & 7 & 7 & 15 & 9 & 7 \\
$\geq 17,1$ & 8 & 10 & 20 & 4 & 29 \\
\hline Total & 35 & 28 & 53 & 30 & 49 \\
\hline
\end{tabular}

Percebe-se que no grupo A houve maior concentração de cultivares com bagas de comprimento menor que $13,0 \mathrm{~mm}$ e que no grupo $E$, a maior concentração ocorreu em bagas com comprimento $\geq 17,1 \mathrm{~mm}$.

Em relação à largura, pode-se observar na Tabela 14 que os cultivares estão predominantemente distribuídos entre as faixas de 12,1 a $16,0 \mathrm{~mm}$. Todavia, no grupo $\mathrm{E}$ houve grande número de cultivares com bagas $\geq$ $16,1 \mathrm{~mm}$.

Tabela 14. Distribuição dos cultivares, dentro de cada grupo, em relação à largura média das bagas.

\begin{tabular}{ccccccc}
\hline Largura & \multicolumn{5}{c}{ Total de cultivares } \\
\cline { 2 - 6 } das bagas (mm) & $\mathrm{A}$ & $\mathrm{B}$ & $\mathrm{C}$ & $\mathrm{D}$ & $\mathrm{E}$ \\
\hline$\leq 12,0$ & 12 & 3 & 4 & 0 & 4 \\
$12,1-14,0$ & 10 & 8 & 14 & 9 & 8 \\
$14,1-16,0$ & 6 & 5 & 20 & 18 & 7 \\
$\geq 16,1$ & 7 & 12 & 15 & 3 & 30 \\
\hline Total & 35 & 28 & 53 & 30 & 49 \\
\hline \hline
\end{tabular}

Quanto à forma, nota-se na Tabela 15 que as bagas tiveram predominância da forma oval, em todos os grupos. 
Tabela 15. Distribuição dos cultivares, dentro de cada grupo, em relação à forma das bagas.

\begin{tabular}{cccccc}
\hline Forma & \multicolumn{5}{c}{ Total de cultivares } \\
\cline { 2 - 6 } das bagas & $\mathrm{A}$ & $\mathrm{B}$ & $\mathrm{C}$ & $\mathrm{D}$ & $\mathrm{E}$ \\
\hline Oval & 22 & 17 & 40 & 12 & 35 \\
Esférica & 13 & 11 & 13 & 18 & 14 \\
\hline Total & 35 & 28 & 53 & 30 & 49 \\
\hline
\end{tabular}

Tabela 16. Distribuição dos cultivares, dentro de cada grupo, em relação ao número de sementes por baga.

\begin{tabular}{ccccccc}
\hline Número & & \multicolumn{4}{c}{ Total de cultivares } & \\
de sementes & $\mathrm{A}$ & $\mathrm{B}$ & $\mathrm{C}$ & $\mathrm{D}$ & $\mathrm{E}$ \\
\hline 0 & 35 & 0 & 0 & 0 & 0 \\
1 & 0 & 4 & 6 & 0 & 4 \\
2 & 0 & 14 & 39 & 15 & 27 \\
3 & 0 & 10 & 8 & 15 & 18 \\
\hline Total & 35 & 28 & 53 & 30 & 49 \\
\hline \hline
\end{tabular}

Os cultivares distribuíram-se, em relação ao número de sementes, entre duas e três, principalmente, sendo que o número de duas sementes por baga foi o predominante.

Tabela 17. Distribuição dos cultivares, dentro de cada grupo, em relação ao tamanho das sementes.

\begin{tabular}{ccccccc}
\hline Tamanho & \multicolumn{5}{c}{ Total de cultivares } & \\
\cline { 2 - 6 } das sementes & $\mathrm{A}$ & $\mathrm{B}$ & $\mathrm{C}$ & $\mathrm{D}$ & $\mathrm{E}$ \\
\hline Pequeno & 0 & 7 & 8 & 5 & 7 \\
Médio & 0 & 14 & 36 & 23 & 29 \\
Grande & 0 & 7 & 9 & 2 & 13 \\
Total & 0 & 28 & 53 & 30 & 49 \\
\hline \hline
\end{tabular}

Observa-se que a maioria dos cultivares apresentou tamanho médio de sementes 
Tabela 18. Distribuição dos cultivares, dentro de cada grupo, em relação à textura das bagas.

\begin{tabular}{ccccccc}
\hline Textura & \multicolumn{5}{c}{ Total de cultivares } \\
\cline { 2 - 6 } das bagas & $\mathrm{A}$ & $\mathrm{B}$ & $\mathrm{C}$ & $\mathrm{D}$ & $\mathrm{E}$ \\
\hline Fundente & 7 & 11 & 36 & 17 & 31 \\
Média & 15 & 8 & 10 & 12 & 12 \\
Trincante & 13 & 9 & 7 & 1 & 6 \\
\hline Total & 35 & 28 & 53 & 30 & 49 \\
\hline
\end{tabular}

Foi verificado que a maior parte dos cultivares ficou distribuída entre texturas fundente e média, com exceção daqueles pertencentes ao grupo A que se apresentaram com textura de bagas entre media e trincante.

Percebe-se, na Tabela 19, que os cultivares apresentaram sabor das bagas predominantemente neutro, ocorrendo, todavia, no grupo E maior número de cultivares com sabor foxado.

Tabela 19. Distribuição dos cultivares, dentro de cada grupo, em relação ao sabor das bagas.

\begin{tabular}{cccccc}
\hline Sabor & \multicolumn{5}{c}{ Total de cultivares } \\
\cline { 2 - 6 } das bagas & $\mathrm{A}$ & $\mathrm{B}$ & $\mathrm{C}$ & $\mathrm{D}$ & $\mathrm{E}$ \\
\hline Foxado & 2 & 1 & 0 & 0 & 28 \\
Neutro & 30 & 25 & 50 & 30 & 18 \\
Moscatel & 3 & 2 & 3 & 0 & 3 \\
\hline Total & 35 & 28 & 53 & 30 & 49 \\
\hline \hline
\end{tabular}

Tabela 20. Distribuição dos cultivares, dentro de cada grupo, em relação ao teor médio de sólidos solúveis totais das bagas.

\begin{tabular}{cccccc}
\hline SST & \multicolumn{5}{c}{ Total de cultivares } \\
$\left({ }^{\circ}\right.$ Brix $)$ & A & B & C & D & E \\
\hline$\leq 12,9$ & 4 & 1 & 2 & 1 & 3 \\
$13,0-14,9$ & 12 & 9 & 11 & 3 & 12 \\
$15,0-17,9$ & 17 & 16 & 35 & 25 & 34 \\
$\geq 18,0$ & 2 & 2 & 5 & 1 & 0 \\
\hline Total & 35 & 28 & 53 & 30 & 49 \\
\hline \hline
\end{tabular}


Verifica-se a ocorrência de maior número de cultivares possuindo teores médios de sólidos solúveis totais compreendidos entre $13,0 \mathrm{e}$ $17,9^{\circ} \mathrm{Brix}$, com predomínio, porém, na faixa de 15,0 a $17,9^{\circ} \mathrm{Brix}$

Tabela 21. Distribuição dos cultivares, dentro de cada grupo, em relação ao pH das bagas.

\begin{tabular}{|c|c|c|c|c|c|}
\hline \multirow[b]{2}{*}{$\mathrm{pH}$} & \multicolumn{5}{|c|}{ Total de cultivares } \\
\hline & $\mathrm{A}$ & $\mathrm{B}$ & $\mathrm{C}$ & D & $E$ \\
\hline$\leq 2,79$ & 2 & 1 & 3 & 0 & 5 \\
\hline $2,80-2,99$ & 13 & 2 & 14 & 4 & 5 \\
\hline $3,00-3,19$ & 14 & 13 & 21 & 14 & 16 \\
\hline$\geq 3,20$ & 6 & 12 & 15 & 12 & 23 \\
\hline Total & 35 & 28 & 53 & 30 & 49 \\
\hline
\end{tabular}

Ao observar a Tabela 21 , nota-se a ocorrência de maior número de cultivares mostrando valores de $\mathrm{pH}$ acima de 2,80 , sobretudo nas faixas compreendidas acima de 3,00 .

Estudando o comportamento fenológico e as características pomológicas de 20 cultivares americanos de videira na região de Jundiaí, SILVA et al. (1990), considerando a apresentação como uvas de mesa, destacaram os cultivares Highland, Göethe, August Giant e Golden Muscat. Apresentaram, em suas observações, as seguintes caracteristicas, em média:

- Cachos: peso $>145 \mathrm{~g}$, comprimento $>12,0 \mathrm{~cm}$, largura $>7,6 \mathrm{~cm}$; compactação média; forma cônica, número de bagas 50 .

- Bagas: peso $>4,7 \mathrm{~g}$, comprimento $22 \mathrm{~mm}$; largura $20 \mathrm{~mm}$; número de sementes 2 a 3 ; teor de sólidos solúveis $>12,7^{\circ} \mathrm{Brix}$; forma esférica; sabor foxado, textura fundente.

Ao comparar os cultivares estudados com as observações desses autores, percebeu-se que grande parte dos dados coincidiram com as médias por eles consideradas para caracterização de uvas de mesa. No entanto, as informações não concordam no que diz respeito ao peso dos cachos em relação à maioria dos cultivares do grupo $\mathrm{A}$, onde o peso médio foi $\leq 150 \mathrm{~g}$. 
Em relação às características das bagas, também não houve concordância em relação ao peso, visto que a maioria dos cultivares situou-se no intervalo entre $\leq 2,0 \mathrm{~g}$ e $3,0 \mathrm{~g}$, bem como quanto ao comprimento e largura, já que somente os cultivares do grupo E mostraram medidas aproximadas.

Quanto ao sabor, somente os cultivares do grupo $E$ apresentaram sabor foxado, enquanto que os demais, em sua maioria, evidenciaram sabor neutro, o que também não está em concordância com o verificado por aqueles autores.

Considerando como mais importantes, dentre as características agronómicas, o peso de cachos e bagas, número de bagas e o teor de sólidos solúveis totais, foi possível relacionar, dentro de cada grupo, os cultivares que se destacaram e, em seguida, comparar seus períodos fenológicos com os observados para Niagara Rosada', constantes na Tabela 22 .

Tabela 22. Ciclo total, da poda à colheita, em dias e em graus-dia, para o cultivar Niagara Rosada. Jundiai, 1991 e 1993.

\begin{tabular}{ccc}
\hline Ano & Dias & Graus-Dia \\
\hline 1991 & 160 & 1617 \\
1993 & 158 & 1562 \\
\hline Média & 159,0 & 1589,5 \\
\hline
\end{tabular}

Na Figura 2, estão distribuídos os ciclos dos cultivares, em número de dias, quando comparados ao ciclo do cultivar Niagara Rosada.

\begin{tabular}{|l|l|l|l|l|}
\multicolumn{2}{c}{149} & 154 & 159 & 164 \\
\hline muito curto & curto & ciclo médio & longo & muito longo \\
\hline
\end{tabular}

\section{'Niagara Rosada'}

Figura 2. Distribuição dos ciclos dos cultivares, em dias, em relação ao ciclo do 'Niagara Rosada'.

Assim, na Tabela 23 observam-se os dados referentes aos cultivares pertencentes ao grupo $A$ e que foram destacados quanto às características agronômicas. 
Tabela 23. Médias de peso (g) de cachos e bagas, número de bagas e teor de sólidos solúveis totais (SST) dos cultivares destacados no grupo A.

\begin{tabular}{|c|c|c|c|c|c|}
\hline \multicolumn{2}{|c|}{ Cultivar } & \multicolumn{2}{|c|}{ Peso } & \multirow{2}{*}{$\begin{array}{l}\text { Número } \\
\text { de bagas }\end{array}$} & \multirow{2}{*}{$\begin{array}{r}\text { SST } \\
\circ \text { Brix } \\
\end{array}$} \\
\hline No & Nome & cacho & baga & & \\
\hline 58 & Ruby Seedless & 755,0 & 3,54 & 303 & 16,0 \\
\hline 9 & Beauty Seedless & 570,8 & 2,32 & 215 & 15,5 \\
\hline 10 & Flame Seedless & 325,8 & 2,56 & 110 & 15,5 \\
\hline 95 & A Dona & 262,1 & 2,49 & 117 & 14,8 \\
\hline 47 & Maria & 270,0 & 2,91 & 96 & 16,5 \\
\hline 161 & IAC $512-11$ & 269,7 & 2,78 & 97 & 15,0 \\
\hline 79 & IAC 772-41 & 267,8 & 2,50 & 107 & 17,0 \\
\hline 156 & IAC 503-25 & 260,8 & 1,75 & 149 & 15,3 \\
\hline 51 & LAC 547-2 & 253,3 & 0,86 & 287 & 16,2 \\
\hline 111 & IAC 915-2 & 243,3 & 1,75 & 139 & 16,1 \\
\hline 40 & Paulistinha & 222,8 & 1,98 & 119 & 15,4 \\
\hline
\end{tabular}

'Ruby Seedless' destacou-se, dentro do grupo, quanto às suas características físicas, seguido por 'Beauty Seedless' no tocante ao peso de cacho. Ainda em relação a esse aspecto, todos os outros cultivares que se destacaram dentro do grupo, apresentaram peso de cacho semelhante, mesmo considerando que alguns deles (Paulistinha, IAC 503-25, IAC 915-2 e IAC 547-2) tenham apresentado peso de bagas inferior a $2 \mathrm{~g}$. Esse fato, possivelmente, se deve a não aplicação de reguladores vegetais nesses anos.

O IAC 547-2 apresentou número de bagas elevado e peso de bagas pequeno, o que demonstra a necessidade de realização de tratos culturais específicos, tais como desbaste dos cachos e aplicação de reguladores vegetais, ou ainda incisão anelar, recomendados por, SANTOS NETO (1984), CALÒ et al. (1989), AHMEDULLAH \& HIMELRICK (1990) e TERRA et al. (1993) para promoção do aumento do tamanho das bagas e conseqüente produção de cachos com padrão comercial. Possivelmente, esses tratamentos poderiam apresentar resultados positivos, caso fossem adequadamente aplicados em outros cultivares do grupo, considerando tratarem-se de uvas sem sementes, como os encontrados em trabalhos de pesquisa desenvolvidos por PIRES (1988) e POMMER et al. (1993)

Sugere-se, por esse motivo, a continuidade das pesquisas buscando melhor conhecer o potencial de outros cultivares apirenos. 
Em relação aos teores médios de sólidos solúveis totais, os cultivares apresentaram valores compreendidos numa faixa adequada e que, de modo geral, atende à preferência do consumidor.

Dos 35 cultivares do grupo A, doze destacaram-se em relação ao curto comprimento do ciclo, o que pode ser observado na Tabela 24.

Tabela 24. Número total e média de dias e graus-dia acumulados no ciclo total das plantas, da poda à colheita $(\mathrm{P} / \mathrm{C})$, para os cultivares que se destacaram no grupo A (sem sementes). Jundiai, 1991 e 1993.

\begin{tabular}{|c|c|c|c|c|c|c|}
\hline \multicolumn{2}{|r|}{ Cultivar } & \multirow[b]{2}{*}{ Ano } & \multicolumn{2}{|c|}{ Dias } & \multicolumn{2}{|c|}{ Graus-Dia } \\
\hline № & Nome & & $\mathrm{P} / \mathrm{C}$ & $\mathrm{M}$ & $\mathrm{P} / \mathrm{C}$ & $\mathrm{M}$ \\
\hline \multirow[t]{2}{*}{9} & Beauty Seedless & 91 & 125 & & 1209 & \\
\hline & & 93 & 143 & 134,0 & 1398 & 1303,5 \\
\hline \multirow[t]{2}{*}{10} & Flame Seedless & 91 & 125 & & 1209 & \\
\hline & & 93 & 143 & 134,0 & 1398 & 1303,5 \\
\hline \multirow[t]{2}{*}{40} & Paulistinha & 91 & 110 & & 1025 & \\
\hline & & 93 & 143 & 126,5 & 1398 & 1211,5 \\
\hline \multirow[t]{2}{*}{78} & IAC 768-2 & 91 & 146 & & 1549 & \\
\hline & & 93 & 152 & 149,0 & 1484 & 1516,5 \\
\hline \multirow[t]{2}{*}{101} & IAC $901-1$ & 91 & 146 & & 1549 & \\
\hline & & 93 & 143 & 144,5 & 1398 & 1473,5 \\
\hline \multirow[t]{2}{*}{131} & IAC 1238-8 & 91 & 146 & & 1549 & \\
\hline & & 93 & 143 & 144,5 & 1398 & 1473,5 \\
\hline \multirow[t]{2}{*}{156} & IAC 503-25 & 91 & 146 & & 1549 & \\
\hline & & 93 & 143 & 144,5 & 1398 & 1473,5 \\
\hline \multirow[t]{2}{*}{158} & $\mathrm{IAC} 504-1$ & 91 & 110 & & 1025 & \\
\hline & & 93 & 143 & 126,5 & 1398 & 1211,5 \\
\hline \multirow[t]{2}{*}{159} & IAC $510-8$ & 91 & 146 & & 1549 & \\
\hline & & 93 & 137 & 141,5 & 1336 & 1442,5 \\
\hline \multirow[t]{2}{*}{164} & IAC $540-3$ & 91 & 146 & & 1549 & \\
\hline & & 93 & 152 & 149,0 & 1484 & 1516,5 \\
\hline \multirow[t]{2}{*}{360} & H. 4.49 .69 & 91 & 146 & & 1549 & \\
\hline & & 93 & 143 & 144,5 & 1398 & 1473,5 \\
\hline \multirow[t]{2}{*}{459} & Suffolk Red Seedless & 91 & 125 & & 1209 & \\
\hline & & 93 & 137 & 131,0 & 1336 & 1272,5 \\
\hline
\end{tabular}


Comparando com o ciclo fenológico do 'Niagara Rosada', percebe-se, por essa tabela, que os cultivares Beauty Seedless, Flame Seedless, Paulistinha, IAC $901-1$, IAC 1238-8, IAC 503-25, IAC 504-1, IAC 510-8, H 4.49.69 e Suffolk Red Seedless, apresentaram ciclos muito curtos (abaixo de 149 dias) e os cultivares IAC $768-2$ e IAC 540-3 tiveram ciclo curto ( 149 dias, em média).

Os cultivares mais precoces foram Paulistinha e IAC 504-1, com ciclo de 126 dias e acumulando 1211,5 graus-dia, em média. Os de ciclos mais longos, porém ainda precoces em relação ao 'Niagara Rosada', foram o IAC $768-2$ e IAC $540-3$, com 149 dias e 1516,5 graus-dia acumulados.

Dentre os doze que apresentaram ciclo mais curto que o 'Niagara Rosada', somente os cultivares Beauty Seedless, Flame Seedless, Paulistinha e IAC 503-25 mostraram, também, características mais desejáveis como uvas de mesa.

'Beauty Seedless' produziu cachos de tamanho grande que mediram $21,6 \mathrm{~cm}$ de comprimento, com peso médio de $570,8 \mathrm{~g}$ e de forma sempre alada. Apresentou compacidade média, apesar do grande número de bagas, 215 em média. Bagas de coloração avermelhada, de forma oval, tamanho médio $(17,9 \mathrm{~mm})$ e com peso médio de $2,32 \mathrm{~g}$. Textura trincante, sabor neutro e teor de sólidos solúveis de $15,5^{\circ} \mathrm{Brix}$.

'Flame Seedless' mostrou cachos grandes, medindo $21,8 \mathrm{~cm}$ de comprimento, peso médio de $325,8 \mathrm{~g}$ e de forma cônica e alada. Apresentou cachos soltos com 110 bagas, em média. Bagas de coloração rosada, grandes $(18,9 \mathrm{~mm})$, pesando em média $2,56 \mathrm{~g}$ e de forma oval. Com textura trincante, sabor neutro e teor médio de sólidos solúveis de $15,5^{\circ} \mathrm{Brix}$.

'Paulistinha' apresentou cachos compridos $(18,1 \mathrm{~cm})$, peso médio de $222,8 \mathrm{~g}$ e forma cilíndrica Compacidade média, com 119 bagas por cacho. Bagas brancas, de tamanho médio $(16,4 \mathrm{~mm})$, com peso médio de $1,98 \mathrm{~g}$ e de forma oval. Textura média, sabor neutro e com teor médio de sólidos solúveis de $15,4^{\circ} \mathrm{Brix}$.

IAC $503-25$ produziu cachos pequenos $(13,3 \mathrm{~cm})$, peso médio de $260,8 \mathrm{~g}$ e forma cônica. Cachos soltos, com 149 bagas em média, de 
tamanho médio $(15,3 \mathrm{~mm})$. Bagas de coloração branca, de forma oval e pesando em média $1,75 \mathrm{~g}$. Textura média, sabor neutro e com teor de sólidos solúveis totais de $15,0^{\circ} \mathrm{Brix}$.

Nas Tabelas 1 a 5 do Apêndice, encontram-se os dados referentes às observações fenológicas e agronômicas, realizadas para todos os cultivares que compuseram o grupo $\mathrm{A}$.

Os dados referentes aos cultivares pertencentes ao grupo B e que foram destacados quanto às caracteristicas agronomicas, podem ser observados na Tabela 25 .

Tabela 25. Médias de peso ( $\mathrm{g}$ ) de cachos e bagas, número de bagas e teor de sólidos solúveis totais (SST), dos cultivares destacados no grupo B.

\begin{tabular}{rrrrrrr}
\hline & Cultivar & \multicolumn{2}{c}{ Peso } & Número & SST \\
\cline { 2 - 6 } No & Nome & cacho & baga & de bagas & o Brix \\
\hline 97 & Patricia & 595,0 & 5,68 & 110 & 14,5 \\
138 & Ligia & 358,8 & 4,75 & 89 & 17,8 \\
148 & Fada & 353,8 & 3,79 & 103 & 16,3 \\
133 & Traviú & 327,8 & 2,45 & 140 & 16,3 \\
6 & Madalena & 226,0 & 2,62 & 84 & 14,5 \\
\hline \hline
\end{tabular}

'Patrícia' apresentou características físicas que se destacaram dentro do grupo, produzindo cachos com $595,0 \mathrm{~g}$ em média, o que está de acordo com a descrição realizada por PEREIRA (1982) e SANTOS NETO (1976). Apesar do teor de solidos solúveis totais não ter alcançado índices mais elevados, ainda situou-se em faixa aceitavel pelo consumidor. Esse valores não coincidiram com os indices encontrados por aqueles autores, variando em torno de 18 e até $20^{\circ}$ Brix para esse cultivar. Da mesma forma, o 'Madalena' teve o teor de sólidos solúveis totais na mesma faixa do 'Patrícia'.

Os demais cultivares relacionados mostraram características desejáveis como uvas de mesa, inclusive situando seus teores de sólidos solúveis em valores mais elevados, acima de $16^{\circ} \mathrm{Brix}$.

No grupo B, dezesseis cultivares se destacaram em relação ao curto comprimento do ciclo, o que pode ser observado na Tabela 26. 
Tabela 26. Número total e média de dias e graus-dia acumulados no ciclo total das plantas, da poda a colheita $(\mathrm{P} / \mathrm{C})$, para os cultivares que se destacaram no grupo B (cultivares IAC, SR e Jd). Jundiai, 1991 e 1993.

\begin{tabular}{|c|c|c|c|c|c|c|}
\hline \multicolumn{2}{|c|}{ Cultivar } & \multirow[b]{2}{*}{ Ano } & \multicolumn{2}{|c|}{ Dias } & \multicolumn{2}{|c|}{ Graus-Dia } \\
\hline № & Nome & & $\mathrm{P} / \mathrm{C}$ & $M$ & $\mathrm{P} / \mathrm{C}$ & $\mathrm{M}$ \\
\hline \multirow[t]{2}{*}{12} & Máximo & 91 & 146 & & 1459 & \\
\hline & & 93 & 137 & 141,5 & 1336 & 1397,5 \\
\hline \multirow[t]{2}{*}{23} & SR 496-26 & 91 & 146 & & 1459 & \\
\hline & & 93 & 152 & 149,0 & 1484 & 1471,5 \\
\hline \multirow[t]{2}{*}{24} & SR 507-8 & 91 & 146 & & 1459 & \\
\hline & & 93 & 143 & 144,5 & 1398 & 1428,5 \\
\hline \multirow[t]{2}{*}{44} & Soraya & 91 & 146 & & 1459 & \\
\hline & & 93 & 152 & 149,0 & 1484 & 1471,5 \\
\hline \multirow[t]{2}{*}{46} & Isaura & 91 & 139 & & 1375 & \\
\hline & & 93 & 143 & 141,0 & 1398 & 1386,5 \\
\hline \multirow[t]{2}{*}{48} & SR 5.010-8 & 91 & 146 & & 1459 & \\
\hline & & 93 & 127 & 136,5 & 1239 & 1349,0 \\
\hline \multirow[t]{2}{*}{55} & SR $507-38$ & 91. & 146 & & 1459 & \\
\hline & & 93 & 143 & 144,5 & 1398 & 1428,5 \\
\hline \multirow[t]{2}{*}{87} & SR $501-17$ & 91 & 146 & & 1459 & \\
\hline & & 93 & 143 & 144,5 & 1398 & 1428,5 \\
\hline \multirow[t]{2}{*}{93} & SR $5.010-21$ & 91 & 146 & & 1459 & \\
\hline & & 93 & 143 & 144,5 & 1398 & 1428,5 \\
\hline \multirow[t]{2}{*}{133} & Traviú & 91 & 119 & & 1132 & \\
\hline & & 93 & 143 & 131,0 & 1398 & 1265,0 \\
\hline \multirow[t]{2}{*}{138} & Lígia & 93 & 146 & & 1459 & \\
\hline & & 91 & 152 & 149,0 & 1484 & 1471,5 \\
\hline \multirow[t]{2}{*}{140} & Marta & 93 & 119 & & 1132 & \\
\hline & & 91 & 143 & 131,0 & 1398 & 1265,0 \\
\hline \multirow[t]{2}{*}{148} & Fada & 93 & 125 & & 1209 & \\
\hline & & 91 & 143 & 134,0 & 1398 & 1303,5 \\
\hline \multirow[t]{2}{*}{149} & Branca de Neve & 91 & 146 & & 1459 & \\
\hline & & 93 & 143 & 144,5 & 1398 & 1428,5 \\
\hline \multirow[t]{2}{*}{217} & SR 496-9 & 91 & 146 & & 1459 & \\
\hline & & 93 & 143 & 144,5 & 1398 & 1428,5 \\
\hline \multirow[t]{2}{*}{218} & Dr. Júlio & 91 & 146 & & 1459 & \\
\hline & & 93 & 143 & 144,5 & 1398 & 1428,5 \\
\hline
\end{tabular}

Percebe-se, por essa tabela, que os cultivares Máximo, SR 507-

8. Isaura, SR 5.010-8, SR 507-38, SR 501-17, SR 5.010-21, Traviú, Marta, Fada, Branca de Neve, SR 496-9 e Dr. Júlio apresentaram ciclos muito curtos (abaixo de 149 dias) e os cultivares SR 496-26, Soraya e Ligia tiveram ciclo curto (149 dias, em média). 
Os cultivares mais precoces desse grupo foram Traviú e Marta, ambos com ciclo de 131 dias e acumulando 1265 graus-dia em média. Os de ciclo um pouco mais longos, porém ainda precoces em relação ao Niagara Rosada', foram o SR 496-26, Soraya e Lígia, todos com 149 dias e 1471,5 graus-dia acumulados, em média.

'Máximo', apesar de precoce, não apresentou as características desejáveis como fruta de mesa, lembrando suas descrições realizadas por PEREIRA (1982b), POMMER (1993) e SANTOS NETO (1968), destacando-o como um bom cultivar de uva para vinho.

RIBAS (1973), em São Roque-SP, obteve uma série (SR) de uvas para vinho e, apesar dos cultivares em estudo, pertencentes a essa série, terem apresentado ciclos mais curtos do que o 'Niagara Rosada', não foram selecionados, por não apresentarem características de uvas de mesa.

'Soraya', que nesse trabalho não apresentou as características desejáveis para mesa, não sendo por isso selecionado, foi citado por POMMER (1993) como cultivar de uva para mesa mas com o grande defeito de rachar as bagas no período das chuvas, o que praticamente o eliminou das regióes de cultivo e por ALVARENGA \& ABRAHÃO (1984), que o definiram como uva fina de mesa, chegando a ser confundido no mercado com o 'Itália!.

Portanto, somente três dos 16 cultivares precoces desse grupo mostraram boas caracteristicas para mesa, sendo eles 'Traviú', 'Lígia' e 'Fada'.

Referindo-se ao cultivar Traviú, TERRA (1991) afirmou ser recomendável seu cultivo nas regiões tradicionais de produção de uvas de mesa do Estado de São Paulo, considerando sua precocidade e a possibilidade de colheita em fins de novembro, o que faz com que alcance preços elevados.

O cultivar Traviú produziu cachos pequenos, com $11,7 \mathrm{~cm}$ de comprimento, todavia com peso de $327,8 \mathrm{~g}$. O número elevado de bagas $(140)$ confere ao cacho um alto grau de compacidade. Sua forma é cônica e quase sempre alada. As bagas são tintas, esféricas, de tamanho médio $(15,7 \mathrm{~mm})$ e pesando cada uma $2,45 \mathrm{~g}$, em média. A textura é trincante, sabor neutro e o teor médio de sólidos solúveis é de $16,3^{\circ}$ Brix. Possui duas sementes de tamanho pequeno por baga. 
De acordo com SANTOS NETO (1983), 'Traviú' apresenta acentuada precocidade, pois a maturação de seus frutos geralmente tem inicio a partir de meados de novembro, prolongando-se por quase todo o mês de dezembro. Sua principal característica - a precocidade, possivelmente, foi herdada do 'Pérola de Csaba', que está presente na sua genealogia e que é considerado um dos cultivares mais precoces no mundo. $O$ mesmo autor descreveu esse cultivar com cachos médios, connicos, frutos pretos de tamanho médio, com excelente sabor neutro e elevado teor de açúcar, características semelhantes às observadas no presente trabalho. Todavia, o autor descreveu os cachos como mais ou menos soltos o que não coincide com as observaçóes realizadas, que demonstraram os mesmos possuirem alto grau de compacidade.

'Lígia' apresentou cachos pequenos $(12,0 \mathrm{~cm}$ de comprimento), mas com peso de $358,8 \mathrm{~g}$ e 89 bagas. Cacho de média compacidade e forma cônica e alada. Bagas brancas, de forma oval, grandes $(20,3 \mathrm{~mm})$, pesando, em media, $4,75 \mathrm{~g}$, com 3 sementes de tamanho médio por baga. A textura é média, sabor neutro, com teor de sólidos solúveis de $17,8^{\circ} \mathrm{Brix}$.

Apresentando cachos de tamanho e peso médio, $14,8 \mathrm{~cm}$ e $353,8 \mathrm{~g}$, respectivamente, 'Fada' pode ser considerada uma boa variedade para mesa. Os cachos possuem, em média, 103 bagas e forma cônica. Bagas de forma oval, cor branca, peso médio de $3,79 \mathrm{~g}$ e duas sementes de tamanho médio por baga. A textura é trincante. $O$ sabor é neutro, com teor de sólidos solúveis de $16,3^{\circ} \mathrm{Brix}$.

Lígia' e 'Fada' são cultivares citados por POMMER (1993) tendo sido obtidos no programa de melhoramento genético da videira no Instituto Agronômico de Campinas. Em trabalho realizado por FERRI \& POMMER (1994), os autores selecionaram tais cultivares como preferenciais num programa de cruzamentos para uvas de mesa.

Os dados referentes às observações fenológicas e agronômicas, realizadas para todos os cultivares que compuseram o grupo B, encontram-se nas Tabelas 6 a 10 do Apêndice. 
Na Tabela 27 observam-se os dados referentes aos cultivares pertencentes ao grupo $\mathrm{C}$ e que foram destacados quanto à características agronômicas.

Tabela 27. Médias de peso ( $\mathrm{g}$ ) de cachos e bagas, número de bagas e teor de sólidos solúveis totais (SST), dos clones destacados no grupo C.

\begin{tabular}{|c|c|c|c|c|c|}
\hline \multicolumn{2}{|c|}{ Cultivar } & \multicolumn{2}{|l|}{ Peso } & \multirow{2}{*}{$\begin{array}{l}\text { Número } \\
\text { de bagas }\end{array}$} & \multirow{2}{*}{$\begin{array}{c}\text { SST } \\
{ }^{\circ} \mathrm{Brix} \\
\end{array}$} \\
\hline № & Nome & cacho & baga & & \\
\hline 22 & IAC 282 & 441,6 & 5,03 & 70 & 15,3 \\
\hline 70 & IAC 699-1 & 425,8 & 2,60 & 172 & 15,0 \\
\hline 119 & IAC 994-7 & 374,2 & 2,16 & 157 & 15,9 \\
\hline 21 & IAC $274-16$ & 361,9 & 3,48 & 104 & 15,3 \\
\hline 143 & IAC 1742 & 343,8 & 3,55 & 104 & 15,2 \\
\hline 41 & IAC $407-26$ & 337,0 & 3,98 & 91 & 15,4 \\
\hline 20 & IAC $202-43$ & 323,6 & 3,31 & 91 & 15,2 \\
\hline 74 & IAC $720-1$ & 313,0 & 2,36 & 102 & 16,0 \\
\hline 30 & LAC $353-3$ & 294,8 & 5,49 & 53 & 16,0 \\
\hline 66 & IAC $670-1$ & 290,8 & 2,62 & 98 & 14,8 \\
\hline 316 & IAC 1319 & 287,0 & 3,82 & 69 & 15,5 \\
\hline 75 & IAC $740-1$ & 280,0 & 2,89 & 109 & 16,3 \\
\hline 145 & IAC $82-1$ & 265,5 & 3,45 & 60 & 16,0 \\
\hline 11 & IAC $137-4$ & 258,4 & 2,10 & 130 & 14,5 \\
\hline 76 & IAC 746-3 & 258,0 & 2,69 & 86 & 16,0 \\
\hline 96 & IAC $871-18$ & 255,0 & 5,70 & 37 & 14,5 \\
\hline 152 & IAC $486-3$ & 254,3 & 2,76 & 81 & 14,5 \\
\hline 73 & IAC 719-7 & 252,8 & 2,18 & 125 & 16,5 \\
\hline 31 & IAC 387 & 238,0 & 3,27 & 75 & 15,9 \\
\hline 16 & IAC 192-54 & 200,1 & 2,63 & 78 & 17,0 \\
\hline
\end{tabular}

Os 20 clones que se destacaram no grupo C, apresentaram características agronômicas semelhantes e interessantes que permitem classificá-los como uvas de mesa. Foram obtidos em trabalhos de melhoramento da videira desenvolvido pelo Instituto Agronòmico de Campinas, conforme relato de FERRI \& POMMER (1994). Trata-se, dessa maneira, de material que possui elevado potencial como opção para produção de uvas de mesa, devendo, todavia, participar de um programa de pesquisa fitotécnica que comprove sua qualidade. 
No grupo C, composto por 53 clones IAC, 19 destacaram-se em relação ao tamanho curto ou longo do ciclo, o que se observa na Tabela 28.

Tabela 28. Número total e média de dias e graus-dia acumulados no ciclo total das plantas, da poda a colheita $(\mathrm{P} / \mathrm{C})$, para os cultivares que se destacaram no grupo C (clones IAC). Jundiai, 1991 e 1993.

\begin{tabular}{|c|c|c|c|c|c|c|}
\hline \multicolumn{2}{|c|}{ Cultivar } & \multirow[b]{2}{*}{ Ano } & \multicolumn{2}{|c|}{ Dias } & \multicolumn{2}{|c|}{ Graus-Dia } \\
\hline № & Nome & & $\mathrm{P} / \mathrm{C}$ & $\mathrm{M}$ & $\mathrm{P} / \mathrm{C}$ & $\mathrm{M}$ \\
\hline \multirow[t]{2}{*}{4} & IAC 23-8 & 91 & 146 & & 1459 & \\
\hline & & 93 & 137 & 141,5 & 1562 & 1510,5 \\
\hline \multirow[t]{2}{*}{11} & IAC $137-4$ & 91 & 146 & & 1459 & \\
\hline & & 93 & 143 & 144,5 & 1336 & 1397,5 \\
\hline \multirow[t]{2}{*}{19} & LAC 202-28 & 91 & 146 & & 1459 & \\
\hline & & 93 & 152 & 149,0 & 1781 & 1620,0 \\
\hline \multirow[t]{2}{*}{21} & IAC 274-16 & 91 & 146 & & 1459 & \\
\hline & & 93 & 152 & 149,0 & 1562 & 1510,5 \\
\hline \multirow[t]{2}{*}{41} & IAC $407-26$ & 91 & 146 & & 1459 & \\
\hline & & 93 & 137 & 141,5 & 1781 & 1620,0 \\
\hline \multirow[t]{2}{*}{116} & LAC $960-12$ & 91 & 146 & & 1459 & \\
\hline & & 93 & 143 & 144,5 & 1398 & 1428,5 \\
\hline \multirow[t]{2}{*}{118} & IAC $966-1$ & 91 & 146 & & 1459 & \\
\hline & & 93 & 143 & 144,5 & 1398 & 1428,5 \\
\hline \multirow[t]{2}{*}{153} & IAC $496-15$ & 91 & 146 & & 1459 & \\
\hline & & 93 & 143 & 144,5 & 1398 & 1428,5 \\
\hline \multirow[t]{2}{*}{37} & IAC 403-1 & 91 & 179 & & 1842 & \\
\hline & & 93 & 164 & 171,5 & 1562 & 1702,0 \\
\hline \multirow[t]{2}{*}{38} & IAC $405-6$ & 91 & 179 & & 1842 & \\
\hline & & 93 & 175 & 177,0 & 1636 & 1739,0 \\
\hline \multirow[t]{2}{*}{61} & IAC 592-1 & 91 & 179 & & 1842 & \\
\hline & & 93 & 164 & 171,5 & 1562 & 1702,0 \\
\hline \multirow[t]{2}{*}{81} & IAC $778-4$ & 91 & 179 & & 1842 & \\
\hline & & 93 & 175 & 177,0 & 1562 & 1702,0 \\
\hline \multirow[t]{2}{*}{82} & IAC $804-13$ & 91 & 179 & & 1842 & \\
\hline & & 93 & 175 & 177,0 & 1781 & 1811,5 \\
\hline \multirow[t]{2}{*}{91} & IAC $861-3$ & 91 & 179 & & 1842 & \\
\hline & & 93 & 164 & 171,5 & 1636 & 1739,0 \\
\hline \multirow[t]{2}{*}{96} & IAC $871-18$ & 91 & 179 & & 1842 & \\
\hline & & 93 & 164 & 171,5 & 1636 & 1739,0 \\
\hline \multirow[t]{2}{*}{99} & IAC $877-2$ & 91 & 179 & & 1842 & \\
\hline & & 93 & 164 & 171,5 & 1636 & 1739,0 \\
\hline \multirow[t]{2}{*}{100} & IAC 882-11 & 91 & 179 & & 1842 & \\
\hline & & 93 & 168 & 173,5 & 1687 & 1764,5 \\
\hline \multirow[t]{2}{*}{104} & IAC $904-11$ & 91 & 179 & & 1842 & \\
\hline & & 93 & 164 & 171,5 & 1636 & 1739,0 \\
\hline \multirow[t]{2}{*}{122} & IAC $1035-12$ & 91 & 179 & & 1842 & \\
\hline & & 93 & 168 & 173,5 & 1687 & 1764,5 \\
\hline
\end{tabular}


Percebe-se, por essa tabela, que os clones IAC 23-8, IAC 1374, IAC 407-26, IAC 960-12, IAC 966-1 e IAC 496-15 mostraram ciclos muito curtos (abaixo de 149 dias), os clones IAC 202-28 e IAC 274-16, ciclo curto (149 dias) e os clones IAC $403-1$, IAC 405-6, IAC 592-1, IAC 778-4, IAC 804-13, IAC 861-3, IAC 871-18, IAC 877-2, IAC 882-11, IAC 904-11 e IAC $1035-12$ tiveram o ciclo muito longo (acima de 169 dias).

Os clones mais precoces desse grupo foram o IAC $23-8$ e o IAC 407-26, ambos com ciclo de 141,5 dias e acumulando 1510,5 graus-dia, em média. Os mais tardios foram o IAC $405-6$, IAC $778-4$ e IAC $804-13$, com ciclo de 177 dias e acumulando mais de 1700 graus-dia.

Um clone muito precoce (IAC 407-26), um precoce (IAC 274-16) e um muito tardio (IAC 871-18), além de possuírem boas caracteristicas como uvas de mesa, demostraram a possibilidade de colheita fora do período de produção do 'Niagara Rosada'.

IAC $407-26$ apresentou cachos de tamanho médio $(14,7 \mathrm{~cm})$, com peso médio de $337,0 \mathrm{~g}$ e forma cônica. Compacidade média com 94 bagas, em média, por cacho. Bagas brancas, grandes $(19,1 \mathrm{~mm})$, pesando em média $3,98 \mathrm{~g}$ e com três sementes de tamanho médio por baga. Sabor moscatel, textura trincante e teor de sólidos solúveis $15,4^{\circ} \mathrm{Brix}$.

IAC 274-16 apresentou cachos de tamanho pequeno, com $12,3 \mathrm{~cm}$ de comprimento, peso médio de $361,0 \mathrm{~g}$, medianamente compactos, com 104 bagas por cacho e de forma cilíndrica e alada. Bagas ovais, de tamanho médio $(17,7 \mathrm{~mm})$, pesando em média $3,48 \mathrm{~g}$, com duas sementes de tamanho médio, por baga. Textura fundente, de cor branca, sabor neutro e teor de sólidos solúveis de $15,3^{\circ} \mathrm{Brix}$.

IAC 871-18 mostrou cachos de tamanho médio $(14,4 \mathrm{~cm})$, peso $255,0 \mathrm{~g}$, de forma cônica e alada. Cachos soltos com 37 bagas em média. Bagas de coloração rosada, grandes $(22,4 \mathrm{~mm})$, de forma oval e com duas sementes grandes por baga. Textura media, sabor neutro e teor médio de sólidos solúveis $14,5^{\circ}$ Brix. 
Nas Tabelas 11 a 15 do Apêndice, encontram-se os dados referentes às características fenológicas e agronomicas de todos os clones componentes do grupo $\mathrm{C}$.

Observam-se, na Tabela 29 , os dados referentes aos cultivares pertencentes ao grupo D, que se sobressairam pelas suas características agronômicas.

Tabela 29. Médias de peso ( $\mathrm{g}$ ) de cachos e bagas, número de bagas e teor de sólidos solúveis totais (SST), dos cultivares destacados do grupo D.

\begin{tabular}{|c|c|c|c|c|c|}
\hline \multicolumn{2}{|c|}{ Cultivar } & \multicolumn{2}{|l|}{ Peso } & \multirow{2}{*}{$\begin{array}{l}\text { Número } \\
\text { de bagas }\end{array}$} & \multirow{2}{*}{$\begin{array}{r}\text { SST } \\
{ }^{\circ} \mathrm{Brix} \\
\end{array}$} \\
\hline № & Nome & cacho & baga & & \\
\hline 250 & Seibel 60 & 265,8 & 3,33 & 84 & 16,3 \\
\hline 291 & Seibel 13.693 & 257,3 & 2,68 & 96 & 16,8 \\
\hline 280 & Seibel 8.724 & 254,0 & 2,16 & 104 & 15,3 \\
\hline 266 & Seibel 5.213 & 248,5 & 2,09 & 155 & 17,4 \\
\hline 259 & Seibel 4.643 & 248,0 & 3,80 & 77 & 17,2 \\
\hline 279 & Seibel 8.712 & 234,3 & 2,66 & 117 & 15,6 \\
\hline
\end{tabular}

Pode-se perceber que, neste grupo, somente cultivares da série Seibel foram destacados.

Este grupo foi composto por cultivares de uvas para produção de vinhos, conforme descrição de BÁN (1979), RIBAS (1973), SOUSA (1969) e DIAS (1959). Apesar dessa especialização, verifica-se que suas características agronômicas apresentaram valores adequados para classificação também como uvas de mesa.

O grupo D é composto por 30 cultivares, com dois da série Couderc e 28 da série Seibel. Desse grupo, seis se destacaram em relação ao comprimento curto ou longo do ciclo, o que se observa na Tabela 30 .

Percebe-se por essa tabela, que os cultivares Seibel 2.021, Seibel 4.643 , Seibel 10.878 e Seibel 11.813 apresentaram ciclos muito curtos (abaixo de 149 dias), o cultivar Seibel 4.995 mostrou ciclo curto (149 dias) e, o cultivar Seibel 12.583 teve o ciclo muito longo (acima de 169 dias). 
Tabela 30 . Número total e média de dias e graus-dia acumulados no ciclo total das plantas, da poda a colheita $(P / C)$, para os cultivares que se destacaram no grupo D (cultivares Seibel, Couderc). Jundiai, 1991 e 1993.

\begin{tabular}{|c|c|c|c|c|c|c|}
\hline \multicolumn{2}{|c|}{ Cultivar } & \multirow[b]{2}{*}{ Ano } & \multicolumn{2}{|c|}{ Dias } & \multicolumn{2}{|c|}{ Graus-Dia } \\
\hline № & Nome & & $\mathrm{P} / \mathrm{C}$ & $\mathrm{M}$ & $\mathrm{P} / \mathrm{C}$ & $\mathrm{M}$ \\
\hline \multirow[t]{2}{*}{165} & Seibel 4.995 & 91 & 146 & & 1459 & \\
\hline & & 93 & 152 & 149,0 & 1484 & 1471,5 \\
\hline \multirow[t]{2}{*}{215} & Seibel 2.021 & 91 & 146 & & 1459 & \\
\hline & & 93 & 143 & 144,5 & 1398 & 1428,5 \\
\hline \multirow[t]{2}{*}{259} & Seibel 4.643 & 91 & 146 & & 1459 & \\
\hline & & 93 & 143 & 144,5 & 1398 & 1428,5 \\
\hline \multirow[t]{2}{*}{285} & Seibel 10.878 & 91 & 146 & & 1459 & \\
\hline & & 93 & 137 & 141,5 & 1336 & 1397,5 \\
\hline \multirow[t]{2}{*}{304} & Seibel 11.813 & 91 & 125 & & 1209 & \\
\hline & & 93 & 137 & 131,0 & 1336 & 1272,5 \\
\hline \multirow[t]{2}{*}{287} & Seibel 12.583 & 91 & 179 & & 1842 & \\
\hline & & 93 & 175 & 177,0 & 1781 & 1811,5 \\
\hline
\end{tabular}

O cultivar mais precoce desse grupo foi Seibel 11.813, com ciclo de 131 dias e acumulando 1272,5 graus-dia, em média. O mais tardio foi Seibel 12.583 , com ciclo de 177 dias e acumulando mais de 1811 graus-dia.

Apesar da precocidade observada para alguns cultivares do grupo, aqueles destacados por suas características agronômicas não apresentaram, também, a mesma precocidade, coincidindo seu ciclo com o do 'Niagara Rosada'. Por esse motivo, não foram selecionados como op̧̧ões para cultivo como uvas de mesa.

No Apêndice, Tabelas de 16 a 20 , encontram-se os dados referentes às características fenológicas e agronômicas dos cultivares do grupo D.

Na Tabela 31 podem ser observados os dados referentes aos cultivares pertencentes ao grupo E, destacados quanto às suas características agronômicas. 
Tabela 31. Médias de peso (g) de cachos e bagas, número de bagas e teor de sólidos solúveis totais (SST), dos cultivares destacados do grupo E.

\begin{tabular}{|c|c|c|c|c|c|}
\hline \multicolumn{2}{|c|}{ Cultivar } & \multicolumn{2}{|c|}{ Peso } & \multirow{2}{*}{$\begin{array}{l}\text { Número } \\
\text { de bagas }\end{array}$} & \multirow{2}{*}{$\begin{array}{r}\text { SST } \\
{ }^{\circ} \mathrm{Brix} \\
\end{array}$} \\
\hline № & Nome & cacho & baga & & \\
\hline 3 & Niabel & 418,2 & 8,11 & 56 & 15,5 \\
\hline 5 & Bicane & 270,4 & 5,16 & 62 & 14,5 \\
\hline 300 & Chenin Blanc & 252,5 & 2,03 & 152 & 17,5 \\
\hline 326 & Diamante Negro & 258,4 & 3,22 & 90 & 17,0 \\
\hline 175 & Golden Muscat & 210,9 & 5,15 & 54 & 15,7 \\
\hline 456 & Patricia Branca & 203,0 & 5,35 & 46 & 14,8 \\
\hline 176 & Göethe & 218,6 & 5,39 & 45 & 16,5 \\
\hline 427 & Highland & 207,6 & 7,08 & 34 & 14,8 \\
\hline 445 & J $7.602-44$ & 236,9 & 2,82 & 84 & 15,5 \\
\hline 315 & Japonesa & 207,2 & 10,36 & 20 & 17,0 \\
\hline
\end{tabular}

Quanto às caracteristicas físicas, os cultivares destacados apresentaram pesos de cacho proporcionais ao peso e número de bagas, com exceção de 'Chenin Blanc' e Japonesa' que mostraram uma relação inversa entre esses parâmetros, apresentando maior número e menor peso de bagas e menor número e maior peso de bagas, respectivamente.

Os teores médios de solidos solúveis totais, para todos os cultivares destacados, enquadraram-se numa faixa adequada ao consumo.

Dos cultivares pertencentes a esse grupo, Diamante Negro', 'Chenin Blanc', Göethe', 'Golden Muscat' e 'Highland' participaram como progenitores no programa de melhoramento da videira desenvolvido no Instituto Agronômico de Campinas, conforme citação de FERRI \& POMMER (1994).

No grupo E, composto por 29 cultivares, doze se destacaram em relação ao comprimento curto ou longo do ciclo.

Verificou-se que os cultivares Bicane, Lubeck, Syrah, Moscatel Nazareno, Gold, Chardonnay, Niagara Rosada Escura, Niagara Branca Oval e Ananaz apresentaram ciclos muito curtos (abaixo de 149 dias), os cultivares Niabel e J 7.602-44 mostraram ciclo curto (149 dias) e o cultivar Highland teve o ciclo muito longo (acima de 169 dias). 
Os cultivares mais precoces desse grupo foram Bicane, Syrah Chardonnay e Ananaz com ciclo de 141,5 dias e acumulando 1397,5 graus-dia em média. O mais tardio foi Highland, com 171,5 dias e acumulando 1739 graus -dia.

As observações referentes ao ciclo fenológico dos cultivares pertencentes ao grupo E, podem ser visualizadas na Tabela 32 .

Tabela 32. Número total e média de dias e graus-dia acumulados no ciclo total das plantas, da poda a colheita $(\mathrm{P} / \mathrm{C})$, para os que se destacaram no grupo E (outros). Jundiaí, 1991 e 1993.

\begin{tabular}{|c|c|c|c|c|c|c|}
\hline \multicolumn{2}{|r|}{ Cultivar } & \multirow[b]{2}{*}{ Ano } & \multicolumn{2}{|c|}{ Dias } & \multicolumn{2}{|c|}{ Graus-Dia } \\
\hline № & Nome & & $\mathrm{P} / \mathrm{C}$ & $\mathrm{M}$ & $\mathrm{P} / \mathrm{C}$ & $\mathrm{M}$ \\
\hline \multirow[t]{2}{*}{3} & Niabel & 91 & 146 & & 1459 & \\
\hline & & 93 & 152 & 149,0 & 1484 & 1471,5 \\
\hline \multirow[t]{2}{*}{5} & Bicane & 91 & 146 & & 1459 & \\
\hline & & 93 & 137 & 141,5 & 1336 & 1397,5 \\
\hline \multirow[t]{2}{*}{204} & Lubeck & 91 & 146 & & 1459 & \\
\hline & & 93 & 143 & 144,5 & 1398 & 1428,5 \\
\hline \multirow[t]{2}{*}{224} & Syrah & 91 & 146 & & 1459 & \\
\hline & & 93 & 137 & 141,5 & 1336 & 1397,5 \\
\hline \multirow[t]{2}{*}{294} & Moscatel Nazareno & 91 & 146 & & 1459 & \\
\hline & & 93 & 143 & 144,5 & 1398 & 1428,5 \\
\hline \multirow[t]{2}{*}{303} & Gold & 91 & 149 & & 1488 & \\
\hline & & 93 & 137 & 143,0 & 1336 & 1412,0 \\
\hline \multirow[t]{2}{*}{307} & Chardonnay & 91 & 146 & & 1459 & \\
\hline & & 93 & 137 & 141,5 & 1336 & 1397,5 \\
\hline \multirow[t]{2}{*}{377} & Niagara Rosada Escura & 91 & 146 & & 1459 & \\
\hline & & 93 & 143 & 144,5 & 1398 & 1428,5 \\
\hline \multirow[t]{2}{*}{380} & Niagara Branca Oval & 91 & 146 & & 1459 & \\
\hline & & 93 & 143 & 144,5 & 1398 & 1428,5 \\
\hline \multirow[t]{2}{*}{410} & Ananaz & 91 & 146 & & 1459 & \\
\hline & & 93 & 137 & 141,5 & 1336 & 1397,5 \\
\hline \multirow[t]{2}{*}{445} & $J 7.602-44$ & 91 & 146 & & 1459 & \\
\hline & & 93 & 152 & 149,0 & 1484 & 1471,5 \\
\hline \multirow[t]{2}{*}{427} & Highland & 91 & 179 & & 1842 & \\
\hline & & 93 & 164 & 171,5 & 1636 & 1739,0 \\
\hline
\end{tabular}


Desse grupo, 'Syrah' foi descrita por RIBAS (1973) como uma das melhores variedades para as condições de São Paulo, por produzir ótimo vinho tinto de características européias, não sendo, assim, selecionado como uva de mesa.

Desses doze cultivares, quatro deles também se destacaram quanto às características agronômicas: 'Bicane', com ciclo muito curto; Niabel' e J 7.602-44, com ciclo curto e 'Highland' com ciclo muito longo.

'Bicane' apresentou cachos de tamanho médio $(17,5 \mathrm{~cm})$, peso médio de $319,9 \mathrm{~g}$, compacidade média, com 62 bagas por cacho e de forma cônica. Bagas brancas, ovais, grandes $(20,4 \mathrm{~mm})$, pesando em média $5,16 \mathrm{~g}$, com duas sementes de tamanho médio por baga. Textura média, sabor neutro, teor de sólidos solúveis de $14,5^{\circ}$ Brix.

'Niabel' mostrou cachos de tamanho médio $(16,7 \mathrm{~cm})$, com peso médio de $454,2 \mathrm{~g}$, compactos, com 56 bagas por cacho e de forma cônica e alada. Bagas vermelhas, ovais, grandes $(24,9 \mathrm{~mm})$, pesando em média $8,11 \mathrm{~g}$, com três sementes de tamanho grande por baga. Textura fundente, sabor foxado, teor de sólidos solúveis de $15,5^{\circ} \mathrm{Brix}$.

'J 7.602-44', apresentou bagas de cor vermelha, fundentes, sabor moscatel e teor de sólidos solúveis de $15,5^{\circ} \mathrm{Brix}$. Os cachos apresentaram-se de tamanho pequeno $(14,1 \mathrm{~cm})$, pesando $236,9 \mathrm{~g}$, de forma cônica e média compacidade com 84 bagas por cacho. O peso médio das bagas foi de $2,82 \mathrm{~g}$ e de tamanho grande $(20,2 \mathrm{~mm})$ e com duas sementes de tamanho médio por baga

'Highland' mostrou cachos de tamanho médio $(15,3 \mathrm{~cm})$, com peso médio de $240,7 \mathrm{~g}$, compacidade média, com 34 bagas por cacho e de forma cônica e alada. Bagas rosadas, esféricas, grandes $(22,7 \mathrm{~mm})$, pesando em média $7,1 \mathrm{~g}$, com três sementes de tamanho grande por baga. Textura fundente, sabor foxado, teor de sólidos solúveis de $14,8^{\circ} \mathrm{Brix}$.

Os dados referentes às características fenológicas e agronômicas de todos os cultivares do grupo $E$ podem ser observados no Apêndice, Tabelas de 21 a 25 . 
Dessa maneira, verificou-se, na coleção, a existência de cultivares e clones que apresentaram possibilidades de uso para produção de uvas de mesa, na região de Jundiaí. Estes, todavia, deverão participar de novas pesquisas que permitam melhores avaliações de seu potencial e que possam indicá-los como novas opções aos viticultores. 


\section{CONCLUSÕES}

Para as condições em que foi desenvolvido o presente trabalho, considerando os resultados obtidos, pode-se concluir que:

1. A coleção de videiras da Estação Experimental do Instituto Agronômico de Campinas, em Jundial, possui 52 cultivares e clones que apresentaram potencial para sua utilização como uvas de mesa, de acordo com suas características agronômicas: Ruby Seedless, Beauty Seedless, A Dona, Flame Seedless, Maria, Paulistinha, Patricia, Lígia, Fada, Traviú, Madalena, Seibel 5.213, Seibel 8.712, Seibel 4.643, Seibel 60, Seibel 13.693, Seibel 8.724, Niabel, Bicane, Diamante Negro, Chenin Blanc, Göethe, Golden Muscat, Highland, Patricia Branca, Japonesa e J 7.602-44, IAC 512-11, IAC 772-41, IAC 503-25, IAC 547-2, IAC 915-2, IAC 699-1, IAC 407-26, IAC 1742, IAC 274-16, IAC 282, IAC 994-7, IAC 740-1, IAC 82-1, IAC 202-43, IAC 353-3, IAC 137-4, IAC 719-7, IAC 1319, IAC 670-1, IAC 387, IAC 720-1, IAC 746-3, IAC 486-3, IAC 871-18, IAC 192-54.

2. Dentre estes, 14 cultivares e clones se destacaram por apresentarem periodos de colheita diferente da época tradicional do cultivar Niagara Rosada:

a)- precoces: 'Beauty Seedless', 'Flame Seedless', 'Paulistinha', IAC 503-25, 'Traviú', 'Fada', 'Lígia', 'Bicane', Niabel' e J 7.602-44, IAC $407-26$, IAC 274-16,;

b)-tardios: IAC 871-18 e 'Highland'. 


\section{CONCLUSÕES}

Para as condições em que foi desenvolvido o presente trabalho, considerando os resultados obtidos, pode-se concluir que:

1. A coleção de videiras da Estação Experimental do Instituto Agronomico de Campinas, em Jundiaí, possui 52 cultivares e clones que apresentaram potencial para sua utilização como uvas de mesa, de acordo com suas características agronômicas: Ruby Seedless, Beauty Seedless, A Dona, Flame Seedless, Maria, Paulistinha, Patrícia, Lígia, Fada, Traviú, Madalena, Seibel 5.213, Seibel 8.712, Seibel 4.643, Seibel 60, Seibel 13.693, Seibel 8.724, Niabel, Bicane, Diamante Negro, Chenin Blanc, Göethe, Golden Muscat, Highland, Patricia Branca, Japonesa, J 7.602-44, IAC 512-11, IAC 772-41, IAC 503-25, IAC 547-2, IAC 915-2, IAC 699-1, IAC 407-26, IAC 1742, IAC 274-16, IAC 282, IAC 994-7, IAC 740-1, IAC 82-1, IAC 202-43, IAC 353-3, IAC 137-4, IAC 719-7, IAC 1319, IAC 670-1, IAC 387, IAC 720-1, IAC 746-3, IAC 486-3, IAC 871-18, IAC 192-54.

2. Dentre estes, 14 cultivares e clones se destacaram por apresentarem periodos de colheita diferente da época tradicional do cultivar Niagara Rosada:

a)- precoces: 'Beauty Seedless', 'Flame Seedless', 'Paulistinha', 'Traviú', 'Fada', 'Lígia', 'Bicane', 'Niabel', J 7.602-44, IAC 407-26, IAC 274-16; IAC 503-25,

b)- tardios: IAC $871-18$ e 'Highland'. 


\section{REFERÊNCIAS BIBLIOGRÁFICAS}

ABRAHÃO, E. \& NOGUEIRA, D.J.P. Estudo do comportamento fenológico de híbridos franceses e americanos de videiras no sul de Minas Belo Horizonte, EPAMIG, 1992. 24p. (EPAMIG. Boletim Técnico, 39).

AHMEDULLAH, M. \& HIMELRICK, D.G. Grape Management. In: GALLETTA, G.J. \& HIMELRICK, D.G. Small fruit crop management. Englewood Cliffs, Prentice-Hall, 1990. cap. 10, p. $387-$ 471 .

ALMEIDA, J.L.F. Possibilidades de produção de uvas de mesa em Moçâmedes e em Roçadas. Angola, Instituto de Investigação Agronômica de Angola, 1972. 19p.

ALVARENGA, L.R. \& ABRAHÃO, E. Escolha de cultivares na viticultura. Informe Agropecuário, Belo Horizonte, 10(117):15-21, 1984.

ALVIM, P.T. Los factores de la productividad agricola. In: Instituto Interamericano de Ciencias Agricolas, Lima, Zona Andina. Curso Internacional de bases fisiológicas de la produccion agricola, Lima, 1962.

AMERINE, M.A. \& OUGH, C.S. Wine and must analysis. New York, John Wiley, 1974. 121p.

AZZI, G. Ecología agrária. Barcelona, Salvat, 1959.449p. 
BÁN, A.D. Estudo ampelográfico das principais cultivares do Estado do Rio Grande do Sul. Porto Alegre, Instituto de Pesquisas Agronômicas, 1979.166p. (Boletim Técnico, 5).

BIOLETTI, F. Outline of ampelography for the Vinifera grapes in California. Hilgardia, Berkeley, 11(6):227-93, 1938.

CAMARGO, U.A. \& DIAS, M.F. Identificação a mpelográfica de videiras americanas e híbridas cultivadas na MRH 311 . Bento Gonçalves, EMBRAPA/CNPUV, 1986. (EMBRAPA/CNPUV Circular Técnica, 12).

CARVALHO, V. Algumas características de uvas cultivadas no município de Caldas (MG) com vistas ao aproveitamento industrial do produto. São Paulo, 1972. 65p. (Doutorado-Faculdade de Ciências Farmacêuticas/USP).

CARVALHO, V.D. \& CHITARRA, M.I.F. Aspectos qualitativos da uva. Informe Agropecuário, Belo Horizonte, 10(117):75-9, 1984.

CHITARRA, M.I.F. \& CHITARRA, A.B. Pós-colheita de frutos e hortaliças; fisiologia e manuseio. Lavras, ESAL/FAEPE, 1990. 320p.

CALO, A.; LIUNI, C.S.; COSTACURTA, A,; COLAPIETRA, M, RENNA, D. Le uve da tavola. Conegliano Veneto, Instituto Sperimentale per la Viticoltura, $1989,319 \mathrm{p}$

De FINA, A.L. \& RAVELO, A.C. Fenologia In: De FINA, A.L \& RAVELO, A.C. Climatologia y fenologia agricolas. Buenos Aires, EUDEBA, 1973. p. $201-9$.

DIAS, M.F. A variedade na renovação dos vinhedos riograndesenses. Agronomia Sulriograndense, Porto Alegre, 4(1):43-55, 1959. 
FERRI, C.P. \& POMMER, C.V. Quarenta e oito anos de melhoramento da videira em São Paulo Brasil. Scientia Agricola, Piracicaba, 1994. (no prelo).

GALET, P. Précis d'ampelographie pratique. Montpellier, Imprimerie Dehán, 1976. 266p.

GALET, P. Précis de viticulture 4a. ed. Montpellier, Imprimerie Dehán, 1983. $584 p$

GAYET, JP. Características das frutas de exportação. In: NETTO, A.G.; GAYET, J.P., BLEINROTH, E.F.G.; MATALLO, M.; GARCIA, E.; GARCIA, A.E.; ARDITO, E.F.G; BORDIN, M. Uvas para exportação; procedimentos de colheita e pós-colheita. Brasília, FRUPEX, 1993, 40p.

GOBBATO, C. Manual do viti-vinicultor brasileiro. Porto Alegre, Globo, 1940 v.1, 422p.

HIDALGO, L. Equivalentes meteorologicos de la vid. INIA, Madrid, 16:175-209, 1956.

HIDALGO, L. Tratado de viticultura Madrid, Mundi-Prensa, 1993. $983 \mathrm{p}$.

JANICK, J, A ciência da horticultura. Rio de Janeiro, USAID, 1966. $485 p$.

KLIEWER, W:M. Changes in concentration of glucose, fructose, and total soluble solids in flowers and berries of Vitis vinifera. American Journal of Enolology and Viticulture, 16:101-10, 1965. 
KUHN, G.B.; LOVATEL, J.L.; PREZOTTO, O.P.; RIVALDO, O.F. O cultivo da videira; informações básicas. 2a.ed. EMBRAPA/CNPUV, 1986. 42p. (EMBRAPA/CNPUV. Circular Técnica, 10).

MANDELLI, F. Comportamento fenológico das principais cultivares de Vitis vinifera L. para a região de Bento Gonçalves, R.S. Piracicaba, 1984. 125p. (Mestrado-Escola Superior de Agricultura "Luiz de Queiroz"/USP).

MATHIEU, G. Appréciation de la maturité des raisins de table. Annalles Agronomiques, 7(2):249-56, 1937.

NELSON, K.E. Harvesting and handling California table grapes for market. Agricultural Experiment Station, California, 1985. 72p. (Bulletin, 1913).

NIMER, E. Clima. In: Geografia do Brasil - IBGE, 5:35-79, 1977.

PEDRO JÚNIOR, M.J. Videira \& Clima. In: Curso de Viticultura de Mesa, IAC, Campinas, outubro/1991.19p.(mimeografado).

PEDRO JÚNIOR, M.J, RIBEIRO, I.J.A.; POMMER, C.V.; MARTINS, F.P. Caracterização de estádios fenológicos de videira Niagara Rosada. In: CONGRESSO BRASILEIRO DE FRUTICULTURA, 10, Fortaleza, 1989. Anais. Fortaleza, 1989. p. 453-6.

PEDRO JÚNIOR, M.J; SENTELHAS, P.C.; POMMER, C.V.; MARTINS, F.P.; GALLO, P.B., SANTOS, R.R.; BOVI, V.; SABINO, J.C. Caracterização fenológica da videira 'Niagara Rosada' em diferentes regiões paulistas. Bragantia, Campinas, 52(2):153-160, 1993. 
PEREIRA, F.M. Uvas rústicas para mesa - Normas gerais para formação do vinhedo, seus tratos culturais e fitossanitários. Jaboticabal, FCAV/UNESP, 1982a. $7 \mathrm{p}$.

PEREIRA, F.M. Caracterização das principais variedades de videira em cultivo no Estado de São Paulo Jaboticabal, FCAV-UNESP, 1982b. 6 p.

PEREIRA, F.M. \& MARTINS, F.P. Instruções para a cultura da videira. Campinas, Instituto Agronómico, 1972. 48p. (IAC. Boletim, 199).

PIRES, E.J.P. Efeitos do ácido giberélico nas características dos cachos e das bagas em uva cultivar Maria (IAC 514-6). Piracicaba, ESALQ, 1988. 73p. (Mestrado-Escola Superior de Agricultura "Luiz de Queiroz"/USP.).

POMMER, C.V. Uva In: Furlani, A.M.C. \& Viegas, G.P. 0 melhoramento de plantas no Instituto Agronômico. Campinas, Instituto Agronômico, 1993 v. 1, p.489-524.

POMMER, C.V.; TERRA, M.M.; PIRES, E.J.P.; PICINI, A.H.; PASSOS, I.R.S. Influência do anelamento e do ácido giberélico nas caracter'sticas do cultivar de uvas sem sementes Maria. In: INTERNATIONAL SYMPOSIUM ON TABLE GRAPES, Baro $\mathrm{e}$ Palermo, 1991. Proceedings. 1993. Itália.

RIBAS, W.C. Contribuição à ampelologia nacional. II- Melhores variedades da coleção ampelográfica da Estação Experimental de São Roque, SP Campinas, Instituto Agronômico, 1973. 76p. (IAC. Circular, 28).

ROJA, M.L. Viticultura y vinificacion. Santiago, Ed. Nascimento, 1934. 780p. 
SANTOS NETO, J.R.A. Patrícia e Piratininga, variedades de uvas finas de mesa para climas tropicais. Bragantia, Campinas, nota 24 . p. CXIXCXXIII. 1976

SANTOS NETO, J.R.A. Cartilha do viticultor. Belo Horizonte, UVALE, 1983. $46 \mathrm{p}$

SANTOS NETO, J.R.A. Apirenia na videira. Belo Horizonte, UVALE, 1984. $14 \mathrm{p}$.

SANTOS NETO, J.R.A.;PEREIRA, F.M.; MARTINS, F.P.; LEITÃO FILHO, H.F. Características e possibilidades do cultivar IAC $138-22$, O Agronômico, Campinas, 20(9-10):1-8, 1968.

SHOEMAKER, J.S. Small fruit culture. 5a. ed. Westport, Connecticut, The AVI, 1977. $358 \mathrm{p}$.

SILVA, A.C.P.; PEREIRA, F.M.; MARTINS, F.P. Comportamento de cultivares americanos de videira na região de Jundial-SP. Científica, São Paulo, 18(1):61-70, 1990.

SOUSA, J.S.I. Uvas para o Brasil. São Paulo, Melhoramentos, 1969. 454p.

SOUSA, J.S.I. Cultura da videira. Melhoramentos, São Paulo, 1959. $295 \mathrm{p}$.

TERRA, M.M. Colheita da videira. In: Curso de viticultura de mesa, Instituto Agronòmico, Campinas, 1991.19p.

TERRA, M.M., PIRES, E.J.P.; PASSOS, I.R.S.; POMMER, C.V. Videira. In: JORGE, J.A.; LOURENÇÃO, A.L.; ARANHA, C. Instruções agrícolas para o Estado de São Paulo Campinas, Instituto Agronômico, 1990, p.209-10. 
TERRA, M.M.; PIRES, E.J.P; NOGUEIRA, N.A.M. Tecnologia para a produção de uva Itália na região noroeste do Estado de São Paulo. Campinas, Coordenadoria de Assistência Técnica Integral, 1993. 51p. (CATI. Documento Técnico, 97).

TERRA, M.M, POMMER, C.V.; PIRES, E.J.P. Considerações para elaboração de um plano nacional para a vitivinicultura. $\mathbf{O}$ Agronômico, Campinas, 41(2):122-31, 1989.

TRIPOLI, M.J.O \& MÜLLER, L. Desenvolvimento do fruto em algumas cultivares de videira no Rio Grande do Sul Agronomia Sulriograndense, Porto Alegre, 17:305-339, 1981 .

VALADARES, J; LEPSCH, I, KUPPER, A. Levantamento pedológico detalhado da Estação Experimental de Jundiaí-SP. Bragantia, Campinas, $\mathbf{3 0}(25): 337-86,1971$.

VEGA, J. Factores que condizionan la cantidad y calidad en la produción de uva. IDIA, Mendoza, 261:9-56, 1969.

VILLA NOVA, N.A.; PEDRO JÚNIOR, M.J., PEREIRA, A.R.; OMETTO, J.C. Estimativa de graus-dia acumulados acima de qualquer temperatura-base, em função das temperaturas máxima e mínima. São Paulo, USP-Instituto de Geografia, 1972. 8p. (Caderno de Ciências da Terra, 30 ).

VILLASECA, S.C., NOVOA, R. S-A.; MUÑOZ, I.H, Fenologia y suma de temperaturas en 24 variedades de vid. Agricultura Tecnica Chile, Santiago, $46(1): 63-7,1986$.

WINKLER, A.J Viticultura México, Continental, 1965. 792p. 
APENNDICE 
Tabela 1. Número de dias e graus-dia da poda ao início da brotação $(\mathrm{P} / \mathrm{B})$, da poda à colheita $(\mathrm{P} / \mathrm{C})$, e do início da brotação à colheita $(\mathrm{B} / \mathrm{C})$, correspondentes aos cultivares do grupo A (sem semente). Jundiaí, 1991.

\begin{tabular}{llllllll}
\hline \multicolumn{1}{c}{ Cultivar } & \multicolumn{3}{c}{ № de dias } & \multicolumn{3}{c}{ Graus-Dias } \\
\hline Nome & P/B & P/C & B/C & P/B & P/C & B/C \\
\hline 9 Beauty Seedless & 17 & 125 & 108 & 130,0 & 1209 & 1079 \\
10 Flame Seedless & 19 & 125 & 106 & 147,0 & 1209 & 1062 \\
40 Paulistinha & 21 & 110 & 89 & 159,0 & 1025 & 866 \\
47 Maria & 21 & 160 & 139 & 159,0 & 1617 & 1458 \\
50 IAC 544-14 & 13 & 160 & 147 & 90,3 & 1617 & 1527 \\
51 IAC 547-2 & 4 & 160 & 156 & 22,8 & 1617 & 1594 \\
58 Ruby Seedless & 21 & 160 & 139 & 159,0 & 1617 & 1458 \\
78 IAC 768-2 & 19 & 146 & 127 & 147,0 & 1549 & 1402 \\
79 IAC 772-41 & 21 & 160 & 139 & 159,0 & 1617 & 1458 \\
80 Aurora & 21 & 160 & 139 & 159,0 & 1617 & 1458 \\
90 IAC 860-5 & 21 & 160 & 139 & 159,0 & 1617 & 1458 \\
94 Gen & 24 & 160 & 136 & 110,0 & 1617 & 1507 \\
95 A Dona & 21 & 160 & 139 & 159,0 & 1617 & 1458 \\
101 IAC 901-1 & 19 & 146 & 127 & 147,0 & 1549 & 1402 \\
103 IAC 903-47 & 19 & 160 & 141 & 147,0 & 1617 & 1470 \\
105 IAC 904-30 & 16 & 160 & 144 & 121,0 & 1617 & 1496 \\
106 IAC 904-41 & 21 & 160 & 139 & 159,0 & 1617 & 1458 \\
107 IAC 904-47 & 21 & 160 & 139 & 159,0 & 1617 & 1458 \\
110 IAC 911-2 & 21 & 160 & 139 & 159,0 & 1617 & 1458 \\
111 IAC 915-2 & 19 & 160 & 141 & 147,0 & 1617 & 1470 \\
123 IAC 1117-6 & 15 & 146 & 131 & 110,0 & 1549 & 1439 \\
129 IAC 1193 & 21 & 146 & 125 & 159,0 & 1549 & 1390 \\
131 IAC 1238-8 & 24 & 146 & 122 & 178,0 & 1549 & 1371 \\
144 IAC 1851-2 & 15 & 160 & 145 & 110,0 & 1617 & 1507 \\
150 IAC 460-1 & 24 & 179 & 155 & 178,0 & 1842 & 1664 \\
156 IAC 503-25 & 19 & 146 & 127 & 147,0 & 1549 & 1402 \\
158 IAC 504-1 & 19 & 110 & 91 & 147,0 & 1025 & 878 \\
159 IAC 510-8 & 19 & 146 & 127 & 147,0 & 1549 & 1402 \\
161 IAC 512-11 & 19 & 146 & 127 & 147,0 & 1549 & 1402 \\
164 IAC 540-3 & 21 & 146 & 125 & 159,0 & 1549 & 1390 \\
170 IAC 733-39 & 21 & 160 & 139 & 159,0 & 1617 & 1458 \\
206 Sultanina Branca & 26 & 160 & 134 & 193,0 & 1617 & 1424 \\
360 H. 4.49.69 & 21 & 146 & 125 & 159,0 & 1549 & 1390 \\
373 Rosinha & 15 & 146 & 131 & 110,0 & 1549 & 1390 \\
459 Suffolk Red & 19 & 125 & 106 & 147,0 & 1209 & 1062 \\
\hline & & & & & & \\
\hline & & & & & & \\
\hline
\end{tabular}


Tabela 2. Número de dias e graus-dia da poda ao início da brotação $(\mathrm{P} / \mathrm{B})$, da poda à colheita $(\mathrm{P} / \mathrm{C})$, e do inicio da brotação à colheita $(\mathrm{B} / \mathrm{C})$, correspondentes aos cultivares do grupo A (sem semente). Jundiaí, 1993.

\begin{tabular}{|c|c|c|c|c|c|c|c|}
\hline \multicolumn{2}{|r|}{ Cultivar } & \multicolumn{3}{|c|}{ № de dias } & \multicolumn{3}{|c|}{ Graus-Dias } \\
\hline № & Nome & $\mathrm{P} / \mathrm{B}$ & $\mathrm{P} / \mathrm{C}$ & $B / C$ & $\mathrm{P} / \mathrm{B}$ & $\mathrm{P} / \mathrm{C}$ & $B / C$ \\
\hline 9 & Beauty Seedless & 13 & 143 & 130 & 68,9 & 1398 & 1329,1 \\
\hline 10 & Flame Seedless & 11 & 143 & 132 & 50,2 & 1398 & 1347,8 \\
\hline 40 & Paulistinha & 15 & 143 & 128 & 90,7 & 1398 & 1307,3 \\
\hline 47 & Maria & 13 & 152 & 139 & 68,9 & 1484 & 1415,1 \\
\hline 50 & IAC 544-14 & 13 & 158 & 145 & 68,9 & 1562 & 1493,1 \\
\hline 51 & IAC 547-2 & 13 & 164 & 151 & 68,9 & 1636 & 1567,1 \\
\hline 58 & Ruby Seedless & 15 & 158 & 143 & 90,7 & 1562 & 1471,3 \\
\hline 78 & IAC $768-2$ & 15 & 152 & 137 & 90,7 & 1484 & 1393,3 \\
\hline 79 & IAC $772-41$ & 15 & 158 & 143 & 90,7 & 1562 & 1471,3 \\
\hline 80 & Aurora & 31 & 164 & 133 & 198,0 & 1636 & 1438,0 \\
\hline 90 & IAC $860-5$ & 21 & 164 & 143 & 144,0 & 1636 & 1492,0 \\
\hline 94 & Geni & 33 & 175 & 142 & 215,0 & 1781 & 1566,0 \\
\hline 95 & A Dona & 31 & 175 & 144 & 198,0 & 1781 & 1583,0 \\
\hline 101 & IAC $901-1$ & 15 & 143 & 128 & 90,7 & 1398 & 1307,3 \\
\hline 103 & LAC $903-47$ & 15 & 137 & 122 & 90,7 & 1336 & 1245,3 \\
\hline 105 & IAC $904-30$ & 13 & 164 & 151 & 68,9 & 1636 & 1567,1 \\
\hline 106 & IAC $904-41$ & 11 & 158 & 147 & 50,2 & 1562 & 1511,8 \\
\hline 107 & IAC $904-47$ & 13 & 168 & 155 & 68,9 & 1687 & 1618,1 \\
\hline 110 & IAC $911-2$ & 13 & 158 & 145 & 68,9 & 1562 & 1493,1 \\
\hline 111 & IAC $915-2$ & 15 & 168 & 153 & 90,7 & 1687 & 1596,3 \\
\hline 123 & IAC 1117-6 & 15 & 168 & 153 & 90,7 & 1687 & 1596,3 \\
\hline 129 & IAC 1193 & 15 & 168 & 153 & 90,7 & 1687 & 1596,3 \\
\hline 131 & IAC $1238-8$ & 13 & 143 & 130 & 68,9 & 1398 & 1329,1 \\
\hline 144 & IAC $1851-2$ & 21 & 175 & 154 & 144,0 & 1781 & 1637,0 \\
\hline 150 & IAC $460-1$ & 13 & 164 & 151 & 68,9 & 1636 & 1567,1 \\
\hline 156 & IAC 503-25 & 13 & 143 & 130 & 68,9 & 1398 & 1329,1 \\
\hline 158 & IAC 504-1 & 15 & 143 & 128 & 90,7 & 1398 & 1307,3 \\
\hline 159 & IAC $510-8$ & 15 & 137 & 122 & 90,7 & 1336 & 1245,3 \\
\hline 161 & IAC 512-11 & 45 & 175 & 130 & 313,0 & 1781 & 1468,0 \\
\hline 164 & IAC $540-3$ & 15 & 152 & 137 & 90,7 & 1484 & 1393,3 \\
\hline 170 & IAC 733-39 & 13 & 137 & 124 & 68,9 & 1336 & 1267,1 \\
\hline 206 & Sultanina Branca & 15 & 168 & 153 & 90,7 & 1687 & 1596,3 \\
\hline 360 & H. 4.49 .69 & 13 & 143 & 130 & 68,9 & 1398 & 1329,1 \\
\hline 373 & Rosinha & 15 & 158 & 143 & 90,7 & 1562 & 1471,3 \\
\hline 459 & Suffolk Red & 15 & 137 & 122 & 90,7 & 1336 & 1245,3 \\
\hline
\end{tabular}


Tabela 3. Médias de peso $(\mathrm{g})$, comprimento $(\mathrm{cm})$, largura $(\mathrm{cm})$, número de bagas (NB), compacidade e forma dos cachos, correspondentes aos cultivares do grupo A (cultivares sem semente).Jundiaí, 1989-91, 1993.

\begin{tabular}{|c|c|c|c|c|c|c|}
\hline CULTIVAR & Peso & Comp & Larg & NB & Compacl & Forma $^{2}$ \\
\hline 58 Ruby Seedless & 755,0 & 14,80 & 7,50 & 303 & $\mathrm{M}$ & $\mathrm{Co} / \mathrm{A}$ \\
\hline 9 Beauty Seedless & 570,8 & 21,60 & 14,50 & 215 & M & $\mathrm{Co} / \mathrm{A}$ \\
\hline 10 Flame Seedless & 325,8 & 21,80 & 17,70 & 110 & $\mathrm{~s}$ & $\mathrm{Co} / \mathrm{A}$ \\
\hline 47 Maria & 270,0 & 6,60 & 4,40 & 96 & $M$ & $\mathrm{Co} / \mathrm{A}$ \\
\hline 161 IAC 512-11 & 269,7 & 17,10 & 7,10 & 97 & $M$ & $\mathrm{Ci}$ \\
\hline 79 IAC $772-41$ & 267,8 & 17,10 & 9,70 & 107 & $\mathrm{~S}$ & $\mathrm{Co} / \mathrm{A}$ \\
\hline 95 A Dona & 262,1 & 16,70 & 10,60 & 117 & $M$ & $\mathrm{Co} / \mathrm{A}$ \\
\hline 156 IAC 503-25 & 260,8 & 13,30 & 10,10 & 149 & $\mathrm{~S}$ & Co \\
\hline 51 IAC $547-2$ & 253,3 & 16,30 & 10,60 & 287 & $M$ & $\mathrm{Co} / \mathrm{A}$ \\
\hline 111 IAC $915-2$ & 243,3 & 17,00 & 9,00 & 139 & $\mathrm{~S}$ & $\mathrm{Co} / \mathrm{A}$ \\
\hline 40 Paulistinha & 222,8 & 18,10 & 9,20 & 119 & $\mathrm{M}$ & $\mathrm{Ci}$ \\
\hline 80 Aurora & 198,0 & 12,80 & 9,80 & 65 & $\mathrm{~s}$ & $\mathrm{Ci}$ \\
\hline 360 H. 4.49 .69 & 177,5 & 15,30 & 8,60 & 99 & $\mathrm{M}$ & $\mathrm{Co}$ \\
\hline 459 Suffolk Red & 166,0 & 15,60 & 6,00 & 46 & $M$ & $\mathrm{Ci}$ \\
\hline 101 IAC $901-1$ & 164,0 & 15,60 & 7,30 & 113 & C & $\mathrm{Ci}$ \\
\hline 206 Sultanina Branca & 163,4 & 10,40 & 7,60 & 36 & C & $\mathrm{Ci}$ \\
\hline 50 IAC 544-14 & 152,0 & 17,90 & 9,00 & 194 & $\mathrm{~S}$ & $\mathrm{Co} / \mathrm{A}$ \\
\hline 94 Geni & 146,4 & 15,60 & 10,10 & 80 & $M$ & $\mathrm{Co} / \mathrm{A}$ \\
\hline 110 IAC $911-2$ & 143,0 & 14,10 & 7,60 & 55 & $\mathrm{~S}$ & $\mathrm{Co} / \mathrm{A}$ \\
\hline 159 IAC $510-8$ & 142,3 & 9,80 & 7,70 & 90 & $\mathrm{M}$ & Co \\
\hline 105 IAC $904-30$ & 139,0 & 10,90 & 9,90 & 92 & $\mathrm{~S}$ & $\mathrm{Co} / \mathrm{A}$ \\
\hline $78 \mathrm{IAC} 768-2$ & 138,6 & 13,30 & 10,10 & 99 & $S$ & $\mathrm{Co}$ \\
\hline $150 \mathrm{IAC} 460-1$ & 137,0 & 15,70 & 8,70 & 33 & $S$ & $\mathrm{Co} / \mathrm{A}$ \\
\hline 131 IAC $1238-8$ & 136,2 & 14,60 & 8,10 & 136 & $\mathrm{~S}$ & $\mathrm{Co} / \mathrm{A}$ \\
\hline 90 IAC $860-5$ & 127,5 & 13,50 & 9,00 & 95 & $\mathrm{~S}$ & $\mathrm{Co} / \mathrm{A}$ \\
\hline 103 IAC $903-47$ & 122,4 & 12,00 & 7,40 & 80 & M & $\mathrm{Co}$ \\
\hline 164 LAC 540-3 & 88,1 & 15,00 & 8,00 & 113 & $\mathrm{~S}$ & $\mathrm{Co} / \mathrm{A}$ \\
\hline 129 IAC 1193 & 87,3 & 9,60 & 7,50 & 123 & C & $\mathrm{Ci}$ \\
\hline 170 IAC $733-39$ & 81,5 & 12,00 & 8,70 & 97 & $\mathrm{~S}$ & $\mathrm{~A}$ \\
\hline 107 IAC $904-47$ & 74,0 & 17,10 & 7,70 & 63 & $\mathrm{~S}$ & $\mathrm{Co} / \mathrm{A}$ \\
\hline 158 IAC 504-1 & 65,2 & 10,40 & 4,20 & 40 & $M$ & $\mathrm{Ci}$ \\
\hline $106 \mathrm{IAC} 904-41$ & 59,0 & 12,20 & 7,70 & 72 & $\mathrm{C}$ & Co \\
\hline 373 Rosinha & 54,0 & 9,20 & 5,60 & 25 & $\mathrm{M}$ & Co \\
\hline 123 IAC $1117-6$ & 39,6 & 11,30 & 6,30 & 41 & $\mathrm{~S}$ & $\mathrm{Ci}$ \\
\hline 144 IAC $1851-2$ & 35,5 & 15,50 & 9,10 & 27 & $\mathrm{~S}$ & $\mathrm{Co}$ \\
\hline
\end{tabular}

1. Compacidade: $\mathrm{M}$ - media, $\mathrm{C}$ - compacto e S- solto;

2. Forma: Co-connico, Ci- cilindrico e A- alado. 
Tabela 4. Médias de peso $(\mathrm{g})$, comprimento $(\mathrm{mm})$, largura $(\mathrm{mm})$, forma número de sementes(NS) e tamanho das sementes (TS) das bagas, correspondentes aos cultivares do grupo A (sem sementes). Jundiai, 1989-91, 1993,

\begin{tabular}{|c|c|c|c|c|c|c|c|}
\hline № & CULTIVAR & Peso & Compr. & Larg. & forma $^{1}$ & NS & TS \\
\hline 170 & IAC 733-39 & 0,84 & 11,50 & 11,50 & E & - & - \\
\hline 144 & IAC $1851-2$ & 0,92 & 11,40 & 11,40 & $E$ & - & - \\
\hline 50 & IAC $544-14$ & 0,97 & 10,30 & 9,60 & 0 & - & - \\
\hline 206 & Sultanina Branca & 4,18 & 19,40 & 18,20 & 0 & - & - \\
\hline 150 & IAC $460-1$ & 2,79 & 17,80 & 17,20 & $E$ & - & - \\
\hline 164 & IAC $540-3$ & 0,78 & 9,10 & 8,80 & $E$ & - & - \\
\hline 58 & Ruby Seedless & 3,54 & 18,40 & 16,80 & $\mathrm{O}$ & - & - \\
\hline 9 & Beauty Seedless & 2,32 & 17,90 & 15,90 & $\mathrm{O}$ & - & - \\
\hline 10 & Flame Seedless & 2,56 & 18,90 & 18,40 & 0 & - & - \\
\hline 459 & Suffolk Red Seedless & 3,07 & 16,70 & 16,90 & $\mathrm{O}$ & - & - \\
\hline 94 & Geni & 2,21 & 18,20 & 16,10 & $\mathrm{O}$ & - & - \\
\hline 47 & Maria & 2,91 & 16,70 & 16,10 & E & - & - \\
\hline 161 & IAC 512-11 & 2,78 & 17,50 & 15,00 & $\mathrm{O}$ & - & - \\
\hline 373 & Rosinha & 3,44 & 15,70 & 15,30 & $\mathrm{O}$ & - & - \\
\hline 95 & A Dona & 2,49 & 17,80 & 14,80 & $\mathrm{O}$ & - & - \\
\hline 80 & Aurora & 2,80 & 15,30 & 14,90 & $\mathrm{O}$ & - & - \\
\hline 40 & Paulistinha & 1,98 & 16,40 & 13,90 & 0 & - & - \\
\hline 79 & IAC 772-41 & 2,50 & 15,00 & 14,40 & $\mathrm{O}$ & - & - \\
\hline 110 & IAC $911-2$ & 1,81 & 14,60 & 13,90 & 0 & - & - \\
\hline 156 & IAC 503-25 & 1,75 & 15,30 & 13,10 & $\mathrm{O}$ & - & - \\
\hline 360 & H 4.49.69 & 1,81 & 14,50 & 13,40 & $\mathrm{O}$ & - & - \\
\hline 159 & IAC 510-8 & 1,33 & 14,50 & 13,10 & $\mathrm{O}$ & - & - \\
\hline 111 & IAC $915-02$ & 1,75 & 13,70 & 13,00 & 0 & - & - \\
\hline 103 & LAC $903-47$ & 1,53 & 13,20 & 12,50 & $E$ & - & - \\
\hline 131 & IAC $1238-8$ & 1,19 & 13,20 & 13,10 & $E$ & - & - \\
\hline 158 & IAC 504-1 & 1,63 & 13,70 & 11,80 & $\mathrm{O}$ & - & - \\
\hline 123 & IAC $1117-6$ & 1,35 & 11,60 & 11,00 & $E$ & - & - \\
\hline 107 & IAC $904-47$ & 1,41 & 12,20 & 12,00 & $E$ & - & - \\
\hline 90 & IAC $860-5$ & 1,55 & 11,90 & 12,20 & $E$ & - & - \\
\hline 105 & IAC $904-30$ & 1,15 & 11,80 & 12,30 & $E$ & - & - \\
\hline 101 & IAC $901-1$ & 1,10 & 12,90 & 11,70 & $\mathrm{O}$ & - & - \\
\hline 78 & IAC 768-2 & 1,40 & 13,30 & 11,00 & $\mathrm{O}$ & - & - \\
\hline 129 & IAC 1193 & 0,71 & 10,30 & 10,40 & E & - & - \\
\hline 51 & IAC $547-2$ & 0,86 & 11,50 & 10,50 & $\mathrm{O}$ & - & - \\
\hline 106 & IAC $904-41$ & 0,82 & 10,10 & 10,10 & $E$ & - & - \\
\hline
\end{tabular}


Tabela 5. Textura, sabor, teor de sólidos solúveis totais $\left({ }^{\circ} \mathrm{Brix}\right)$ e $\mathrm{pH}$ dos cultivares do grupo A (sem sementes). Jundiaí, 1989-91, 1993.

\begin{tabular}{|c|c|c|c|c|c|}
\hline \multicolumn{2}{|r|}{ CULTIVAR } & \multicolumn{4}{|c|}{ Características Tecnológicas } \\
\hline № & Nome & text $^{1}$ & sabor $^{2}$ & ${ }^{\circ}$ Brix & $\mathrm{pH}$ \\
\hline 106 & IAC $904-41$ & $\mathrm{M}$ & $\mathrm{N}$ & 19,0 & 3,1 \\
\hline 360 & H. 4.49 .69 & $\mathrm{~T}$ & $\mathrm{~N}$ & 18,3 & 3,0 \\
\hline 101 & LAC $901-1$ & $\mathrm{M}$ & $\mathrm{N}$ & 18,2 & 3,0 \\
\hline 164 & $\mathrm{IAC} 540-3$ & $M$ & $\mathrm{~N}$ & 17,7 & 2,9 \\
\hline 80 & Aurora & $\mathrm{T}$ & Mo & 17,5 & 2,9 \\
\hline 129 & IAC 1193 & $M$ & $\mathrm{~N}$ & 17,3 & 2,7 \\
\hline 50 & IAC 544-14 & $\mathrm{T}$ & $\mathrm{N}$ & 17,3 & 2,9 \\
\hline 170 & IAC 733-39 & $M$ & N & 17,1 & 2,9 \\
\hline 105 & IAC $904-30$ & $\mathrm{~F}$ & $\mathrm{~N}$ & 17,1 & 2,9 \\
\hline 131 & IAC 1238-8 & $\mathrm{M}$ & $N$ & 17,0 & 2,8 \\
\hline 79 & IAC 772-41 & $\mathrm{T}$ & $\mathrm{N}$ & 17,0 & 3,1 \\
\hline 103 & IAC $903-47$ & M & $\mathrm{N}$ & 17,0 & 3,1 \\
\hline 107 & IAC $904-47$ & $\mathrm{~T}$ & $\mathrm{~N}$ & 16,7 & 3,1 \\
\hline 110 & IAC 911-2 & $\mathrm{F}$ & $\mathrm{N}$ & 16,6 & 3,1 \\
\hline 78 & IAC 768-2 & $\mathrm{F}$ & $\mathrm{N}$ & 16,5 & 3,2 \\
\hline 90 & IAC $860-5$ & $M$ & $\mathrm{~N}$ & 16,3 & 2,7 \\
\hline 459 & Suffolk red & $\mathrm{T}$ & $\mathrm{N}$ & 16,3 & 3,0 \\
\hline 111 & IAC $915-2$ & $\mathrm{~F}$ & $\mathrm{~N}$ & 16,1 & 3,0 \\
\hline 51 & IAC $547-2$ & $T$ & $N$ & 16,2 & 3,0 \\
\hline 123 & IAC $1117-6$ & $\mathrm{~F}$ & $\mathrm{~N}$ & 16,0 & 3,2 \\
\hline 58 & Ruby Seedless & $\mathrm{T}$ & $\mathrm{N}$ & 16,0 & 3,3 \\
\hline 9 & Beauty Seedless & $\mathrm{T}$ & $\mathrm{N}$ & 15,5 & 3,1 \\
\hline 159 & IAC $510-8$ & $\mathrm{M}$ & $\mathrm{N}$ & 15,5 & 2,9 \\
\hline 10 & Flame Seedless & $\mathrm{T}$ & $\mathrm{N}$ & 15,5 & 3,4 \\
\hline 40 & Paulistinha & $M$ & $\mathrm{~N}$ & 15,4 & 3,0 \\
\hline 94 & Geni & $\mathrm{T}$ & $\mathrm{N}$ & 15,3 & 3,2 \\
\hline 156 & IAC 503-25 & $\mathrm{M}$ & $\mathrm{N}$ & 15,3 & 3,2 \\
\hline 373 & Rosinha & $\mathrm{F}$ & Fo & 15,0 & 3,1 \\
\hline 144 & IAC $1851-2$ & M & $\mathrm{N}$ & 15,0 & 3,2 \\
\hline 161 & IAC 512-11 & $\mathrm{F}$ & Fo & 15,0 & 2,9 \\
\hline 95 & A Dona & $M$ & M & 14,8 & 3,1 \\
\hline 47 & Maria & $M$ & $\mathrm{M}$ & 16,5 & 3,1 \\
\hline 158 & IAC 504-1 & $M$ & $\mathrm{~N}$ & 13,9 & 3,0 \\
\hline 150 & IAC $460-1$ & $\mathrm{~T}$ & $\mathrm{~N}$ & 13,1 & 3,0 \\
\hline 206 & Sultanina branca & $\mathrm{M}$ & $\mathrm{N}$ & 11,2 & 3,8 \\
\hline
\end{tabular}

1. Textura: M-média, F- fundente; T- trincante.

2. Sabor: N- neutro, Fo- foxado, Mo- moscatel. 
Tabela 6. Número de dias e graus-dia, da poda ao início da brotação (P/B), da poda à colheita $(\mathrm{P} / \mathrm{C})$, e do início da brotação a colheita $(\mathrm{B} / \mathrm{C})$, correspondentes aos cultivares do grupo B (IAC, SR, Jd). Jundiaí, 1991.

\begin{tabular}{|c|c|c|c|c|c|c|c|}
\hline \multicolumn{2}{|r|}{ Cultivar } & \multicolumn{3}{|c|}{ № de dias } & \multicolumn{3}{|c|}{ Graus-Dias } \\
\hline № & Nome & $\mathrm{P} / \mathrm{B}$ & $\mathrm{P} / \mathrm{C}$ & $\mathrm{B} / \mathrm{C}$ & $\mathrm{P} / \mathrm{B}$ & $\mathrm{P} / \mathrm{C}$ & $\mathrm{B} / \mathrm{C}$ \\
\hline 6 & Madalena & 21 & 160 & 139 & 159 & 1617 & 1458 \\
\hline 7 & Rainha & 21 & 146 & 125 & 159 & 1459 & 1300 \\
\hline 12 & Máximo & 21 & 146 & 125 & 159 & 1459 & 1300 \\
\hline 23 & SR 496-26 & 15 & 146 & 131 & 110 & 1459 & 1349 \\
\hline 24 & SR 507-8 & 15 & 146 & 131 & 110 & 1459 & 1349 \\
\hline 32 & Santa Tereza & 21 & 160 & 139 & 159 & 1617 & 1458 \\
\hline 44 & Soraya & 26 & 146 & 120 & 193 & 1459 & 1266 \\
\hline 46 & Isaura & 21 & 139 & 118 & 159 & 1375 & 1216 \\
\hline 48 & SR 5.010-8 & 24 & 146 & 122 & 178 & 1459 & 1281 \\
\hline 55 & SR 507-38 & 19 & 146 & 127 & 147 & 1459 & 1312 \\
\hline 69 & Iara & 19 & 160 & 141 & 147 & 1617 & 1470 \\
\hline 87 & SR 501-17. & 24 & 146 & 122 & 178 & 1459 & 1281 \\
\hline 93 & SR 5.010-21 & 24 & 146 & 122 & 178 & 1459 & 1281 \\
\hline 97 & Patrícia & 15 & 160 & 145 & 110 & 1617 & 1507 \\
\hline 133 & Traviú & 15 & 119 & 104 & 110 & 1132 & 1022 \\
\hline 134 & Ezequiel & 15 & 125 & 110 & 110 & 1209 & 1099 \\
\hline 138 & Lígia & 21 & 146 & 125 & 159 & 1459 & 1300 \\
\hline 139 & Angelina & 15 & 160 & 145 & 110 & 1617 & 1507 \\
\hline 140 & Marta & 15 & 119 & 104 & 110 & 1132 & 1022 \\
\hline 148 & Fada & 17 & 125 & 108 & 130 & 1209 & 1079 \\
\hline 149 & Branca de Neve & 29 & 146 & 117 & 213 & 1459 & 1246 \\
\hline 183 & Jd 930 & 19 & 160 & 141 & 147 & 1617 & 1470 \\
\hline 217 & SR 496-9 & 21 & 146 & 125 & 159 & 1459 & 1300 \\
\hline 218 & SR 496-15 & 21 & 146 & 125 & 159 & 1459 & 1300 \\
\hline 219 & SR 496-25 & 19 & 160 & 141 & 147 & 1617 & 1470 \\
\hline 222 & SR 5.012-34 & 19 & 160 & 141 & 147 & 1617 & 1470 \\
\hline 246 & Roberta & 17 & 160 & 143 & 130 & 1617 & 1487 \\
\hline 247 & SR 49 & 15 & 160 & 145 & 110 & 1617 & 1507 \\
\hline
\end{tabular}


Tabela 7. Número de dias e graus-dia da poda ao início da brotação $(\mathrm{P} / \mathrm{B})$, da poda à colheita $(\mathrm{P} / \mathrm{C})$, e do início da brotação à colheita $(\mathrm{B} / \mathrm{C})$, correspondentes aos cultivares do grupo B (IAC, SR, Jd). Jundiaí, 1993.

\begin{tabular}{|c|c|c|c|c|c|c|c|}
\hline \multicolumn{2}{|r|}{ Cultivar } & \multicolumn{3}{|c|}{ № de dias } & \multicolumn{3}{|c|}{ Graus-Dias } \\
\hline № & Nome & $\mathrm{P} / \mathrm{B}$ & $\mathrm{P} / \mathrm{C}$ & $\mathrm{B} / \mathrm{C}$ & $\mathrm{P} / \mathrm{B}$ & $\mathrm{P} / \mathrm{C}$ & $\mathrm{B} / \mathrm{C}$ \\
\hline 6 & Madalena & 13 & 143 & 130 & 68,9 & 1398 & 1329,1 \\
\hline 7 & Rainha & 13 & 175 & 162 & 68,9 & 1781 & 1712,1 \\
\hline 12 & Máximo & 13 & 137 & 124 & 68,9 & 1336 & 1267,1 \\
\hline 23 & SR 496-26 & 13 & 152 & 139 & 68,9 & 1484 & 1415,1 \\
\hline 24 & SR 507-8 & 13 & 143 & 130 & 68,9 & 1398 & 1329,1 \\
\hline 32 & Santa Tereza & 13 & 152 & 139 & 68,9 & 1484 & 1415,1 \\
\hline 44 & Soraya & 19 & 152 & 133 & 123,0 & 1484 & 1361,0 \\
\hline 46 & Isaura & 15 & 143 & 128 & 90,7 & 1398 & 1307,3 \\
\hline 48 & SR 5.010-8 & 15 & 127 & 112 & 90,7 & 1239 & 1148,3 \\
\hline 55 & SR 507-38 & 13 & 143 & 130 & 68,9 & 1398 & 1329,1 \\
\hline 69 & Lara & 13 & 164 & 151 & 68,9 & 1636 & 1567,1 \\
\hline 87 & SR 501-17 & 13 & 143 & 130 & 68,9 & 1398 & 1329,1 \\
\hline 93 & SR 5.010-21 & 15 & 143 & 128 & 90,7 & 1398 & 1307,3 \\
\hline 97 & Patrícia & 13 & 158 & 145 & 68,9 & 1562 & 1493,1 \\
\hline 133 & Traviú & 13 & 143 & 130 & 68,9 & 1398 & 1329,1 \\
\hline 134 & Ezequiel & 13 & 158 & 145 & 68,9 & 1562 & 1493,1 \\
\hline 138 & Lígia & 15 & 152 & 137 & 90,7 & 1484 & 1393,3 \\
\hline 139 & Angelina & 13 & 137 & 124 & 68,9 & 1336 & 1267,1 \\
\hline 140 & Marta & 15 & 143 & 128 & 90,7 & 1398 & 1307,3 \\
\hline 148 & Fada & 15 & 143 & 128 & 90,7 & 1398 & 1307,3 \\
\hline 149 & Branca de Neve & 15 & 143 & 128 & 90,7 & 1398 & 1307,3 \\
\hline 183 & Jd 930 & 21 & 152 & 131 & 144,0 & 1484 & 1340,0 \\
\hline 217 & SR 496-9 & 13 & 143 & 130 & 68,9 & 1398 & 1329,1 \\
\hline 218 & SR 496-15 & 15 & 143 & 128 & 90,7 & 1398 & 1307,3 \\
\hline 219 & SR 496-25 & 13 & 143 & 130 & 68,9 & 1398 & 1329,1 \\
\hline 222 & SR 5.012-34 & 13 & 143 & 130 & 68,9 & 1398 & 1329,1 \\
\hline 246 & Roberta & 13 & 143 & 130 & 68,9 & 1398 & 1329,1 \\
\hline 247 & SR 49 & 28 & 143 & 115 & 176,0 & 1398 & 1222,0 \\
\hline
\end{tabular}


Tabela 8. Médias de peso $(\mathrm{g})$, comprimento $(\mathrm{cm})$, largura $(\mathrm{cm})$, número de bagas $(\mathrm{NB})$, compacidade e forma dos cachos, correspondentes aos cultivares do grupo B (IAC, SR, Jd) Jundiai, 1988-91, 1993.

\begin{tabular}{rlrrrrrr}
\hline \hline № & Cultivar & Peso & Comp & Larg & NB & Compac Forma $^{2}$ \\
\hline 97 & Patrícia & 595,0 & 16,00 & 10,10 & 110 & $\mathrm{C}$ & $\mathrm{Co} / \mathrm{A}$ \\
138 Lígia & 358,0 & 12,00 & 7,00 & 89 & $\mathrm{M}$ & $\mathrm{Co} / \mathrm{A}$ \\
148 Fada & 353,8 & 14,80 & 9,80 & 103 & $\mathrm{C}$ & $\mathrm{Co}$ \\
133 Traviú & 327,8 & 11,70 & 7,00 & 140 & $\mathrm{C}$ & $\mathrm{Co} / \mathrm{A}$ \\
6 Madalena & 253,0 & 14,40 & 8,20 & 84 & $\mathrm{M}$ & $\mathrm{Co}$ \\
44 & Soraya & 253,0 & 13,80 & 7,40 & 28 & $\mathrm{~S}$ & $\mathrm{Ci}$ \\
222 & SR 5.012-34 & 224,7 & 15,50 & 10,10 & 137 & $\mathrm{C}$ & $\mathrm{Co}$ \\
7 Rainha & 219,0 & 14,60 & 8,90 & 144 & $\mathrm{C}$ & $\mathrm{Co} / \mathrm{A}$ \\
140 & Marta & 209,9 & 13,90 & 11,10 & 66 & $\mathrm{M}$ & $\mathrm{Co} / \mathrm{A}$ \\
12 & Máximo & 209,6 & 14,50 & 10,00 & 138 & $\mathrm{C}$ & $\mathrm{Co}$ \\
219 & SR 496-25 & 199,3 & 13,60 & 9,20 & 114 & $\mathrm{C}$ & $\mathrm{Co} / \mathrm{A}$ \\
149 & Branca de Neve & 197,7 & 12,60 & 9,90 & 30 & $\mathrm{~S}$ & $\mathrm{Ci}$ \\
69 & Iara & 187,0 & 14,00 & 9,90 & 98 & $\mathrm{M}$ & $\mathrm{Co} / \mathrm{A}$ \\
32 & Santa Tereza & 185,8 & 17,20 & 7,10 & 38 & $\mathrm{M}$ & $\mathrm{Co}$ \\
139 & Angelina & 181,4 & 12,30 & 8,20 & 34 & $\mathrm{~S}$ & $\mathrm{Co}$ \\
246 & Roberta & 180,9 & 11,50 & 7,20 & 90 & $\mathrm{M}$ & $\mathrm{Co} / \mathrm{A}$ \\
183 & Jd 930 & 174,5 & 14,20 & 6,80 & 63 & $\mathrm{~S}$ & $\mathrm{Ci}$ \\
87 & SR 501-17 & 164,0 & 12,50 & 7,60 & 52 & $\mathrm{C}$ & $\mathrm{Ci}$ \\
48 & SR 5.010-08 & 158,0 & 15,90 & 9,70 & 176 & $\mathrm{M}$ & $\mathrm{Co} / \mathrm{A}$ \\
218 & SR 496-15 & 156,2 & 13,80 & 8,40 & 137 & $\mathrm{M}$ & $\mathrm{Co} / \mathrm{A}$ \\
134 & Ezequiel & 147,6 & 13,30 & 7,20 & 41 & $\mathrm{~S}$ & $\mathrm{Co} / \mathrm{A}$ \\
46 & Isaura & 141,5 & 14,30 & 10,00 & 47 & $\mathrm{~S}$ & $\mathrm{Co}$ \\
55 & SR 507-38 & 138,0 & 10,60 & 6,30 & 68 & $\mathrm{M}$ & $\mathrm{Co}$ \\
217 & SR 496-09 & 135,7 & 13,40 & 10,20 & 87 & $\mathrm{C}$ & $\mathrm{Co}$ \\
93 & SR 5.010-21 & 135,0 & 11,70 & 8,40 & 144 & $\mathrm{M}$ & $\mathrm{Co}$ \\
247 & SR 49 & 125,3 & 12,80 & 7,80 & 75 & $\mathrm{M}$ & $\mathrm{Co}$ \\
23 & SR 496-26 & 123,2 & 11,00 & 6,90 & 91 & $\mathrm{C}$ & $\mathrm{Co}$ \\
24 & SR 507-08 & 111,6 & 8,90 & 7,00 & 79 & $\mathrm{C}$ & $\mathrm{Co} / \mathrm{A}$ \\
\hline \hline
\end{tabular}

1. Compacidade: $\mathrm{M}$ - média, $\mathrm{C}$ - compacto e $\mathrm{S}$ - solto;

2. Forma: Co-cônico, Ci- cilíndrico e A- alado. 
Tabela 9. Médias de peso $(\mathrm{g})$, comprimento $(\mathrm{mm})$, largura $(\mathrm{mm})$, forma, número dè sementes (NS) e tamanho das sementes (TS) das bagas, correspondentes aos cultivares do grupo B (IAC, SR, Jd). Jundiai, 1988-91, 1993.

\begin{tabular}{clrrrrrr}
\hline \hline No Cultivar & Peso & Compr. & Larg. & forma & NS & TS \\
\hline 44 Soraya & 7,83 & 28,2 & 20,9 & $\mathrm{O}$ & 1 & $\mathrm{G}$ \\
139 Angelina & 5,69 & 22,1 & 20,2 & $\mathrm{O}$ & 2 & $\mathrm{G}$ \\
97 Patricia & 5,68 & 22,0 & 20,2 & $\mathrm{O}$ & 2 & $\mathrm{G}$ \\
32 Santa Tereza & 5,13 & 22,6 & 19,2 & $\mathrm{O}$ & 2 & $\mathrm{M}$ \\
138 Ligia & 4,75 & 20,3 & 19,1 & $\mathrm{O}$ & 3 & $\mathrm{M}$ \\
134 Ezequiel & 4,38 & 20,9 & 17,7 & $\mathrm{O}$ & 2 & $\mathrm{G}$ \\
148 Fada & 3,79 & 19,7 & 17,5 & $\mathrm{O}$ & 2 & $\mathrm{M}$ \\
46 Isaura & 3,47 & 17,4 & 17,4 & $\mathrm{E}$ & 3 & $\mathrm{M}$ \\
149 Branca de Neve & 3,35 & 19,5 & 16,1 & $\mathrm{O}$ & 1 & $\mathrm{M}$ \\
140 Marta & 3,18 & 16,7 & 16,8 & $\mathrm{O}$ & 2 & $\mathrm{P}$ \\
183 Jd 930 & 2,77 & 17,2 & 16,2 & $\mathrm{E}$ & 2 & $\mathrm{P}$ \\
6 Madalena & 2,62 & 16,4 & 15,9 & $\mathrm{O}$ & 2 & $\mathrm{P}$ \\
87 SR 501-17 & 2,50 & 15,9 & 15,6 & $\mathrm{E}$ & 1 & $\mathrm{M}$ \\
133 Traviú & 2,45 & 15,7 & 15,7 & $\mathrm{E}$ & 2 & $\mathrm{P}$ \\
246 Roberta & 2,01 & 15,3 & 14,6 & $\mathrm{O}$ & 3 & $\mathrm{G}$ \\
69 Iara & 1,93 & 14,5 & 14,3 & $\mathrm{O}$ & 3 & $\mathrm{P}$ \\
12 Máximo & 1,76 & 15,2 & 13,7 & $\mathrm{O}$ & 3 & $\mathrm{P}$ \\
219 SR 496-25 & 1,69 & 13,8 & 12,7 & $\mathrm{E}$ & 2 & $\mathrm{G}$ \\
247 SR 49 & 1,67 & 13,9 & 16,6 & $\mathrm{E}$ & 3 & $\mathrm{M}$ \\
24 SR 507-8 & 1,66 & 14,8 & 12,3 & $\mathrm{O}$ & 3 & $\mathrm{M}$ \\
222 SR 5.012-34 & 1,64 & 15,3 & 13,0 & $\mathrm{O}$ & 2 & $\mathrm{M}$ \\
217 SR 496-9 & 1,56 & 13,2 & 12,8 & $\mathrm{E}$ & 2 & $\mathrm{M}$ \\
7 Rainha & 1,54 & 13,2 & 13,1 & $\mathrm{E}$ & 2 & $\mathrm{M}$ \\
55 SR 507-38 & 1,47 & 12,9 & 12,6 & $\mathrm{E}$ & 1 & $\mathrm{G}$ \\
23 SR 496-26 & 1,31 & 13,1 & 13,3 & $\mathrm{O}$ & 3 & $\mathrm{M}$ \\
218 SR 496-15 & 1,14 & 11,5 & 11,5 & $\mathrm{O}$ & 2 & $\mathrm{M}$ \\
93 SR 5.010-21 & 1,07 & 11,6 & 11,7 & $\mathrm{E}$ & 3 & $\mathrm{M}$ \\
48 SR 5.010-8 & 1,04 & 11,7 & 11,6 & $\mathrm{E}$ & 3 & $\mathrm{P}$ \\
\hline \hline
\end{tabular}

Forma das bagas: $\mathrm{O}$ - oval; $\mathrm{E}$ - esférica

2 Tamanho das sementes: P- pequena; M- média; G- grande 
Tabela 10. Textura, sabor, teor de sólidos solúveis ( $\left.{ }^{\circ} \mathrm{Brix}\right), \mathrm{e} \mathrm{pH}$ dos cultivares do grupo B (IAC, SR, Jd).Jundiaí, 1988-91, 1993.

\begin{tabular}{|c|c|c|c|c|c|}
\hline \multicolumn{2}{|r|}{ Cultivar } & \multicolumn{4}{|c|}{ Caracteristicas Tecnológicas } \\
\hline No & Nome & text $t^{1}$ & sabor $^{2}$ & Brix & $\mathrm{pH}$ \\
\hline 7 & Rainha & $F$ & $\mathrm{~N}$ & 18,3 & 3,04 \\
\hline 218 & SR 496-15 & $\mathrm{F}$ & $N$ & 18,2 & 3,03 \\
\hline 138 & Ligia & $M$ & $\mathrm{~N}$ & 17,8 & 3,25 \\
\hline 134 & Ezequiel & $\mathrm{M}$ & $N$ & 17,3 & 3,14 \\
\hline 87 & SR 501-17 & $\mathrm{M}$ & $\mathrm{N}$ & 16,6 & 3,37 \\
\hline 222 & SR $5.012-34$ & $\mathrm{~F}$ & $N$ & 16,6 & 3,15 \\
\hline 93 & SR 5.010-21 & $\mathrm{M}$ & $\mathrm{N}$ & 16,5 & 3,09 \\
\hline 23 & SR 496-26 & $\mathrm{M}$ & $\mathrm{N}$ & 16,4 & 3,37 \\
\hline 148 & Fada & $T$ & $N$ & 16,3 & 3,22 \\
\hline 133 & Traviú & $T$ & $\mathrm{~N}$ & 16,3 & 3,15 \\
\hline 247 & SR 49 & $F$ & $\mathrm{~N}$ & 16,3 & 3,22 \\
\hline 55 & SR 507-38 & $F$ & $\mathrm{~N}$ & 16,0 & 3,28 \\
\hline 48 & SR 5.010-8 & $F$ & $\mathrm{~N}$ & 16,0 & 2,98 \\
\hline 217 & SR $496-9$ & $\mathrm{M}$ & $\mathrm{N}$ & 15,8 & 3,29 \\
\hline 139 & Angelina & $\mathrm{M}$ & $N$ & 15,8 & 3,29 \\
\hline 69 & Iara & $F$ & $\mathrm{~N}$ & 15,5 & 3,04 \\
\hline 32 & Santa Tereza & $\mathrm{T}$ & $N$ & 15,5 & 3,34 \\
\hline 46 & Isaura & $\mathrm{T}$ & $N$ & 15,1 & 3,67 \\
\hline 149 & Branca de Neve & $\mathrm{T}$ & Fo & 14,8 & 2,88 \\
\hline 24 & SR 507-8 & $\mathrm{F}$ & $\mathrm{N}$ & 14,7 & 3,01 \\
\hline & Patrícia & $\mathrm{T}$ & $N$ & 14,5 & 2,65 \\
\hline 219 & SR 496-25 & $\mathrm{F}$ & $N$ & 14,3 & 3,12 \\
\hline 140 & Marta & $T$ & $N$ & 14,3 & 3,32 \\
\hline 183 & $\mathrm{Jd} 930$ & $\mathrm{~T}$ & Mo & 14,0 & 3,11 \\
\hline 44 & Soraya & $\mathrm{T}$ & $\mathrm{N}$ & 13,3 & 3,23 \\
\hline 246 & Roberta & $\mathrm{M}$ & $N$ & 13,3 & 3,21 \\
\hline 6 & Madalena & $F$ & Mo & 13,0 & 3,16 \\
\hline 12 & Máximo & $\mathrm{F}$ & $\mathrm{N}$ & 12,5 & 3,08 \\
\hline
\end{tabular}

Textura: M-média, F- fundente; T- trincante;

2. Sabor: N- neutro, Fo- foxado, Mo- moscatel, 
Tabela 11. Número de dias e graus-dia da poda ao inicio da brotação $(\mathrm{P} / \mathrm{B})$, da poda à colheita $(\mathrm{P} / \mathrm{C})$, e do início da brotação à colheita $(\mathrm{B} / \mathrm{C})$, correspondentes aos cultivares do grupo $\mathrm{C}$ (clones IAC). Jundiai, 1991.

\begin{tabular}{|c|c|c|c|c|c|c|c|}
\hline \multicolumn{2}{|r|}{ Cultivar } & \multicolumn{3}{|c|}{ № de dias } & \multicolumn{3}{|c|}{ Graus-Dias } \\
\hline № & Nome & $\mathrm{P} / \mathrm{B}$ & $\mathrm{P} / \mathrm{C}$ & $\mathrm{B} / \mathrm{C}$ & $\mathrm{P} / \mathrm{B}$ & $\mathrm{P} / \mathrm{C}$ & $\mathrm{B} / \mathrm{C}$ \\
\hline & IAC $16-2$ & 21 & 146 & 125 & 159,0 & 1459 & 1300,0 \\
\hline & IAC 23-8 & 21 & 146 & 125 & 159,0 & 1459 & 1300,0 \\
\hline 11 & IAC $137-4$ & 19 & 146 & 127 & 147,0 & 1459 & 1312,0 \\
\hline 13 & IAC $158-12$ & 19 & 160 & 141 & 147,0 & 1617 & 1470,0 \\
\hline 16 & IAC 192-54 & 19 & 160 & 141 & 147,0 & 1617 & 1470,0 \\
\hline 18 & IAC $202-24$ & 19 & 110 & 91 & 147,0 & 1025 & 878,0 \\
\hline 19 & IAC 202-28 & 17 & 146 & 129 & 130,0 & 1459 & 1329,0 \\
\hline 20 & IAC $202-43$ & 19 & 160 & 141 & 147,0 & 1617 & 1470,0 \\
\hline 21 & IAC 274-16 & 21 & 146 & 125 & 159,0 & 1459 & 1300,0 \\
\hline 22 & IAC 282 & 17 & 160 & 143 & 130,0 & 1617 & 1487,0 \\
\hline 25 & IAC $338-4$ & 15 & 160 & 145 & 110,0 & 1617 & 1507,0 \\
\hline 26 & IAC $339-3$ & 15 & 160 & 145 & 110,0 & 1617 & 1507,0 \\
\hline 27 & IAC $341-2$ & 15 & 160 & 145 & 110,0 & 1617 & 1507,0 \\
\hline 29 & IAC $351-5$ & 21 & 160 & 139 & 159,0 & 1617 & 1458,0 \\
\hline 30 & IAC $353-3$ & 19 & 146 & 127 & 147,0 & 1459 & 1312,0 \\
\hline 31 & IAC 387 & 19 & 179 & 160 & 147,0 & 1842 & 1695,0 \\
\hline & IAC $393-4$ & 19 & 160 & 141 & 147,0 & 1617 & 1470,0 \\
\hline 34 & IAC 393-5 & 19 & 160 & 141 & 147,0 & 1617 & 1470,0 \\
\hline 37 & IAC 403-1 & 15 & 179 & 164 & 110,0 & 1842 & 1732,0 \\
\hline 38 & IAC $405-6$ & 1 & 179 & 178 & 9,3 & 1842 & 1832,7 \\
\hline 41 & IAC $407-26$ & 19 & 146 & 127 & 147,0 & 1459 & 1312,0 \\
\hline 56 & IAC 583-3 & 11 & 160 & 149 & 70,2 & 1617 & 1546,8 \\
\hline 57 & IAC 584-53 & 19 & 160 & 141 & 147,0 & 1617 & 1470,0 \\
\hline 59 & IAC 588-12 & 19 & 160 & 141 & 147,0 & 1617 & 1470,0 \\
\hline 60 & IAC 589-2 & 17 & 160 & 143 & 130,0 & 1617 & 1487,0 \\
\hline & IAC 592-1 & 13 & 179 & 166 & 90,3 & 1842 & 1751,7 \\
\hline 66 & IAC $670-1$ & 17 & 160 & 143 & 130,0 & 1617 & 1487,0 \\
\hline 70 & IAC 699-1 & 21 & 160 & 139 & 159,0 & 1617 & 1458,0 \\
\hline
\end{tabular}


Tabela 11. Número de dias e graus-dia da poda ao início da brotação $(\mathrm{P} / \mathrm{B})$, da poda à colheita $(\mathrm{P} / \mathrm{C})$, e do início da brotação à colheita $(\mathrm{B} / \mathrm{C})$, correspondentes aos cultivares do grupo C (clones IAC). Jundiai, 1991.

\begin{tabular}{lllllll}
73 IAC 719-17 & 21 & 160 & 139 & 159,0 & 1617 & 1458,0 \\
74 IAC 720-1 & 15 & 160 & 145 & 110,0 & 1617 & 1507,0 \\
75 IAC 740-1 & 19 & 160 & 141 & 147,0 & 1617 & 1470,0 \\
76 IAC 746-3 & 19 & 160 & 141 & 147,0 & 1617 & 1470,0 \\
81 IAC 778-4 & 21 & 179 & 158 & 159,0 & 1842 & 1683,0 \\
82 IAC 804-13 & 19 & 179 & 160 & 147,0 & 1842 & 1695,0 \\
83 IAC 813-1 & 21 & 160 & 139 & 159,0 & 1617 & 1458,0 \\
85 IAC 822-21 & 21 & 160 & 139 & 159,0 & 1617 & 1458,0 \\
91 IAC $861-3$ & 24 & 179 & 155 & 178,0 & 1842 & 1664,0 \\
96 IAC 871-18 & 26 & 179 & 153 & 193,0 & 1842 & 1649,0 \\
99 IAC 877-2 & 21 & 179 & 158 & 159,0 & 1842 & 1683,0 \\
100 IAC 882-11 & 17 & 179 & 162 & 130,0 & 1842 & 1712,0 \\
104 IAC 904-11 & 24 & 179 & 155 & 178,0 & 1842 & 1664,0 \\
116 IAC 960-11 & 15 & 160 & 145 & 110,0 & 1617 & 1507,0 \\
117 IAC 960-12 & 17 & 146 & 129 & 130,0 & 1459 & 1329,0 \\
118 IAC 966-1 & 21 & 146 & 125 & 159,0 & 1459 & 1300,0 \\
119 IAC 994-7 & 19 & 146 & 127 & 147,0 & 1459 & 1312,0 \\
122 IAC 1035-12 & 29 & 179 & 150 & 213,0 & 1842 & 1629,0 \\
127 IAC 1193-1 & 15 & 160 & 145 & 110,0 & 1617 & 1507,0 \\
143 IAC 1742 & 15 & 146 & 131 & 110,0 & 1459 & 1349,0 \\
145 IAC 82-1 & 19 & 160 & 141 & 147,0 & 1617 & 1470,0 \\
151 IAC 473-7 & 15 & 146 & 131 & 110,0 & 1459 & 1349,0 \\
152 IAC 486-3 & 24 & 160 & 136 & 178,0 & 1617 & 1439,0 \\
153 IAC 496-15 & 23 & 146 & 123 & 171,0 & 1459 & 1288,0 \\
316 IAC 1319 & 21 & 160 & 139 & 159,0 & 1617 & 1458,0 \\
\hline \hline & & & & & & \\
\hline
\end{tabular}


Tabela 12. Número de dias e graus-dia da poda ao início da brotação (P/B), da poda à colheita $(\mathrm{P} / \mathrm{C})$, e do início da brotação à colheita $(\mathrm{B} / \mathrm{C})$, correspondentes aos cultivares do grupo C (clones IAC). Jundiai, 1993.

\begin{tabular}{|c|c|c|c|c|c|c|c|}
\hline \multicolumn{2}{|r|}{ Cultivar } & \multicolumn{3}{|c|}{ № de dias } & \multicolumn{3}{|c|}{ Graus-Dias } \\
\hline № & Nome & $\mathrm{P} / \mathrm{B}$ & $\mathrm{P} / \mathrm{C}$ & $\mathrm{B} / \mathrm{C}$ & $\mathrm{P} / \mathrm{B}$ & $\mathrm{P} / \mathrm{C}$ & $\mathrm{B} / \mathrm{C}$ \\
\hline 1 & IAC $16-2$ & 15 & 158 & 143 & 90,7 & 1781 & 1690,3 \\
\hline 4 & IAC $23-8$ & 13 & 137 & 124 & 68,9 & 1562 & 1493,1 \\
\hline 11 & IAC $137-4$ & 15 & 143 & 128 & 90,7 & 1336 & 1245,0 \\
\hline 13 & IAC $158-12$ & 13 & 152 & 139 & 68,9 & 1398 & 1329,0 \\
\hline 16 & IAC 192-54 & 15 & 152 & 137 & 90,7 & 1484 & 1393,0 \\
\hline 18 & IAC $202-24$ & 13 & 175 & 162 & 68,9 & 1484 & 1415,0 \\
\hline 19 & IAC 202-28 & 13 & 152 & 139 & 68,9 & 1781 & 1712,0 \\
\hline 20 & IAC $202-43$ & 13 & 158 & 145 & 68,9 & 1484 & 1415,0 \\
\hline 21 & IAC 274-16 & 13 & 152 & 139 & 68,9 & 1562 & 1493,0 \\
\hline 22 & IAC 282 & 15 & 179 & 164 & 90,7 & 1484 & 1393,0 \\
\hline 25 & IAC $338-4$ & 13 & 158 & 145 & 68,9 & 1835 & 1766,0 \\
\hline 26 & IAC $339-3$ & 13 & 164 & 151 & 68,9 & 1562 & 1493,0 \\
\hline 27 & IAC $341-2$ & 13 & 164 & 151 & 68,9 & 1636 & 1567,0 \\
\hline 29 & IAC $351-5$ & 21 & 152 & 131 & 144 & 1636 & 1492,0 \\
\hline 30 & IAC $353-3$ & 15 & 158 & 143 & 90,7 & 1484 & 1393,0 \\
\hline 31 & IAC 387 & 13 & 158 & 145 & 68,9 & 1562 & 1493,0 \\
\hline 33 & IAC $393-4$ & 15 & 164 & 149 & 90,7 & 1562 & 1471,0 \\
\hline 34 & IAC $393-5$ & 15 & 158 & 143 & 90,7 & 1636 & 1545,0 \\
\hline 37 & IAC $403-1$ & 13 & 164 & 151 & 68,9 & 1562 & 1493,0 \\
\hline 38 & IAC $405-6$ & 13 & 175 & 162 & 68,9 & 1636 & 1567,0 \\
\hline 41 & IAC $407-26$ & 15 & 137 & 122 & 90,7 & 1781 & 1690,0 \\
\hline 56 & IAC 583-3 & 13 & 158 & 145 & 68,9 & 1336 & 1267,1 \\
\hline 57 & IAC $584-53$ & 15 & 164 & 149 & 90,7 & 1562 & 1471,3 \\
\hline 59 & IAC $588-12$ & 15 & 158 & 143 & 90,7 & 1636 & 1545,3 \\
\hline 60 & IAC 589-2 & 13 & 158 & 145 & 68,9 & 1562 & 1493,1 \\
\hline 61 & IAC 592-1 & 13 & 164 & 151 & 68,9 & 1562 & 1493,1 \\
\hline 66 & IAC $670-1$ & 13 & 158 & 145 & 68,9 & 1636 & 1567,1 \\
\hline 70 & IAC $699-1$ & 15 & 158 & 143 & 90,7 & 1562 & 1471,3 \\
\hline
\end{tabular}


Tabela 12. Número de dias e graus-dia da poda ao início da brotação $(\mathrm{P} / \mathrm{B})$, da poda à colheita $(\mathrm{P} / \mathrm{C})$, e do início da brotação à colheita $(\mathrm{B} / \mathrm{C})$, correspondentes aos cultivares do grupo C (clones IAC). Jundiaí, 1993.

\begin{tabular}{lllllll} 
73 IAC 719-17 & 15 & 158 & 143 & 90,7 & 1562 & 1471,0 \\
74 IAC 720-1 & 13 & 158 & 145 & 68,9 & 1562 & 1493,0 \\
75 IAC 740-1 & 13 & 158 & 145 & 68,9 & 1562 & 1493,0 \\
76 IAC 746-3 & 15 & 158 & 143 & 90,7 & 1562 & 1471,0 \\
81 IAC 778-4 & 13 & 175 & 162 & 68,9 & 1562 & 1493,0 \\
82 IAC 804-13 & 13 & 175 & 162 & 68,9 & 1781 & 1712,0 \\
83 IAC 813-1 & 15 & 158 & 143 & 90,7 & 1562 & 1471,0 \\
85 IAC 822-21 & 13 & 164 & 151 & 68,9 & 1636 & 1567,0 \\
91 IAC 861-3 & 15 & 164 & 149 & 90,7 & 1636 & 1545,0 \\
96 IAC 871-18 & 21 & 164 & 143 & 144,0 & 1636 & 1492,0 \\
99 IAC 877-2 & 13 & 164 & 151 & 68,9 & 1636 & 1567,0 \\
100 IAC 882-11 & 15 & 168 & 153 & 90,7 & 1687 & 1596,0 \\
104 IAC 904-11 & 15 & 164 & 149 & 90,7 & 1636 & 1545,0 \\
116 IAC 960-11 & 13 & 168 & 155 & 68,9 & 1687 & 1618,0 \\
117 IAC 960-12 & 15 & 143 & 128 & 90,7 & 1398 & 1307,0 \\
118 IAC 966-1 & 13 & 143 & 130 & 68,9 & 1398 & 1329,0 \\
119 IAC 994-7 & 15 & 168 & 153 & 90,7 & 1687 & 1596,0 \\
122 IAC 1035-12 & 21 & 168 & 147 & 144,0 & 1687 & 1543,0 \\
127 IAC 1193-1 & 15 & 137 & 122 & 90,7 & 1336 & 1245,0 \\
143 IAC 1742 & 15 & 175 & 160 & 90,7 & 1781 & 1690,0 \\
145 IAC 82-1 & 15 & 168 & 153 & 90,7 & 1687 & 1596,0 \\
151 IAC 473-7 & 15 & 168 & 153 & 90,7 & 1687 & 1596,0 \\
152 IAC 486-3 & 15 & 168 & 153 & 90,7 & 1687 & 1596,0 \\
153 IAC 496-15 & 13 & 143 & 130 & 68,9 & 1398 & 1329,0 \\
316 IAC 1319 & 15 & 175 & 160 & 90,7 & 1781 & 1690,0 \\
\hline
\end{tabular}


Tabela 13. Médias de peso $(\mathrm{g})$, comprimento $(\mathrm{cm})$, largura $(\mathrm{cm})$, número de bagas $(\mathrm{NB})$, compacidade e forma dos cachos, correspondentes aos cultivares do grupo C (clones IAC).Jundiaí, 1988-91, 1993.

\begin{tabular}{|c|c|c|c|c|c|c|c|}
\hline № & CULTIVAR & Peso & Comp & Larg & NB & Compacl & Forma ${ }^{2}$ \\
\hline 74 & IAC $720-1$ & 3130 & 15,45 & 8,15 & 102 & C & $\mathrm{Co} / \mathrm{A}$ \\
\hline 38 & IAC $405-6$ & 503,6 & 15,94 & 8,96 & 218 & $M$ & $\mathrm{Co} / \mathrm{A}$ \\
\hline 22 & $\mathrm{IAC} 282$ & 441,6 & 13,85 & 10,81 & 70 & $S$ & $\mathrm{Co} / \mathrm{A}$ \\
\hline 70 & IAC $699-1$ & 425,8 & 15,34 & 9,79 & 172 & $\mathrm{~S}$ & $\mathrm{Co} / \mathrm{A}$ \\
\hline 37 & IAC $403-1$ & 399,5 & 11,77 & 9,02 & 221 & $\mathrm{M}$ & $\mathrm{Co}$ \\
\hline 85 & IAC $822-21$ & 388,2 & 11,28 & 7,13 & 249 & M & $\mathrm{Co} / \mathrm{A}$ \\
\hline 119 & IAC $994-7$ & 374,2 & 12,32 & 8,35 & 157 & $\mathrm{~S}$ & $\mathrm{Co} / \mathrm{A}$ \\
\hline 21 & IAC $274-16$ & 361,0 & 12,29 & 8,03 & 104 & $\mathrm{M}$ & $\mathrm{Ci} / \mathrm{A}$ \\
\hline 143 & IAC 1742 & 343,8 & 10,27 & 7,11 & 104 & $M$ & $\mathrm{Co} / \mathrm{A}$ \\
\hline 41 & IAC $407-26$ & 337,0 & 14,74 & 10,77 & 94 & $M$ & Co \\
\hline 20 & IAC 202-43 & 323,6 & 19,66 & 8,36 & 91 & $\mathrm{~S}$ & $\mathrm{Co} / \mathrm{A}$ \\
\hline 30 & IAC $353-3$ & 294,8 & 15,90 & 10,21 & 53 & $M$ & Co \\
\hline 66 & IAC $670-1$ & 290,8 & 11,88 & 7,02 & 98 & $M$ & $\mathrm{Co} / \mathrm{A}$ \\
\hline 56 & IAC 583-3 & 288,4 & 11,32 & 6,22 & 222 & C & $\mathrm{Co} / \mathrm{A}$ \\
\hline 316 & IAC 1319 & 287,0 & 14,72 & 9,57 & 69 & $\mathrm{M}$ & Co \\
\hline 75 & IAC $740-1$ & 280,0 & 15,12 & 11,04 & 109 & $\mathrm{~S}$ & $\mathrm{Co} / \mathrm{A}$ \\
\hline 145 & $\mathrm{IAC} 82-1$ & 265,5 & 13,99 & 8,66 & 60 & $S$ & $\mathrm{Co}$ \\
\hline 11 & IAC $137-4$ & 258,4 & 13,88 & 8,02 & 130 & $\mathrm{M}$ & $\mathrm{Co} / \mathrm{A}$ \\
\hline 76 & IAC $746-3$ & 258,0 & 14,25 & 7,91 & 86 & $M$ & Co \\
\hline 96 & IAC $871-18$ & 255,0 & 14,35 & 7,30 & 37 & $\mathrm{~S}$ & $\mathrm{Co} / \mathrm{A}$ \\
\hline 152 & IAC $486-3$ & 254,3 & 11,79 & 8,42 & 81 & $M$ & $\mathrm{Co} / \mathrm{A}$ \\
\hline 73 & IAC 719-7 & 252,8 & 17,52 & 10,63 & 125 & $\mathrm{C}$ & $\mathrm{Co} / \mathrm{A}$ \\
\hline 116 & IAC $960-12$ & 246,4 & 13,70 & 8,53 & 129 & $\mathrm{M}$ & Co \\
\hline 31 & IAC 387 & 238,0 & 13,86 & 8,58 & 75 & $\mathrm{~S}$ & $\mathrm{Ci}$ \\
\hline 81 & IAC 778-4 & 231,2 & 8,60 & 5,60 & 69 & $\mathrm{~S}$ & $\mathrm{Co}$ \\
\hline 19 & IAC 202-28 & 224,5 & 19,28 & 8,93 & 81 & $S$ & $\mathrm{Co} / \mathrm{A}$ \\
\hline 122 & IAC $1035-12$ & 220,2 & 9,22 & 6,41 & 136 & $S$ & $\mathrm{Co} / \mathrm{A}$ \\
\hline 100 & IAC $882-11$ & 202,9 & 12,57 & 7,35 & 155 & $M$ & $\mathrm{Co} / \mathrm{A}$ \\
\hline 16 & IAC $192-54$ & 200,1 & 11,46 & 7,54 & 78 & $M$ & Co \\
\hline
\end{tabular}


Tabela 13. Médias de peso $(\mathrm{g})$, comprimento $(\mathrm{cm})$, largura $(\mathrm{cm})$, número de bagas $(\mathrm{NB})$, compacidade e forma dos cachos, correspondentes aos cultivares do grupo C (clones IAC).Jundiai, 1988-91, 1993.

\begin{tabular}{|c|c|c|c|c|c|c|c|}
\hline 29 & IAC $351-5$ & 191,2 & 17,79 & 10,28 & 47 & $M$ & $\mathrm{Co} / \mathrm{A}$ \\
\hline 117 & IAC $960-11$ & 188,2 & 6,72 & 4,38 & 128 & $\mathrm{M}$ & $\mathrm{Co} / \mathrm{A}$ \\
\hline 91 & IAC $861-3$ & 181,2 & 15,64 & 8,71 & 91 & $\mathrm{M}$ & $\mathrm{Co} / \mathrm{A}$ \\
\hline 82 & IAC $804-13$ & 172,4 & 15,62 & 8,16 & 87 & $M$ & $\mathrm{Co} / \mathrm{A}$ \\
\hline 18 & IAC $202-24$ & 171,4 & 13,18 & 8,68 & 51 & $M$ & $\mathrm{Co} / \mathrm{A}$ \\
\hline 153 & IAC 496-15 & 168,0 & 11,75 & 8,96 & 137 & $M$ & $\mathrm{Co} / \mathrm{A}$ \\
\hline 57 & IAC 584-53 & 166,2 & 11,68 & 8,51 & 161 & C & Co \\
\hline 1 & IAC $16-2$ & 156,3 & 11,97 & 7,21 & 50 & $S$ & Co \\
\hline 83 & IAC $813-1$ & 155,1 & 16,28 & 9,19 & 87 & $M$ & $\mathrm{Ci}$ \\
\hline 99 & IAC $877-2$ & 154,1 & 9,17 & 4,37 & 70 & $\mathrm{M}$ & $\mathrm{Co} / \mathrm{A}$ \\
\hline 34 & IAC 393-5 & 153,1 & 13,40 & 12,10 & 81 & $\mathrm{~S}$ & $\mathrm{Co}$ \\
\hline 59 & IAC 588-12 & 151,2 & 21,09 & 12,59 & 80 & $\mathrm{~S}$ & $\mathrm{Co} / \mathrm{A}$ \\
\hline 151 & IAC $473-7$ & 145,2 & 22,21 & 10,38 & 30 & M & Co \\
\hline 60 & IAC $589-2$ & 144,6 & 12,48 & 8,77 & 94 & $\mathrm{M}$ & $\mathrm{Co}$ \\
\hline 25 & IAC $338-4$ & 134,8 & 13,75 & 8,79 & 142 & $S$ & $\mathrm{Co} / \mathrm{A}$ \\
\hline 13 & IAC $158-12$ & 134,4 & 14,85 & 9,81 & 72 & $\mathrm{~S}$ & $\mathrm{Co} / \mathrm{A}$ \\
\hline 118 & IAC $966-1$ & 131,1 & 15,43 & 7,31 & 100 & $M$ & $\mathrm{Co} / \mathrm{A}$ \\
\hline 33 & IAC 393-4 & 130,3 & 18,27 & 11,62 & 60 & $M$ & $\mathrm{Co}$ \\
\hline 104 & IAC 904-11 & 112,1 & 11,95 & 7,66 & 57 & $S$ & Co \\
\hline 61 & IAC 592-1 & 109,3 & 15,88 & 10,02 & 110 & $S$ & Co \\
\hline 26 & IAC $339-3$ & 94,1 & 17,48 & 9,52 & 72 & $M$ & Co \\
\hline 27 & IAC $341-2$ & 92,2 & 13,90 & 8,33 & 88 & $S$ & $\mathrm{Co}$ \\
\hline 4 & IAC 23-8 & 82,1 & 15,22 & 7,35 & 65 & $\mathrm{~S}$ & Co \\
\hline 127 & IAC 1193-01 & 55,8 & 9,58 & 5,45 & 42 & $\mathrm{~S}$ & $\mathrm{Co}$ \\
\hline
\end{tabular}

1, Compacidade: M-media C-compacto e S- solto;

2. Forma: $\mathrm{Co}$ - cônico, Ci- cilíndrico e A- alado, 
Tabela 14. Médias de peso $(\mathrm{g})$, comprimento $(\mathrm{mm})$, largura $(\mathrm{mm})$, forma, número de sementes(NS) e tamanho das sementes (TS) das bagas, correspondentes aos cultivares do grupo C (clones IAC). Jundiai, 1988-91, 1993.

\begin{tabular}{|c|c|c|c|c|c|c|c|}
\hline № & CULTIVAR & Peso & Compr. & Larg. & forma ${ }^{1}$ & NS & TS \\
\hline 44 & Soraya & 7,83 & 28,20 & 20,9 & $\mathrm{O}$ & 1 & G \\
\hline 96 & IAC $871-18$ & 5,70 & 22,35 & 19,85 & 0 & 2 & G \\
\hline 30 & IAC $353-3$ & 5,49 & 22,40 & 19,50 & 0 & 1 & G \\
\hline 22 & IAC 282 & 5,03 & 20,50 & 18,85 & 0 & 2 & $\mathrm{G}$ \\
\hline 151 & IAC $473-7$ & 4,84 & 20,95 & 17,90 & $\mathrm{O}$ & 1 & G \\
\hline 41 & IAC $407-26$ & 3,98 & 19,10 & 17,90 & $\mathrm{O}$ & 3 & $M$ \\
\hline 29 & IAC $351-5$ & 3,97 & 19,95 & 17,40 & $\mathrm{O}$ & 1 & $\mathrm{G}$ \\
\hline 316 & IAC 1319 & 3,82 & 20,20 & 17,30 & O & 3 & M \\
\hline 143 & IAC 1742 & 3,55 & 18,50 & 17,35 & $\mathrm{O}$ & 2 & $M$ \\
\hline 1 & IAC $16-2$ & 3,53 & 18,45 & 16,75 & $\mathrm{O}$ & 3 & $M$ \\
\hline 21 & IAC 274-16 & 3,48 & 17,65 & 17,10 & $\mathrm{O}$ & 2 & M \\
\hline 145 & IAC $82-1$ & 3,45 & 18,50 & 16,95 & $\mathrm{O}$ & 2 & $\mathrm{M}$ \\
\hline 18 & IAC 202-24 & 3,36 & 17,85 & 16,75 & $E$ & 2 & $M$ \\
\hline 81 & IAC $778-4$ & 3,35 & 18,70 & 16,00 & $\mathrm{O}$ & 2 & G \\
\hline 20 & IAC 202-43 & 3,31 & 17,60 & 16,90 & 0 & 2 & M \\
\hline 31 & IAC 387 & 3,27 & 17,55 & 16,35 & 0 & 2 & $\mathrm{M}$ \\
\hline 19 & IAC 202-28 & 3,10 & 18,00 & 16,75 & 0 & 3 & $\mathrm{M}$ \\
\hline 75 & IAC $740-1$ & 2,89 & 17,55 & 15,90 & $\mathrm{O}$ & 3 & $M$ \\
\hline 136 & IAC 1506-8 & 2,88 & 16,90 & 16,40 & $\mathrm{O}$ & 2 & $\mathrm{M}$ \\
\hline 152 & IAC $486-3$ & 2,76 & 17,05 & 15,80 & 0 & 2 & $M$ \\
\hline 76 & $\mathrm{IAC} 746-3$ & 2,69 & 17,25 & 15,25 & $\mathrm{O}$ & 3 & $\mathrm{M}$ \\
\hline 16 & IAC 192-54 & 2,63 & 17,40 & 15,30 & $\mathrm{O}$ & 2 & $M$ \\
\hline 66 & IAC 670-1 & 2,62 & 15,15 & 15,10 & $E$ & 2 & G \\
\hline 70 & IAC 699-1 & 2,60 & 16,40 & 15,55 & $\mathrm{O}$ & 2 & $\mathrm{M}$ \\
\hline 37 & IAC $403-1$ & 2,42 & 16,75 & 14,90 & $\mathrm{O}$ & 3 & $M$ \\
\hline 74 & IAC $720-1$ & 2,36 & 15,95 & 14,90 & $E$ & 2 & $\mathrm{P}$ \\
\hline 38 & IAC $405-6$ & 2,31 & 16,40 & 14,10 & $O$ & 2 & $M$ \\
\hline 33 & IAC 393-4 & 2,21 & 16,00 & 14,70 & $\mathrm{O}$ & 2 & M \\
\hline 73 & IAC $719-7$ & 2,18 & 15,70 & 14,60 & $\mathrm{O}$ & 2 & $M$ \\
\hline 119 & IAC $994-7$ & 2,16 & 14,70 & 14,60 & $E$ & 3 & $\mathrm{M}$ \\
\hline
\end{tabular}


Tabela 14. Médias de peso $(\mathrm{g})$, comprimento $(\mathrm{mm})$, largura $(\mathrm{mm})$, forma, número de sementes(NS) e tamanho das sementes (TS) das bagas, correspondentes aos cultivares do grupo C (clones IAC). Jundiai, 1988-91, 1993.

\begin{tabular}{|c|c|c|c|c|c|c|c|}
\hline 4 & IAC $23-8$ & 2,12 & 16,20 & 13,90 & o & 2 & M \\
\hline 11 & IAC $137-4$ & 2,10 & 15,20 & 14,60 & $\mathrm{O}$ & 2 & $P$ \\
\hline 104 & IAC $904-11$ & 2,09 & 15,85 & 13,85 & 0 & 2 & $\mathrm{G}$ \\
\hline 99 & IAC $877-2$ & 2,08 & 15,50 & 14,60 & $E$ & 2 & G \\
\hline 91 & IAC $861-3$ & 2,04 & 15,75 & 13,90 & 0 & 2 & M \\
\hline 85 & IAC 822-21 & 1,93 & 14,15 & 14,15 & E & 2 & M \\
\hline 83 & IAC $813-1$ & 1,93 & 14,40 & 14,25 & $\mathrm{O}$ & 2 & $\mathrm{M}$ \\
\hline 82 & IAC $804-13$ & 1,92 & 15,20 & 13,80 & $E$ & 2 & $M$ \\
\hline 116 & IAC $960-12$ & 1,91 & 14,60 & 14,15 & $\mathrm{O}$ & 2 & M \\
\hline 59 & IAC $588-12$ & 1,89 & 14,50 & 14,15 & $\mathrm{O}$ & 2 & $M$ \\
\hline 34 & IAC $393-5$ & 1,89 & 15,35 & 13,85 & $\mathrm{O}$ & 2 & M \\
\hline 13 & IAC $158-12$ & 1,88 & 15,20 & 13,80 & $\mathrm{O}$ & 2 & M \\
\hline 60 & IAC 589-2 & 1,78 & 13,65 & 13,50 & $E$ & 2 & M \\
\hline 122 & IAC $1035-12$ & 1,65 & 14,10 & 14,60 & $E$ & 2 & $\mathrm{M}$ \\
\hline 26 & IAC 339-3 & 1,52 & 14,35 & 12,90 & $\mathrm{O}$ & 1 & $\mathrm{P}$ \\
\hline 117 & IAC $960-12$ & 1,47 & 13,30 & 12,70 & $E$ & 2 & $\mathrm{P}$ \\
\hline 100 & IAC $882-11$ & 1,46 & 13,50 & 12,70 & 0 & 2 & $\mathrm{M}$ \\
\hline 56 & IAC 583-3 & 1,43 & 12,60 & 12,05 & $\mathrm{O}$ & 2 & $\mathrm{P}$ \\
\hline 118 & IAC $966-1$ & 1,37 & 12,30 & 12,20 & $E$ & 2 & $P$ \\
\hline 27 & IAC $341-2$ & 1,36 & 13,75 & 12,45 & $O$ & 2 & M \\
\hline 153 & IAC $496-15$ & 1,31 & 13,10 & 12,20 & $\mathrm{O}$ & 2 & M \\
\hline 57 & IAC $584-53$ & 1,18 & 13,35 & 11,80 & $\mathrm{O}$ & 2 & $P$ \\
\hline 127 & IAC 1193-1 & 1,12 & 12,00 & 12,20 & $E$ & 1 & $P$ \\
\hline 61 & IAC 592-1 & 1,12 & 13,20 & 11,35 & $E$ & 2 & M \\
\hline 25 & IAC $338-4$ & 0,90 & 11,40 & 10,75 & $\mathrm{O}$ & 1 & $\mathrm{M}$ \\
\hline
\end{tabular}

1 Forma das bagas: O- oval; E- esférica 
Tabela 15. Textura, sabor, teor de sólidos solúveis $\left({ }^{\circ} \mathrm{Brix}\right)$, e $\mathrm{pH}$ dos cultivares do grupo C (clones IAC).Jundiai, 1988-91, 1993.

\begin{tabular}{|c|c|c|c|c|c|}
\hline \multirow[b]{2}{*}{ № } & CULTIVAR & \multicolumn{4}{|c|}{ Caracteristicas Tecnológicas } \\
\hline & Nome & $\operatorname{text}^{1}$ & sabor $^{2}$ & ${ }^{\circ}$ Brix & $\mathrm{pH}$ \\
\hline 153 & IAC $496-15$ & $\mathrm{~F}$ & $\mathrm{~N}$ & 19,25 & 3,07 \\
\hline 1 & $\mathrm{IAC} 16-2$ & $\mathrm{~T}$ & $N$ & 19,00 & 3,50 \\
\hline 4 & $\mathrm{IAC} 23-8$ & $\mathrm{M}$ & $\mathrm{N}$ & 19,00 & 3,38 \\
\hline 151 & $\mathrm{IAC} 473-7$ & $\mathrm{~T}$ & $N$ & 18,50 & 3,13 \\
\hline 13 & IAC 158-12 & $\mathrm{T}$ & $\mathrm{N}$ & 18,00 & 3,16 \\
\hline 18 & IAC $202-24$ & $\mathrm{M}$ & $N$ & 17,90 & 3,35 \\
\hline 116 & IAC $960-12$ & $F$ & $N$ & 17,63 & 3,10 \\
\hline 27 & IAC $341-2$ & $F$ & $N$ & 17,00 & 2,76 \\
\hline 61 & IAC 592-1 & $F$ & $\mathrm{~N}$ & 17,00 & 2,92 \\
\hline 16 & IAC 192-54 & $\mathrm{F}$ & $N$ & 17,00 & 3,24 \\
\hline 99 & IAC $877-2$ & $\mathrm{~F}$ & $\mathrm{~N}$ & 16,75 & 2,93 \\
\hline 29 & IAC $351-5$ & $T$ & $N$ & 16,75 & 3,39 \\
\hline 127 & IAC 1193-1 & $\mathrm{M}$ & $\mathrm{N}$ & 16,50 & 2,89 \\
\hline 73 & IAC 719-7 & $F$ & $N$ & 16,50 & 3,01 \\
\hline 75 & IAC $740-1$ & $F$ & $N$ & 16,25 & 3,30 \\
\hline 59 & IAC 588-12 & $F$ & $\mathrm{~N}$ & 16,25 & 2,94 \\
\hline 122 & IAC $1035-12$ & $F$ & $N$ & 16,25 & 3,04 \\
\hline 30 & IAC 353-3 & $F$ & $N$ & 16,02 & 3,02 \\
\hline 76 & IAC $746-3$ & $M$ & $N$ & 16,00 & 3,31 \\
\hline 74 & IAC 720-1 & $F$ & $N$ & 16,00 & 3,08 \\
\hline 145 & IAC $82-1$ & $T$ & Mo & 16,00 & 3,45 \\
\hline 31 & IAC 387 & $\mathrm{M}$ & $N$ & 15,93 & 3,24 \\
\hline 119 & IAC $994-7$ & $F$ & $N$ & 15,86 & 2,93 \\
\hline 56 & IAC 583-3 & $F$ & $\mathrm{~N}$ & 15,83 & 3,18 \\
\hline 60 & IAC 589-2 & $F$ & $N$ & 15,81 & 2,85 \\
\hline 117 & IAC $960-11$ & $\mathrm{~F}$ & $N$ & 15,66 & 2,83 \\
\hline 57 & IAC $584-53$ & $\mathrm{~F}$ & $N$ & 15,58 & 3,07 \\
\hline 26 & IAC 339-3 & $F$ & $\mathrm{~N}$ & 15,50 & 2,82 \\
\hline 316 & IAC 1319 & $\mathrm{M}$ & $N$ & 15,50 & 3,18 \\
\hline
\end{tabular}


Tabela 15. Textura, sabor, teor de sólidos solúveis ( $\left.{ }^{\circ} \mathrm{Brix}\right)$, e $\mathrm{pH}$ dos cultivares do grupo C (clones IAC).Jundiaí, 1988-91, 1993.

\begin{tabular}{ccccc}
25 IAC 338-4 & $\mathrm{F}$ & $\mathrm{N}$ & 15,50 & 2,65 \\
41 IAC $407-26$ & $\mathrm{~T}$ & $\mathrm{Mo}$ & 15,38 & 3,43 \\
21 IAC $274-16$ & $\mathrm{~F}$ & $\mathrm{~N}$ & 15,30 & 3,19 \\
83 IAC $813-1$ & $\mathrm{~F}$ & $\mathrm{Mo}$ & 15,30 & 3,17 \\
118 IAC $966-1$ & $\mathrm{~F}$ & $\mathrm{~N}$ & 15,26 & 3,07 \\
91 IAC $861-3$ & $\mathrm{~F}$ & $\mathrm{~N}$ & 15,26 & 3,14 \\
22 IAC 282 & $\mathrm{M}$ & $\mathrm{N}$ & 15,25 & 3,19 \\
20 IAC $202-43$ & $\mathrm{~F}$ & $\mathrm{~N}$ & 15,20 & 3,24 \\
143 IAC 1742 & $\mathrm{~F}$ & $\mathrm{~N}$ & 15,15 & 3,37 \\
104 IAC $904-11$ & $\mathrm{~F}$ & $\mathrm{~N}$ & 15,00 & 3,00 \\
70 IAC $699-1$ & $\mathrm{~T}$ & $\mathrm{~N}$ & 15,00 & 2,91 \\
66 IAC $670-1$ & $\mathrm{~F}$ & $\mathrm{~N}$ & 14,75 & 2,81 \\
96 IAC $871-18$ & $\mathrm{M}$ & $\mathrm{N}$ & 14,50 & 2,91 \\
152 IAC $486-3$ & $\mathrm{M}$ & $\mathrm{N}$ & 14,50 & 3,32 \\
11 IAC $137-4$ & $\mathrm{M}$ & $\mathrm{N}$ & 14,50 & 3,09 \\
37 IAC $403-1$ & $\mathrm{~F}$ & $\mathrm{~N}$ & 14,10 & 2,98 \\
33 IAC $393-4$ & $\mathrm{~F}$ & $\mathrm{~N}$ & 14,08 & 3,07 \\
19 IAC $202-28$ & $\mathrm{M}$ & $\mathrm{N}$ & 14,00 & 3,28 \\
34 IAC 393-5 & $\mathrm{F}$ & $\mathrm{N}$ & 14,00 & 3,15 \\
100 IAC $882-11$ & $\mathrm{~F}$ & $\mathrm{~N}$ & 13,75 & 2,70 \\
81 IAC $778-4$ & $\mathrm{~F}$ & $\mathrm{~N}$ & 13,50 & 3,08 \\
82 IAC $804-13$ & $\mathrm{~F}$ & $\mathrm{~N}$ & 13,27 & 2,89 \\
85 IAC $822-21$ & $\mathrm{~F}$ & $\mathrm{~N}$ & 12,75 & 3,21 \\
38 IAC $405-6$ & $\mathrm{~F}$ & $\mathrm{~N}$ & 11,83 & 2,83 \\
\hline \hline
\end{tabular}

1. Textura: M-média, F- fundente; T- trincante;

2. Sabor: N- neutro, Fo- foxado, Mo- moscatel, 
Tabela 16. Número de dias e graus-dia da poda ao inicio da brotação $(P / B)$, da poda à colheita $(\mathrm{P} / \mathrm{C})$, e do início da brotação à colheita $(\mathrm{B} / \mathrm{C})$, correspondentes aos cultivares do grupo D (Seibel, Couderc). Jundiaí, 1991.

\begin{tabular}{|c|c|c|c|c|c|c|c|}
\hline \multicolumn{2}{|r|}{ Cultivar } & \multicolumn{3}{|c|}{ № de dias } & \multicolumn{3}{|c|}{ Graus-Dias } \\
\hline № & Nome & P/B & $\mathrm{P} / \mathrm{C}$ & $\mathrm{B} / \mathrm{C}$ & $\mathrm{P} / \mathrm{B}$ & $\mathrm{P} / \mathrm{C}$ & $\mathrm{B} / \mathrm{C}$ \\
\hline 2 & Seibel 10.146 & 49 & 179 & 130 & 392 & 1842 & 1450 \\
\hline 15 & Couderc 1 & 19 & 160 & 141 & 147 & 1617 & 1470 \\
\hline 36 & Seibel 7.144 & 17 & 160 & 143 & 130 & 1617 & 1487 \\
\hline 136 & Seibel 5.318 & 24 & 179 & 155 & 178 & 1842 & 1664 \\
\hline 165 & Seibel 4.995 & 26 & 146 & 120 & 193 & 1459 & 1266 \\
\hline 205 & Couderc 3 & 15 & 160 & 145 & 110 & 1617 & 1507 \\
\hline 215 & Seibel 2.021 & 19 & 146 & 127 & 147 & 1459 & 1312 \\
\hline 245 & Seibel 11.342 & 21 & 160 & 139 & 159 & 1617 & 1458 \\
\hline 249 & Seibel 2 & 26 & 160 & 134 & 193 & 1617 & 1424 \\
\hline 250 & Seibel 60 & 21 & 160 & 139 & 159 & 1617 & 1458 \\
\hline 251 & Seibel 159 & 15 & 146 & 131 & 110 & 1459 & 1349 \\
\hline 256 & Seibel 1.077 & 29 & 160 & 131 & 213 & 1617 & 1404 \\
\hline 257 & Seibel 1.394 & 15 & 160 & 145 & 110 & 1617 & 1507 \\
\hline 258 & Seibel 4.638 & 21 & 160 & 139 & 159 & 1617 & 1458 \\
\hline 259 & Seibel 4.643 & 21 & 146 & 125 & 159 & 1459 & 1300 \\
\hline 264 & Seibel 5.145 & 21 & 146 & 125 & 159 & 1459 & 1300 \\
\hline 265 & Seibel 5.163 & 35 & 160 & 125 & 275 & 1617 & 1342 \\
\hline 266 & Seibel 5.213 & 21 & 160 & 139 & 159 & 1617 & 1458 \\
\hline 269 & Seibel 5.520 & 21 & 160 & 139 & 159 & 1617 & 1458 \\
\hline 270 & Seibel 5.915 & 21 & 160 & 139 & 159 & 1617 & 1458 \\
\hline 276 & Seibel 7.052 & 15 & 160 & 145 & 110 & 1617 & 1507 \\
\hline 278 & Seibel 8.357 & 21 & 160 & 139 & 159 & 1617 & 1458 \\
\hline 279 & Seibel 8.712 & 21 & 160 & 139 & 159 & 1617 & 1458 \\
\hline 280 & Seibel 8.724 & 21 & 160 & 139 & 159 & 1617 & 1458 \\
\hline 285 & Seibel 10.878 & 21 & 146 & 125 & 159 & 1459 & 1300 \\
\hline 287 & Seibel 12.583 & 35 & 179 & 144 & 275 & 1842 & 1567 \\
\hline 291 & Seibel 13.693 & 21 & 160 & 139 & 159 & 1617 & 1458 \\
\hline 304 & Seibel 11.813 & 19 & 125 & 106 & 147 & 1209 & 1062 \\
\hline 305 & Seibel 7.053 & 21 & 146 & 125 & 159 & 1459 & 1300 \\
\hline 313 & Seibel 5.593 & 19 & 160 & 141 & 147 & 1617 & 1470 \\
\hline
\end{tabular}


Tabela 17. Número de dias e graus-dia da poda ao início da brotação (P/B), da poda à colheita $(\mathrm{P} / \mathrm{C})$, e do inicio da brotação à colheita $(\mathrm{B} / \mathrm{C})$, correspondentes aos cultivares do grupo D (Seibel, Couderc). Jundiaí, 1993.

\begin{tabular}{|c|c|c|c|c|c|c|c|}
\hline \multicolumn{2}{|r|}{ Cultivar } & \multicolumn{3}{|c|}{ № de dias } & \multicolumn{3}{|c|}{ Graus-Dias } \\
\hline № & Nome & $\mathrm{P} / \mathrm{B}$ & $\mathrm{P} / \mathrm{C}$ & $\mathrm{B} / \mathrm{C}$ & $\mathrm{P} / \mathrm{B}$ & $\mathrm{P} / \mathrm{C}$ & $\mathrm{B} / \mathrm{C}$ \\
\hline 2 & Seibel 10.146 & 61 & 143 & 82 & 465,0 & 1398 & 933,0 \\
\hline 15 & Couderc 1 & 19 & 158 & 139 & 123,0 & 1562 & 1439,0 \\
\hline 36 & Seibel 7.144 & 15 & 153 & 138 & 90,7 & 1497 & 1406,3 \\
\hline 136 & Seibel 5.318 & 13 & 158 & 145 & 68,9 & 1562 & 1493,1 \\
\hline 165 & Seibel 4.995 & 15 & 152 & 137 & 90,7 & 1484 & 1393,3 \\
\hline 205 & Couderc 3 & 15 & 168 & 153 & 90,7 & 1687 & 1596,3 \\
\hline 215 & Seibel 2.021 & 15 & 143 & 128 & 90,7 & 1398 & 1307,3 \\
\hline 245 & Seibel 11.342 & 13 & 137 & 124 & 68,9 & 1336 & 1267,1 \\
\hline 249 & Seibel 2 & 13 & 143 & 130 & 68,9 & 1398 & 1329,1 \\
\hline 250 & Seibel 60 & 15 & 143 & 128 & 90,7 & 1398 & 1307,3 \\
\hline 251 & Seibel 159 & 15 & 175 & 160 & 90,7 & 1781 & 1690,3 \\
\hline 256 & Seibel 1.077 & 28 & 143 & 115 & 176,0 & 1398 & 1222,0 \\
\hline 257 & Seibel 1.394 & 13 & 143 & 130 & 68,9 & 1398 & 1329,1 \\
\hline 258 & Seibel 4.638 & 13 & 143 & 130 & 68,9 & 1398 & 1329,1 \\
\hline 259 & Seibel 4.643 & 15 & 143 & 128 & 90,7 & 1398 & 1307,3 \\
\hline 264 & Seibel 5.145 & 15 & 175 & 160 & 90,7 & 1781 & 1690,3 \\
\hline 265 & Seibel 5.163 & 15 & 175 & 160 & 90,7 & 1781 & 1690,3 \\
\hline 266 & Seibel 5.213 & 13 & 175 & 162 & 68,9 & 1781 & 1712,1 \\
\hline 269 & Seibel 5.520 & 15 & 143 & 128 & 90,7 & 1398 & 1307,3 \\
\hline 270 & Seibel 5.915 & 13 & 158 & 145 & 68,9 & 1562 & 1493,1 \\
\hline 276 & Seibel 7.052 & 15 & 168 & 153 & 90,7 & 1687 & 1596,3 \\
\hline 278 & Seibel 8.357 & 15 & 137 & 122 & 90,7 & 1336 & 1245,3 \\
\hline 279 & Seibel 8.712 & 15 & 137 & 122 & 90,7 & 1336 & 1245,3 \\
\hline 280 & Seibel 8.724 & 15 & 175 & 160 & 90,7 & 1781 & 1690,3 \\
\hline 285 & Seibel 10.878 & 15 & 137 & 122 & 90,7 & 1336 & 1245,3 \\
\hline 287 & Seibel 12.583 & 13 & 175 & 162 & 68,9 & 1781 & 1712,1 \\
\hline 291 & Seibel 13.693 & 13 & 175 & 162 & 68,9 & 1781 & 1712,1 \\
\hline 304 & Seibel 11.813 & 13 & 137 & 124 & 68,9 & 1336 & 1267,1 \\
\hline 305 & Seibel 7.053 & 29 & 175 & 146 & 183,0 & 1781 & 1598,0 \\
\hline 313 & Seibel 5.593 & 13 & 137 & 124 & 68,9 & 1336 & 1267,1 \\
\hline
\end{tabular}


Tabela 18. Médias de peso $(\mathrm{g})$, comprimento $(\mathrm{cm})$, largura $(\mathrm{cm})$, número de bagas $(\mathrm{NB})$, compacidade e forma dos cachos, correspondentes aos cultivares do grupo D (Seibel, Couderc).Jundiai, 1989-91, 1993.

\begin{tabular}{|c|c|c|c|c|c|c|c|}
\hline № & CULTIVAR & Peso & Comp & Larg & NB & Compac $^{1}$ & Forma $^{2}$ \\
\hline 136 & Seibel 5.318 & 389,5 & 4,63 & 3,93 & 82 & $\mathrm{~S}$ & Co \\
\hline 36 & Seibel 7.144 & 330,7 & 12,15 & 6,63 & 212 & $M$ & $\mathrm{Co} / \mathrm{A}$ \\
\hline 250 & Seibel 60 & 265,0 & 20,17 & 10,99 & 84 & C & Co \\
\hline 291 & Seibel 13.693 & 257,3 & 11,43 & 6,55 & 96 & $\mathrm{C}$ & $\mathrm{Co} / \mathrm{A}$ \\
\hline 280 & Seibel 8.724 & 254,0 & 11,69 & 9,16 & 104 & C & $\mathrm{Ci}$ \\
\hline 266 & Seibel 5.213 & 248,5 & 7,10 & 5,07 & 155 & $\mathrm{C}$ & Co \\
\hline 259 & Seibel 4.643 & 248,0 & 11,52 & 7,85 & 77 & $\mathrm{C}$ & $\mathrm{Ci}$ \\
\hline 270 & Seibel 5.915 & 242,1 & 13,58 & 9,62 & 91 & C & $\mathrm{Co} / \mathrm{A}$ \\
\hline 276 & Seibel 7.052 & 235,0 & 12,92 & 9,42 & 132 & C & $\mathrm{Co} / \mathrm{A}$ \\
\hline 279 & Seibel 8.712 & 234,3 & 14,89 & 11,00 & 117 & $M$ & $\mathrm{Co}$ \\
\hline 249 & Seibel 2 & 208,8 & 13,96 & 8,82 & 106 & $\mathrm{C}$ & $\mathrm{Co} / \mathrm{A}$ \\
\hline 305 & Seibel 7.053 & 196,5 & 12,00 & 7,17 & 114 & C & $\mathrm{Co}$ \\
\hline 278 & Seibel 8.357 & 190,0 & 10,88 & 7,33 & 60 & $\mathrm{C}$ & $\mathrm{Co}$ \\
\hline 15 & Couderc 1 & 189,7 & 9,87 & 6,96 & 89 & $\mathrm{M}$ & Co \\
\hline 205 & Couderc 3 & 181,8 & 13,46 & 8,30 & 73 & $\mathrm{C}$ & $\mathrm{Co}$ \\
\hline 313 & Seibel 5.593 & 178,6 & 17,07 & 9,46 & 105 & $\mathrm{C}$ & $\mathrm{Co} / \mathrm{A}$ \\
\hline 304 & Seibel 11.813 & 160,8 & 13,00 & 7,90 & 130 & C & $\mathrm{Ci} / \mathrm{A}$ \\
\hline 269 & Seibel 5.520 & 139,6 & 15,70 & 9,58 & 43 & $M$ & $\mathrm{Co}$ \\
\hline 245 & Seibel 11.342 & 128,3 & 11,35 & 7,78 & 47 & $M$ & $\mathrm{Ci}$ \\
\hline 165 & Seibel 4.995 & 127,7 & 6,28 & 5,05 & 68 & C & $\mathrm{Co} / \mathrm{A}$ \\
\hline 257 & Seibel 1.394 & 124,0 & 13,27 & 9,19 & 65 & $\mathrm{C}$ & $\mathrm{Co} / \mathrm{A}$ \\
\hline 265 & Seibel 5.163 & 117,7 & 13,62 & 7,78 & 87 & $\mathrm{M}$ & $\mathrm{Ci}$ \\
\hline 285 & Seibel 10.878 & 117,3 & 11,73 & 6,40 & 78 & $\mathrm{C}$ & $\mathrm{Ci}$ \\
\hline 251 & Seibel 159 & 106,5 & 8,33 & 4,68 & 62 & $\mathrm{M}$ & $\mathrm{Ci}$ \\
\hline 256 & Seibel 1.077 & 96,7 & 13,95 & 9,35 & 83 & $\mathrm{C}$ & $\mathrm{Ci}$ \\
\hline 287 & Seibel 12.583 & 92,7 & 9,98 & 7,86 & 47 & $\mathrm{M}$ & $\mathrm{Co}$ \\
\hline 264 & Seibel 5.145 & 73,6 & 15,55 & 6,93 & 44 & $\mathrm{M}$ & $\mathrm{Co} / \mathrm{A}$ \\
\hline 258 & Seibel 4.638 & 71,8 & 10,77 & 7,60 & 38 & $\mathrm{C}$ & Co \\
\hline 2 & Seibel 10.146 & 61,2 & 8,34 & 5,82 & 46 & $\mathrm{~s}$ & Co \\
\hline 215 & Seibel 2.021 & 57,2 & 11,25 & 9,85 & 50 & $\mathrm{C}$ & $\mathrm{Co}$ \\
\hline
\end{tabular}

1. Compacidade: $\mathrm{M}$ - média, C- compacto e S- solto;

2. Forma: Co- cônico, Ci- cilíndrico e A-alado. 
Tabela 19. Médias de peso $(\mathrm{g})$, comprimento $(\mathrm{mm})$, largura $(\mathrm{mm})$, forma, número de sementes (NS) e tamanho das sementes (TS) das bagas, correspondentes aos cultivares do grupo D (Seibel, Couderc). Jundiai, 1989-91, 1993,

\begin{tabular}{|c|c|c|c|c|c|c|c|}
\hline № & CULTIVAR & Peso & Compr. & Larg. & forma $^{1}$ & NS & $\mathrm{TS}^{2}$ \\
\hline 136 & Seibel 5.318 & 4,75 & 20,30 & 19,10 & $\mathrm{O}$ & 2 & M \\
\hline 259 & Seibel 4.643 & 3,80 & 18,20 & 17,60 & E & 2 & $M$ \\
\hline 250 & Seibel 60 & 3,33 & 17,30 & 16,60 & $\mathrm{O}$ & 3 & $M$ \\
\hline 245 & Seibel 11.342 & 2,73 & 16,40 & 15,90 & $\mathrm{O}$ & 3 & $\mathrm{P}$ \\
\hline 291 & Seibel 13.693 & 2,68 & 16,30 & 16,00 & $E$ & 2 & $M$ \\
\hline 279 & Seibel 8.712 & 2,66 & 17,10 & 15,40 & $\mathrm{O}$ & 3 & $\mathrm{P}$ \\
\hline 270 & Seibel 5.915 & 2,66 & 16,90 & 15,55 & $\mathrm{O}$ & 2 & $M$ \\
\hline 205 & Couderc 3 & 2,49 & 16,45 & 15,50 & $\mathrm{O}$ & 3 & $\mathrm{G}$ \\
\hline 269 & Seibel 5.520 & 2,46 & 15,70 & 15,80 & E & 3 & $\mathrm{P}$ \\
\hline 287 & Seibel 12.583 & 2,41 & 15,75 & 15,05 & $E$ & 3 & $M$ \\
\hline 165 & Seibel 4.995 & 2,32 & 15,15 & 15,15 & $E$ & 2 & $M$ \\
\hline 280 & Seibel 8.724 & 2,16 & 15,50 & 14,60 & $E$ & 3 & $M$ \\
\hline 215 & Seibel 2.021 & 2,16 & 14,80 & 14,50 & $\mathrm{O}$ & 2 & $M$ \\
\hline 266 & Seibel 5.213 & 2,09 & 14,45 & 14,85 & $E$ & 3 & $\mathrm{M}$ \\
\hline 15 & Couderc 1 & 1,97 & 16,40 & 15,25 & $\mathrm{O}$ & 2 & $G$ \\
\hline 249 & Seibel 2 & 1,97 & 14,70 & 14,30 & $\mathrm{O}$ & 2 & M \\
\hline 278 & Seibel 8.357 & 1,95 & 14,50 & 14,60 & $E$ & 3 & $\mathrm{P}$ \\
\hline 257 & Seibel 1.394 & 1,93 & 14,70 & 14,50 & $E$ & 3 & $M$ \\
\hline 305 & Seibel 7.053 & 1,91 & 14,50 & 14,30 & $E$ & 3 & $M$ \\
\hline 313 & Seibel 5.593 & 1,82 & 14,00 & 14,40 & $E$ & 3 & $\mathrm{M}$ \\
\hline 285 & Seibel 10.878 & 1,82 & 14,00 & 13,80 & E & 3 & $M$ \\
\hline 276 & Seibel 7.052 & 1,78 & 13,35 & 13,85 & E & 3 & $M$ \\
\hline 264 & Seibel 5.145 & 1,78 & 13,85 & 13,75 & E & 2 & $M$ \\
\hline 256 & Seibel 1.077 & 1,76 & 14,30 & 14,00 & E & 2 & $M$ \\
\hline 265 & Seibel 5.163 & 1,74 & 13,15 & 14,40 & $E$ & 3 & M \\
\hline 251 & Seibel 159 & 1,69 & 13,95 & 13,95 & $\mathrm{O}$ & 2 & $\mathrm{M}$ \\
\hline 304 & Seibel 11.813 & 1,57 & 13,70 & 12,80 & $\mathrm{O}$ & 2 & $\mathrm{P}$ \\
\hline 36 & Seibel 7.144 & 1,56 & 13,50 & 12,90 & $\mathrm{O}$ & 2 & M \\
\hline 258 & Seibel 4.638 & 1,47 & 12,70 & 12,80 & E & 2 & $\mathrm{M}$ \\
\hline 2 & Seibel 10.146 & 1,33 & 12,60 & 12,70 & E & 2 & $\mathrm{M}$ \\
\hline
\end{tabular}

Forma das bagas: O- oval; E- esférica

${ }^{2}$ Tamanho da semente: $\mathrm{P}$ - pequena; $\mathrm{M}$ - média; G-grande 
Tabela 20. Textura, sabor, teor de sólidos solúveis totais ( $\left.{ }^{\circ} \mathrm{Brix}\right)$, e pH dos cultivares do grupo D (Seibel, Couderc). Jundiaí, 1989-91, 1993.

\begin{tabular}{|c|c|c|c|c|c|}
\hline \multirow[b]{2}{*}{ № } & CULTIVAR & \multicolumn{4}{|c|}{ Caracteristicas Tecnológicas } \\
\hline & Nome & text $^{1}$ & sabor $^{2}$ & ${ }^{\circ} \mathrm{Brix}$ & $\mathrm{pH}$ \\
\hline 287 & Seibel 12.583 & $\mathrm{~F}$ & $\mathrm{~N}$ & 18,75 & 3,33 \\
\hline 266 & Seibel 5.213 & $\mathrm{~F}$ & $N$ & 17,35 & 3,53 \\
\hline 15 & Couderc 1 & $\mathrm{M}$ & $\mathrm{N}$ & 17,30 & 3,11 \\
\hline 259 & Seibel 4.643 & $\mathrm{M}$ & $\mathrm{N}$ & 17,17 & 3,08 \\
\hline 215 & Seibel 2.021 & $\mathrm{M}$ & $N$ & 17,00 & 3,14 \\
\hline 258 & Seibel 4.638 & $\mathrm{M}$ & $N$ & 16,75 & 3,45 \\
\hline 291 & Seibel 13.693 & $T$ & $\mathrm{~N}$ & 16,75 & 3,12 \\
\hline 269 & Seibel 5.520 & $F$ & $\mathrm{~N}$ & 16,75 & 3,33 \\
\hline 250 & Seibel 60 & $M$ & $\mathrm{~N}$ & 16,25 & 2,97 \\
\hline 165 & Seibel 4.995 & $F$ & $\mathrm{~N}$ & 16,17 & 2,85 \\
\hline 305 & Seibel 7.053 & $\mathrm{~F}$ & $N$ & 16,00 & 3,11 \\
\hline 264 & Seibel 5.145 & $\mathrm{~F}$ & $N$ & 16,00 & 3,17 \\
\hline 285 & Seibel 10,878 & $\mathrm{~F}$ & $\mathrm{~N}$ & 16,00 & 3,18 \\
\hline 2 & Seibel 10.146 & $\mathrm{M}$ & $N$ & 16,00 & 3,29 \\
\hline 278 & Seibel 8.357 & $F$ & $\mathrm{~N}$ & 15,75 & 3,11 \\
\hline 251 & Seibel 159 & $\mathrm{M}$ & $\mathrm{N}$ & 15,65 & 3,19 \\
\hline 279 & Seibel 8.712 & $F$ & $\mathrm{~N}$ & 15,60 & 3,36 \\
\hline 265 & Seibel 5.163 & $\mathrm{~F}$ & $N$ & 15,50 & 3,23 \\
\hline 304 & Seibel 11.813 & $\mathrm{M}$ & $\mathrm{N}$ & 15,50 & 3,28 \\
\hline 257 & Seibel 1394 & $\mathrm{~F}$ & $N$ & 15,38 & 3,16 \\
\hline 280 & Seibel 8.724 & $F$ & $N$ & 15,25 & 3,17 \\
\hline 276 & Seibel 7.052 & $F$ & $\mathrm{~N}$ & 15,25 & 2,94 \\
\hline 249 & Seibel 2 & $M$ & $N$ & 15,25 & 3,03 \\
\hline 245 & Seibel 11.342 & $\mathrm{M}$ & $\mathrm{N}$ & 15,00 & 3,35 \\
\hline 313 & Seibel 5.593 & $\mathrm{~F}$ & $\mathrm{~N}$ & 15,00 & 3,28 \\
\hline 205 & Couderc 3 & 2 & $\mathrm{~N}$ & 15,00 & 3,47 \\
\hline 256 & Seibel 1.077 & $\mathrm{~F}$ & $N$ & 14,75 & 3,04 \\
\hline 36 & Seibel 7.144 & $\mathrm{M}$ & $\mathrm{N}$ & 14,00 & 2,91 \\
\hline 270 & Seibel 5.915 & $F$ & $\mathrm{~N}$ & 13,25 & 3,21 \\
\hline 136 & Seibel 5.318 & $\mathrm{~F}$ & $\mathrm{~N}$ & 11,50 & 3,11 \\
\hline
\end{tabular}

1. Textura: M-média, F-fundente; T-trincante;

2. Sabor: N- neutro, Fo- foxado, Mo- moscatel. 
Tabela 21. Número de dias e graus-dia da poda ao início da brotação $(\mathrm{P} / \mathrm{B})$, da poda à colheita $(\mathrm{P} / \mathrm{C})$, e do início da brotação à colheita $(\mathrm{B} / \mathrm{C})$, correspondentes aos cultivares do grupo E (outros). Jundiaí, 1991.

\begin{tabular}{|c|c|c|c|c|c|c|c|}
\hline \multicolumn{2}{|r|}{ Cultivar } & \multicolumn{3}{|c|}{ No de dias } & \multicolumn{3}{|c|}{ Graus-Dias } \\
\hline № & Nome & $\mathrm{P} / \mathrm{B}$ & $\mathrm{P} / \mathrm{C}$ & $\mathrm{B} / \mathrm{C}$ & $\mathrm{P} / \mathrm{B}$ & $\mathrm{P} / \mathrm{C}$ & $\mathrm{B} / \mathrm{C}$ \\
\hline 3 & Niabel & 28 & 146 & 118 & 204 & 1459 & 1255 \\
\hline 5 & Bicane & 18 & 146 & 128 & 140 & 1459 & 1319 \\
\hline 17 & Isabel Sport & 21 & 160 & 139 & 159 & 1617 & 1458 \\
\hline 71 & Concord & 21 & 160 & 139 & 159 & 1617 & 1458 \\
\hline 142 & Elvira & 30 & 160 & 130 & 222 & 1617 & 1395 \\
\hline 172 & Isabelão & 21 & 160 & 139 & 159 & 1617 & 1458 \\
\hline 173 & Isabel & 18 & 160 & 142 & 140 & 1617 & 1477 \\
\hline 174 & Hubard & 21 & 160 & 139 & 159 & 1617 & 1458 \\
\hline 175 & Golden Muscat & 21 & 160 & 139 & 159 & 1617 & 1458 \\
\hline 176 & Goethe & 21 & 160 & 139 & 159 & 1617 & 1458 \\
\hline 185 & Liberty & 18 & 160 & 142 & 140 & 1617 & 1477 \\
\hline 195 & Saint Emilion & 16 & 160 & 144 & 121 & 1617 & 1496 \\
\hline 203 & Aspiran Bousan & 15 & 160 & 145 & 110 & 1617 & 1507 \\
\hline 204 & Lubeck & 15 & 146 & 131 & 110 & 1459 & 1349 \\
\hline 207 & Lindley & 15 & 160 & 145 & 110 & 1617 & 1507 \\
\hline 212 & Aramon & 15 & 160 & 145 & 110 & 1617 & 1507 \\
\hline 224 & Syrah & 21 & 146 & 125 & 159 & 1459 & 1300 \\
\hline 229 & Merlot & 21 & 160 & 139 & 159 & 1617 & 1458 \\
\hline 230 & Baco 22-A & 21 & 160 & 139 & 159 & 1617 & 1458 \\
\hline 237 & Moscatel Azul & 15 & 119 & 104 & 110 & 1132 & 1022 \\
\hline 293 & Moscatel Branca & 23 & 160 & 137 & 171 & 1617 & 1446 \\
\hline 300 & Chenin Blanc & 21 & 146 & 125 & 159 & 1459 & 1300 \\
\hline 303 & Gold & 15 & 149 & 134 & 110 & 1488 & 1378 \\
\hline 307 & Chardonnay & 21 & 146 & 125 & 159 & 1459 & 1300 \\
\hline 315 & Japonesa & 21 & 146 & 125 & 159 & 1459 & 1300 \\
\hline 318 & Bordô & 15 & 160 & 145 & 110 & 1617 & 1507 \\
\hline 320 & Cynthiana & 21 & 160 & 139 & 159 & 1617 & 1458 \\
\hline 324 & Pinot Noir & 16 & 160 & 144 & 121 & 1617 & 1496 \\
\hline
\end{tabular}


Tabela 21. Número de dias e graus-dia da poda ao início da brotação $(\mathrm{P} / \mathrm{B})$, da poda à colheita $(\mathrm{P} / \mathrm{C})$, e do início da brotação à colheita $(\mathrm{B} / \mathrm{C})$, correspondentes aos cultivares do grupo $\mathrm{E}$ (outros). Jundiai, 1991.

\begin{tabular}{lllllll}
326 Diamante Negro & 17 & 146 & 129 & 130 & 1459 & 1329 \\
335 Ives & 21 & 160 & 139 & 159 & 1617 & 1458 \\
344 Herbemont & 16 & 160 & 144 & 121 & 1617 & 1496 \\
377 Niagara Rosada Escura & 21 & 146 & 125 & 159 & 1459 & 1300 \\
380 Niagara Branca Oval & 21 & 146 & 125 & 159 & 1459 & 1300 \\
388 Cunningham & 15 & 160 & 145 & 110 & 1617 & 1507 \\
391 Iona & 15 & 160 & 145 & 110 & 1617 & 1507 \\
395 Dutchess & 15 & 160 & 145 & 110 & 1617 & 1507 \\
399 Lucile & 21 & 160 & 139 & 159 & 1617 & 1458 \\
410 Ananaz & 18 & 146 & 128 & 140 & 1459 & 1319 \\
417 Diamond & 23 & 160 & 137 & 171 & 1617 & 1446 \\
420 Lomanto & 15 & 160 & 145 & 110 & 1617 & 1507 \\
427 Highland & 15 & 179 & 164 & 110 & 1842 & 1642 \\
430 Hidalgo & 15 & 160 & 145 & 110 & 1617 & 1507 \\
436 Fern Munson & 15 & 146 & 131 & 110 & 1459 & 1349 \\
439 Black July & 23 & 160 & 137 & 171 & 1617 & 1446 \\
444 J 7.604-15 & 15 & 160 & 145 & 110 & 1617 & 1507 \\
445 J 7.602-44 & 15 & 146 & 131 & 110 & 1459 & 1359 \\
446 J 7.605-15 & 15 & 160 & 145 & 110 & 1617 & 1507 \\
447 J 7.602-66 & 15 & 160 & 145 & 110 & 1617 & 1507 \\
456 Patricia Branca & 15 & 160 & 145 & 110 & 1617 & 1507 \\
\hline \hline
\end{tabular}


Tabela 22. Número de dias e graus dias da poda ao início da brotação (P/B), da poda à colheita $(\mathrm{P} / \mathrm{C})$, e do início da brotação à colheita $(\mathrm{B} / \mathrm{C})$, correspondentes aos cultivares do grupo $E$ (outros). Jundiai, 1993.

\begin{tabular}{|c|c|c|c|c|c|c|c|}
\hline \multicolumn{2}{|r|}{ Cultivar } & \multicolumn{3}{|c|}{ No de dias } & \multicolumn{3}{|c|}{ Graus-Dias } \\
\hline № & Nome & $\mathrm{P} / \mathrm{B}$ & $\mathrm{P} / \mathrm{C}$ & $\mathrm{B} / \mathrm{C}$ & $\mathrm{P} / \mathrm{B}$ & $\mathrm{P} / \mathrm{C}$ & $\mathrm{B} / \mathrm{C}$ \\
\hline 3 & Niabel & 21 & 152 & 131 & 144,0 & 1484 & 1340,0 \\
\hline 5 & Bicane & 13 & 137 & 124 & 68,9 & 1336 & 1267,1 \\
\hline 17 & Isabel Sport & 13 & 152 & 139 & 68,9 & 1484 & 1415,1 \\
\hline 71 & Concord & 15 & 158 & 143 & 90,7 & 1562 & 1471,3 \\
\hline 142 & Elvira & 28 & 164 & 136 & 176,0 & 1636 & 1460,0 \\
\hline 172 & Isabelão & 21 & 168 & 147 & 144,0 & 1687 & 1543,0 \\
\hline 173 & Isabel & 13 & 168 & 155 & 68,9 & 1687 & 1618,1 \\
\hline 174 & Hubard & 15 & 175 & 160 & 90,7 & 1781 & 1690,3 \\
\hline 175 & Golden Muscat & 13 & 143 & 130 & 68,9 & 1398 & 1329,1 \\
\hline 176 & Goethe & 13 & 168 & 155 & 68,9 & 1687 & 1618,1 \\
\hline 185 & Liberty & 15 & 143 & 128 & 90,7 & 1398 & 1307,3 \\
\hline 195 & Saint Emilion & 13 & 168 & 155 & 68,9 & 1687 & 1618,1 \\
\hline 203 & Aspiran Bousan & 13 & 143 & 130 & 68,9 & 1398 & 1329,1 \\
\hline 204 & Lubeck & 13 & 143 & 130 & 68,9 & 1398 & 1329,1 \\
\hline 207 & Lindley & 15 & 143 & 128 & 90,7 & 1398 & 1307,3 \\
\hline 212 & Aramon & 15 & 143 & 128 & 90,7 & 1398 & 1307,3 \\
\hline 224 & Syrah & 13 & 137 & 124 & 68,9 & 1336 & 1267,1 \\
\hline 229 & Merlot & 15 & 137 & 122 & 90,7 & 1336 & 1245,3 \\
\hline 230 & Baco 22-A & 13 & 134 & 121 & 68,9 & 1309 & 1240,1 \\
\hline 237 & Moscatel Azul & 15 & 168 & 153 & 90,7 & 1687 & 1596,3 \\
\hline 293 & Moscatel Branca & 15 & 175 & 160 & 90,7 & 1781 & 1690,3 \\
\hline 300 & Chenin Blanc & 15 & 175 & 160 & 68,9 & 1781 & 1712,1 \\
\hline 303 & Gold & 15 & 137 & 122 & 90,7 & 1336 & 1245,3 \\
\hline 307 & Chardonnay & 15 & 137 & 122 & 90,7 & 1336 & 1245,3 \\
\hline 315 & Japonesa & 15 & 175 & 160 & 68,9 & 1781 & 1712,1 \\
\hline 318 & Bordô & 15 & 137 & 122 & 90,7 & 1336 & 1245,3 \\
\hline 320 & Cynthiana & 13 & 158 & 145 & 68,9 & 1562 & 1493,1 \\
\hline 324 & Pinot Noir & 15 & 175 & 160 & 68,9 & 1781 & 1712,1 \\
\hline
\end{tabular}


Tabela 22. Número de dias e graus dias da poda ao início da brotação (P/B), da poda à colheita $(\mathrm{P} / \mathrm{C})$, e do início da brotação à colheita $(\mathrm{B} / \mathrm{C})$, correspondentes aos cultivares do grupo $E$ (outros). Jundiai, 1993.

\begin{tabular}{lllllll}
326 Diamante Negro & 15 & 175 & 160 & 68,9 & 1781 & 1712,1 \\
335 Ives & 15 & 143 & 128 & 90,7 & 1398 & 1307,3 \\
344 Herbemont & 13 & 158 & 145 & 68,9 & 1562 & 1493,1 \\
377 Niagara Rosada Escura & 11 & 143 & 132 & 50,2 & 1398 & 1347,8 \\
380 Niagara Branca Oval & 13 & 143 & 130 & 68,9 & 1398 & 1329,1 \\
388 Cunningham & 15 & 164 & 149 & 68,9 & 1636 & 1567,1 \\
391 Iona & 15 & 175 & 160 & 68,9 & 1781 & 1712,1 \\
395 Dutchess & 15 & 152 & 137 & 68,9 & 1484 & 1415,1 \\
399 Lucile & 13 & 152 & 139 & 68,9 & 1484 & 1415,1 \\
410 Ananaz & 15 & 137 & 122 & 90,7 & 1336 & 1245,3 \\
417 Diamond & 15 & 137 & 122 & 90,7 & 1336 & 1245,3 \\
420 Lomanto & 15 & 168 & 153 & 68,9 & 1687 & 1618,1 \\
427 Highland & 13 & 164 & 151 & 68,9 & 1636 & 1567,1 \\
430 Hidalgo & 13 & 175 & 162 & 68,9 & 1781 & 1712,1 \\
436 Fern Munson & 13 & 137 & 124 & 68,9 & 1336 & 1267,1 \\
439 Black July & 15 & 164 & 149 & 68,9 & 1636 & 1567,1 \\
444 J 7.604-15 & 21 & 152 & 139 & 68,9 & 1484 & 1415,1 \\
445 J 7.602-44 & 13 & 152 & 137 & 68,9 & 1484 & 1415,1 \\
446 J 7.605-15 & 13 & 164 & 149 & 68,9 & 1636 & 1567,1 \\
447 J 7.602-66 & 13 & 168 & 153 & 68,9 & 1687 & 1618,1 \\
456 Patricia Branca & 13 & 164 & 151 & 68,9 & 1636 & 1567,1 \\
\hline \hline
\end{tabular}


Tabela 23. Médias de peso $(\mathrm{g})$, comprimento $(\mathrm{cm})$, largura $(\mathrm{cm})$, número de bagas $(\mathrm{NB})$, compacidade e forma dos cachos, correspondentes aos cultivares do grupo $\mathrm{E}$ (outros).Jundiaí, 1989-91, 1993.

\begin{tabular}{lrrrrrrr}
\hline \hline № $\quad$ CULTIVAR & Peso & Comp. & Larg. & NB & Compac $^{1}$ & Forma \\
\hline 3 Niabel & 418,2 & 16,68 & 10,94 & 56 & $\mathrm{C}$ & $\mathrm{Co} / \mathrm{A}$ \\
17 Isabel Sport & 279,8 & 9,03 & 4,69 & 46 & $\mathrm{M}$ & $\mathrm{Ci}$ \\
5 Bicane & 270,4 & 17,51 & 10,35 & 62 & $\mathrm{M}$ & $\mathrm{Co}$ \\
326 Diamante Negro & 258,4 & 12,85 & 7,10 & 90 & $\mathrm{C}$ & $\mathrm{Co} / \mathrm{A}$ \\
300 Chenin Blanc & 252,2 & 20,66 & 11,64 & 152 & $\mathrm{C}$ & $\mathrm{Co} / \mathrm{A}$ \\
436 Fern Munson & 250,8 & 14,99 & 10,05 & 76 & $\mathrm{C}$ & $\mathrm{Co} / \mathrm{A}$ \\
445 J 7.602-44 & 236,9 & 14,10 & 8,30 & 84 & $\mathrm{M}$ & $\mathrm{Co}$ \\
212 Aramon & 236,8 & 12,76 & 7,96 & 119 & $\mathrm{C}$ & $\mathrm{A}$ \\
446 J 7.605-15 & 230,2 & 17,70 & 11,00 & 42 & $\mathrm{~S}$ & $\mathrm{Ci} / \mathrm{A}$ \\
447 J 7.602-66 & 226,0 & 17,20 & 10,30 & 74 & $\mathrm{~S}$ & $\mathrm{Co} / \mathrm{A}$ \\
203 Aspiran Bousan & 218,8 & 14,29 & 9,14 & 117 & $\mathrm{M}$ & $\mathrm{Co} / \mathrm{A}$ \\
176 Göethe & 218,6 & 13,40 & 8,16 & 45 & $\mathrm{C}$ & $\mathrm{Ci}$ \\
175 Golden Muscat & 210,9 & 14,87 & 8,59 & 54 & $\mathrm{M}$ & $\mathrm{Co}$ \\
174 Hubard & 209,6 & 14,08 & 9,85 & 32 & $\mathrm{M}$ & $\mathrm{Ci}$ \\
427 Highland & 207,6 & 15,30 & 9,35 & 34 & $\mathrm{M}$ & $\mathrm{Co} / \mathrm{A}$ \\
315 Japonesa & 207,2 & 17,81 & 11,63 & 20 & $\mathrm{~S}$ & $\mathrm{Co}$ \\
456 Patricia Branca & 203,0 & 8,81 & 6,13 & 46 & $\mathrm{M}$ & $\mathrm{Co}$ \\
224 Syrah & 181,6 & 13,68 & 7,29 & 110 & $\mathrm{C}$ & $\mathrm{Co} / \mathrm{A}$ \\
204 Lubeck & 181,3 & 11,09 & 6,45 & 106 & $\mathrm{M}$ & $\mathrm{Co} / \mathrm{A}$ \\
417 Diamond & 180,2 & 13,40 & 7,73 & 42 & $\mathrm{M}$ & $\mathrm{Co}$ \\
230 Baco 22-A & 175,0 & 14,64 & 8,96 & 68 & $\mathrm{C}$ & $\mathrm{Co}$ \\
388 Cunninghan & 164,8 & 12,50 & 7,02 & 107 & $\mathrm{~S}$ & $\mathrm{Co}$ \\
207 Lindley & 162,6 & 14,77 & 8,88 & 39 & $\mathrm{M}$ & $\mathrm{Co}$ \\
430 Hidalgo & 159,5 & 16,26 & 9,35 & 64 & $\mathrm{M}$ & $\mathrm{Co}$ \\
173 Isabel & 154,3 & 15,03 & 9,19 & 39 & $\mathrm{M}$ & $\mathrm{Co}$ \\
391 Iona & 153,9 & 13,11 & 8,46 & 45 & $\mathrm{M}$ & $\mathrm{Co}$ \\
172 Isabelão & 152,4 & 11,86 & 8,30 & 37 & $\mathrm{M}$ & $\mathrm{Co}$ \\
195 Saint Emilion & 149,2 & 12,06 & 6,23 & 27 & $\mathrm{M}$ & $\mathrm{Co}$ \\
344 Herbemont & 147,6 & 6,29 & 3,37 & 124 & $\mathrm{C}$ & $\mathrm{Co}$
\end{tabular}


Tabela 23. Médias de peso $(\mathrm{g})$, comprimento $(\mathrm{cm})$, largura $(\mathrm{cm})$, número de bagas $(\mathrm{NB})$, compacidade e forma dos cachos, correspondentes aos cultivares do grupo $\mathrm{E}$ (outros).Jundiaí, 1989-91, 1993.

\begin{tabular}{lrrrrrr}
420 Lomanto & 137,9 & 12,69 & 6,17 & 33 & $\mathrm{C}$ & $\mathrm{Co}$ \\
71 Concord & 131,8 & 13,51 & 9,33 & 35 & $\mathrm{M}$ & $\mathrm{Ci}$ \\
335 Ives & 130,5 & 14,85 & 6,90 & 57 & $\mathrm{M}$ & $\mathrm{Ci}$ \\
185 Liberty & 129,7 & 18,15 & 8,74 & 46 & $\mathrm{M}$ & $\mathrm{Co}$ \\
318 Bordô & 119,4 & 14,81 & 8,15 & 52 & $\mathrm{M}$ & $\mathrm{Ci} / \mathrm{A}$ \\
237 Moscatel Azul & 117,9 & 10,19 & 7,46 & 51 & $\mathrm{M}$ & $\mathrm{Co}$ \\
395 Dutchess & 117,2 & 17,08 & 7,78 & 39 & - & $\mathrm{Co} / \mathrm{A}$ \\
320 Cynthiana & 116,4 & 11,19 & 6,25 & 98 & $\mathrm{C}$ & $\mathrm{Co} / \mathrm{A}$ \\
324 Pinot Noir & 114,9 & 11,89 & 6,98 & 77 & $\mathrm{C}$ & $\mathrm{Co}$ \\
377 Niagara Rosada Escura & 114,1 & 11,51 & 7,75 & 21 & $\mathrm{~S}$ & $\mathrm{Co}$ \\
410 Ananaz & 112,6 & 15,12 & 9,42 & 20 & $\mathrm{M}$ & $\mathrm{Co}$ \\
399 Lucile & 106,4 & 8,36 & 5,79 & 26 & $\mathrm{M}$ & $\mathrm{Co}$ \\
229 Merlot & 100,1 & 10,04 & 7,94 & 45 & $\mathrm{M}$ & $\mathrm{Co}$ \\
293 Moscatel Branca & 76,5 & 7,40 & 6,00 & 15 & $\mathrm{M}$ & $\mathrm{Co}$ \\
380 Niagara Branca Oval & 75,8 & 14,92 & 6,32 & 17 & $\mathrm{~S}$ & $\mathrm{Co}$ \\
307 Chardonnay & 56,7 & 22,58 & 10,39 & 46 & $\mathrm{C}$ & $\mathrm{Co}$ \\
303 Gold & 53,4 & 12,87 & 7,90 & 34 & $\mathrm{M}$ & $\mathrm{Co}$ \\
142 Elvira & 45,4 & 16,05 & 8,76 & 24 & $\mathrm{C}$ & $\mathrm{Co}$ \\
444 J 7.604-15 & 43,9 & 10,30 & 7,50 & 15 & $\mathrm{~S}$ & $\mathrm{Co}$ \\
439 Black July & 41,3 & 16,43 & 9,43 & 104 & $\mathrm{C}$ & $\mathrm{Co}$ \\
\hline \hline
\end{tabular}

1. Compacidade: $\mathrm{M}$ - média, $\mathrm{C}$ - compacto e $\mathrm{S}$ - solto;

2. Forma: Co- cônico, $\mathrm{Ci}$ - cilindrico e A-alado. 
Tabela 24. Médias de peso $(\mathrm{g})$, comprimento $(\mathrm{mm})$, largura $(\mathrm{mm})$, forma, número de sementes (NS) e tamanho das sementes (TS), correspondentes aos cultivares do grupo E (outros).Jundiai, 1989-91, 1993.

\begin{tabular}{|c|c|c|c|c|c|c|c|}
\hline № & CULTIVAR & Peso & Compr. & Larg. & formal & NS & $\mathrm{TS}^{2}$ \\
\hline 315 & Japonesa & 10,36 & 27,75 & 23,90 & $\mathrm{O}$ & 2 & $\mathrm{G}$ \\
\hline 3 & Niabel & 8,11 & 24,90 & 22,90 & $\mathrm{O}$ & 3 & G \\
\hline 427 & Highland & 7,08 & 22,70 & 10,80 & $E$ & 3 & $\mathrm{G}$ \\
\hline 174 & Hubard & 6,55 & 22,30 & 21,40 & $\mathrm{O}$ & 3 & $\mathrm{G}$ \\
\hline 17 & Isabel Sport & 6,33 & 22,65 & 20,85 & $E$ & 2 & $\mathrm{G}$ \\
\hline 410 & Ananaz & 5,63 & 20,90 & 20,00 & O & 3 & G \\
\hline 195 & Saint Emilion & 5,52 & 22,10 & 19,45 & $\mathrm{O}$ & 2 & $\mathrm{G}$ \\
\hline 446 & J $7.605-15$ & 5,48 & 17,10 & 19,40 & $\mathrm{O}$ & 2 & M \\
\hline 380 & Niagara Branca Oval & 5,43 & 22,40 & 18,70 & $\mathrm{O}$ & 3 & M \\
\hline 176 & Goethe & 5,39 & 21,70 & 19,70 & $\mathrm{O}$ & 3 & $M$ \\
\hline 456 & Patrícia Branca & 5,35 & 21,90 & 19,55 & $\mathrm{O}$ & 1 & $M$ \\
\hline 377 & Niagara Rosada Escura & 5,26 & 21,00 & 19,40 & $\mathrm{O}$ & 3 & $M$ \\
\hline 5 & Bicane & 5,16 & 20,40 & 18,60 & $\mathrm{O}$ & 2 & $M$ \\
\hline 175 & Golden Muscat & 5,15 & 22,40 & 19,10 & 0 & 3 & $\mathrm{M}$ \\
\hline 399 & Lucile & 4,86 & 20,50 & 19,40 & 0 & 3 & $\mathrm{M}$ \\
\hline 293 & Moscatel Branca & 4,66 & 20,70 & 18,10 & $\mathrm{O}$ & 3 & - \\
\hline 420 & Lomanto & 4,47 & 19,80 & 18,35 & $\mathrm{O}$ & 3 & $\mathrm{M}$ \\
\hline 172 & Isabelão & 4,46 & 20,20 & 18,25 & $\mathrm{O}$ & 2 & $\mathrm{G}$ \\
\hline 417 & Diamond & 4,29 & 19,80 & 18,60 & $\mathrm{O}$ & 3 & $\mathrm{P}$ \\
\hline 444 & J 7.604-15 & 4,20 & 20,20 & 17,20 & 0 & 2 & $\mathrm{M}$ \\
\hline 401 & Lindley & 4,17 & 19,40 & 18,33 & $\mathrm{O}$ & 2 & $\mathrm{M}$ \\
\hline 71 & Concord & 3,87 & 19,00 & 17,35 & O & 2 & G \\
\hline 173 & Isabel & 3,87 & 19,50 & 17,65 & $\mathrm{O}$ & 2 & $\mathrm{G}$ \\
\hline 447 & J $7.602-66$ & 3,58 & 22,10 & 17,40 & $\mathrm{O}$ & 2 & $\mathrm{M}$ \\
\hline 391 & Iona & 3,42 & 18,50 & 16,60 & $\mathrm{O}$ & 3 & M \\
\hline 436 & Fern Munson & 3,30 & 17,80 & 16,10 & $\mathrm{O}$ & 3 & G \\
\hline 326 & Diamante Negro & 3,22 & 17,20 & 16,30 & $\mathrm{O}$ & 2 & $\mathrm{M}$ \\
\hline 430 & Hidalgo & 2,94 & 16,70 & 16,65 & $E$ & 3 & $M$ \\
\hline 303 & Gold & 2,87 & 16,60 & 16,30 & $\mathrm{O}$ & 2 & $\mathrm{G}$ \\
\hline 230 & Baco 22-A & 2,83 & 17,40 & 16,20 & $E$ & 2 & $\mathrm{G}$ \\
\hline
\end{tabular}


Tabela 24. Médias de peso $(\mathrm{g})$, comprimento $(\mathrm{mm})$, largura $(\mathrm{mm})$, forma, número de sementes (NS) e tamanho das sementes (TS), correspondentes aos cultivares do grupo E (outros).Jundiaí, 1989-91, 1993.

\begin{tabular}{llllllll}
185 Liberty & 2,82 & 16,80 & 16,30 & $\mathrm{O}$ & 2 & $\mathrm{M}$ \\
445 J 7.602-44 & 2,82 & 20,20 & 15,90 & $\mathrm{O}$ & 2 & $\mathrm{M}$ \\
237 Moscatel Azul & 2,61 & 15,60 & 14,95 & $\mathrm{O}$ & 2 & $\mathrm{M}$ \\
335 Ives & 2,54 & 15,90 & 15,80 & $\mathrm{O}$ & 2 & $\mathrm{P}$ \\
318 Bordô & 2,35 & 16,10 & 15,60 & $\mathrm{E}$ & 3 & $\mathrm{P}$ \\
229 Merlot & 2,05 & 14,50 & 14,60 & $\mathrm{E}$ & 2 & $\mathrm{P}$ \\
300 Chenin Blanc & 2,03 & 15,50 & 13,75 & $\mathrm{E}$ & 2 & $\mathrm{M}$ \\
212 Aramon & 1,99 & 14,60 & 14,60 & $\mathrm{E}$ & 2 & $\mathrm{P}$ \\
142 Elvira & 1,89 & 14,20 & 13,80 & $\mathrm{E}$ & 2 & $\mathrm{M}$ \\
203 Aspiran Bousan & 1,87 & 14,70 & 14,70 & $\mathrm{E}$ & 1 & $\mathrm{M}$ \\
224 Syrah & 1,87 & 14,70 & 13,60 & $\mathrm{O}$ & 2 & $\mathrm{M}$ \\
307 Chardonnay & 1,80 & 13,30 & 13,30 & $\mathrm{E}$ & 2 & $\mathrm{P}$ \\
395 Dutchess & 1,73 & 14,30 & 13,75 & $\mathrm{O}$ & 1 & $\mathrm{M}$ \\
324 Pinot Noir & 1,73 & 14,05 & 13,20 & $\mathrm{O}$ & 2 & $\mathrm{M}$ \\
204 Lubeck & 1,71 & 14,70 & 13,00 & $\mathrm{O}$ & 3 & $\mathrm{M}$ \\
388 Cunninghan & 1,54 & 13,70 & 12,95 & $\mathrm{O}$ & 2 & $\mathrm{M}$ \\
439 Black July & 1,37 & 12,15 & 11,80 & $\mathrm{E}$ & 2 & $\mathrm{M}$ \\
320 Cynthiana & 1,19 & 11,95 & 11,75 & $\mathrm{E}$ & 3 & $\mathrm{M}$ \\
344 Herbemont & 1,19 & 12,35 & 11,60 & $\mathrm{E}$ & 1 & $\mathrm{P}$ \\
\hline \hline
\end{tabular}

1 Forma das bagas E- esférica; $\mathrm{O}$ - oval.

2 Tamanhos das sementes $P$ - pequena, $M$ - média, G- grande. 
Tabela 25. Textura, sabor, teor de sólidos solúveis ( ${ }^{\circ}$ Brix), acidez e pH dos cultivares do grupo E (outros).Jundiaí, 1989-91, 1993.

\begin{tabular}{|c|c|c|c|c|c|}
\hline \multirow[b]{2}{*}{ № } & \multirow{2}{*}{$\frac{\text { CULTIVAR }}{\text { Nome }}$} & \multicolumn{4}{|c|}{ Características Tecnológicas } \\
\hline & & text ${ }^{1}$ & sabor $^{2}$ & ${ }^{\circ}$ Brix & $\mathrm{pH}$ \\
\hline 300 & Chenin Blanc & $F$ & $\mathrm{~N}$ & 17,5 & 3,14 \\
\hline 229 & Merlot & M & $\mathrm{N}$ & 17,3 & 3,17 \\
\hline 324 & Pinot Noir & $\mathrm{F}$ & $\mathrm{N}$ & 17,3 & 3,23 \\
\hline 204 & Lubeck & $\mathrm{F}$ & $\mathrm{N}$ & 17,2 & 3,28 \\
\hline 326 & Diamante Negro & $\mathrm{T}$ & Mo & 17,0 & 3,61 \\
\hline 315 & Japonesa & M & $\mathrm{N}$ & 17,0 & 3,16 \\
\hline 377 & Niagara Rosada Escura & $\mathrm{F}$ & Fo & 17,0 & 2,55 \\
\hline 224 & Syrah & $\mathrm{F}$ & $\mathrm{N}$ & 17,0 & 2,74 \\
\hline 230 & Baco 22-A & $\mathrm{F}$ & $\mathrm{N}$ & 16,6 & 2,90 \\
\hline 307 & Chardonnay & $\mathrm{F}$ & $\mathrm{N}$ & 16,5 & 3,38 \\
\hline 320 & Cynthiana & $\mathrm{F}$ & $\mathrm{N}$ & 16,5 & 3,51 \\
\hline 237 & Moscatel Azul & $\mathrm{M}$ & Mo & 16,5 & 3,39 \\
\hline 439 & Black July & $\mathrm{F}$ & Fo & 16,3 & 3,46 \\
\hline 344 & Herbemont & $\mathrm{M}$ & Fo & 16,3 & 3,18 \\
\hline 212 & Aramon & $\mathrm{M}$ & Fo & 16,0 & 3,54 \\
\hline 417 & Diamond & M & Fo & 16,0 & 3,10 \\
\hline 142 & Elvira & M & Fo & 16,0 & 3,25 \\
\hline 303 & Gold & $\mathrm{T}$ & Fo & 16,0 & 3,02 \\
\hline 335 & Ives & $\mathrm{T}$ & Fo & 16,0 & 3,61 \\
\hline 195 & Saint Emilion & $F$ & $\mathrm{~N}$ & 16,0 & 3,49 \\
\hline 185 & Liberty & $\mathrm{F}$ & Fo & 15,9 & 3,31 \\
\hline 410 & Ananaz & M & Fo & 15,8 & 2,77 \\
\hline 207 & Lindley & $\mathrm{F}$ & Fo & 15,8 & 3,20 \\
\hline 175 & Golden Muscat & $\mathrm{F}$ & $\mathrm{N}$ & 15,7 & 3,18 \\
\hline 318 & Bordô & M & Fo & 15,5 & 3,66 \\
\hline 71 & Concord & $F$ & Fo & 15,0 & 3,00 \\
\hline 172 & Isabelão & $\mathrm{F}$ & Fo & 15,0 & 3,08 \\
\hline 380 & Niagara Branca Oval & $\mathrm{F}$ & Fo & 15,0 & 2,92 \\
\hline 427 & Highland & $F$ & Fo & 14,8 & 3,14 \\
\hline
\end{tabular}


Tabela 25. Textura, sabor, teor de sólidos solúveis ( $\left.{ }^{\circ} \mathrm{Brix}\right)$, e $\mathrm{pH}$ dos cultivares do grupo E (outros).Jundiaí, 1989-91, 1993.

\begin{tabular}{rlcccc}
456 & Patrícia Branca & $\mathrm{T}$ & $\mathrm{N}$ & 14,8 & 3,02 \\
5 & Bicane & $\mathrm{M}$ & $\mathrm{N}$ & 14,5 & 3,18 \\
430 & Hidalgo & $\mathrm{T}$ & $\mathrm{N}$ & 14,5 & 3,43 \\
17 & Isabel Sport & $\mathrm{F}$ & $\mathrm{Fo}$ & 14,4 & 3,04 \\
388 & Cunninghan & $\mathrm{F}$ & $\mathrm{N}$ & 14,3 & 2,28 \\
395 & Dutchess & $\mathrm{M}$ & $\mathrm{N}$ & 14,3 & 2,74 \\
436. & Fern Munson & $\mathrm{F}$ & Fo & 14,3 & 3,22 \\
174 & Hubard & $\mathrm{F}$ & $\mathrm{Fo}$ & 14,3 & 2,99 \\
173 & Isabel & $\mathrm{F}$ & $\mathrm{Fo}$ & 14,0 & 3,00 \\
391 & Iona & $\mathrm{F}$ & $\mathrm{Fo}$ & 13,5 & 3,34 \\
399 & Lucile & $\mathrm{F}$ & $\mathrm{Fo}$ & 13,5 & 2,87 \\
420 & Lomanto & $\mathrm{M}$ & $\mathrm{N}$ & 12,8 & 3,19 \\
176 & Goethe & $\mathrm{F}$ & $\mathrm{Fo}$ & 16,5 & 3,41 \\
203 & Aspiran Bousan & $\mathrm{F}$ & $\mathrm{N}$ & 16,5 & 3,48 \\
293 & Moscatel Branca & $\mathrm{T}$ & Fo & 16,0 & 3,36 \\
444 & J 7.604-15 & $\mathrm{F}$ & Fo & 16,5 & 3,50 \\
445 & J 7.602-44 & $\mathrm{F}$ & $\mathrm{Mo}$ & 15,5 & 3,91 \\
446 & J 7.605-15 & $\mathrm{F}$ & $\mathrm{N}$ & 11,5 & 3,25 \\
447 & J 7.602-66 & $\mathrm{F}$ & $\mathrm{N}$ & 11,5 & 3,15 \\
3 & Niabel & $\mathrm{F}$ & $\mathrm{Fo}$ & 15,5 & 2,89 \\
\hline \hline
\end{tabular}

1. Textura: M-média, F- fundente; T- trincante;

2. Sabor: N- neutro, Fo- foxado, Mo- moscatel. 